SRR-STI-2011-00285

Publication Date: June 2011

\title{
Annual Radioactive Waste Tank Inspection Program - 2010
}

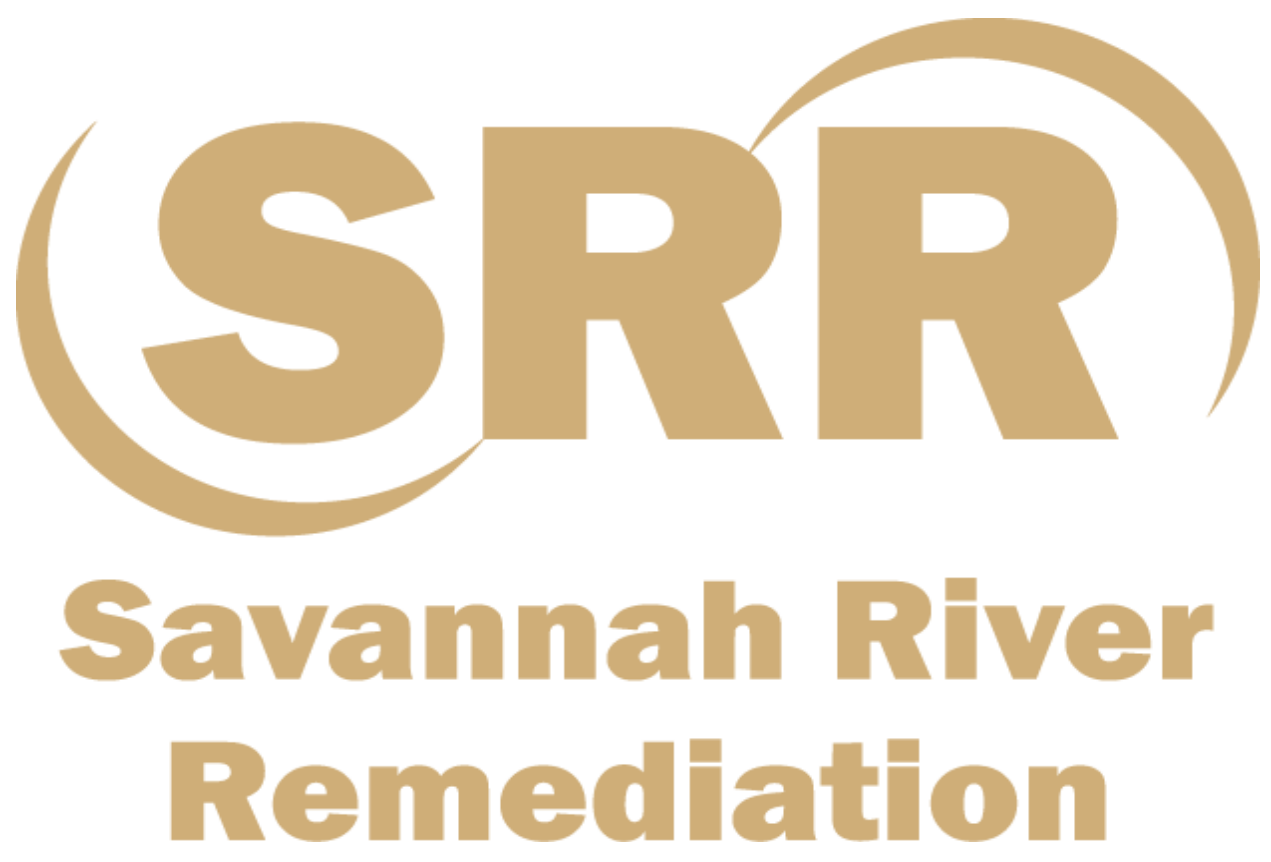

Savannah River Remediation

Savannah River Site

Aiken, SC 29808

Prepared for the U.S. Department of Energy under Contract No. DE-AC09-09SR22505 


Disclaimer
This report was prepared for the United States Department of Energy under
Contract No. DE-AC09-09SR22505 and is an account of work performed
under that contract. Reference herein to any specific commercial product,
process, or service does not necessarily constitute or imply endorsement,
recommendation, or favoring of same by Savannah River Remediation LLC
or by the United States Government or any agency thereof. The views and
opinions of the authors expressed herein do not necessarily state or reflect
those of the United States Government or any agency thereof.


SRR-STI-2011-00285

Publication Date: June 2011

\section{Annual Radioactive Waste Tank Inspection Program - 2010}

R. S. Waltz, Jr.

W. R. West

Savannah River Remediation

Savannah River Site

Aiken, SC 29808

Prepared for the U.S. Department of Energy under Contract No. DE-AC09-09SR22505 
This page intentionally left blank. 


\section{Contents}

Acronyms and Abbreviations .........................................1

Introduction .................................................................. 3

Summary.................................................................. 5

Inspection Program .................................................... 7

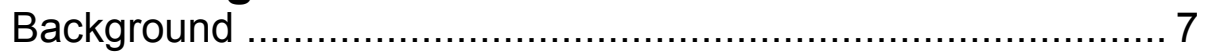

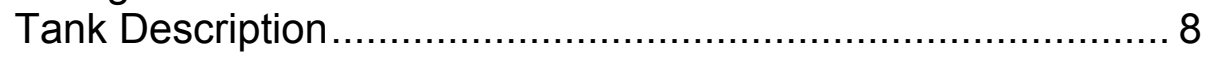

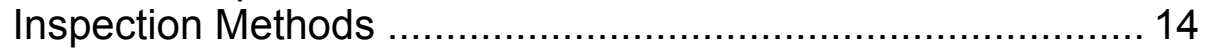

Program Implementation ............................................. 15

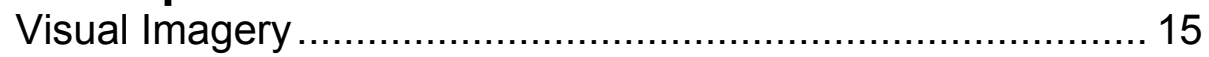

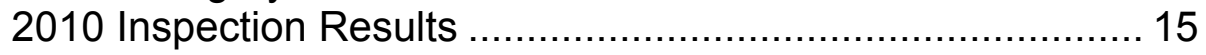

Summary of Inspection Results ........................................... 16

Appendix A-Waste Tanks at SRS ................................29

Appendix B-Summary of 2010 Inspections ................. 31

\section{List of Figures}

1. Type I Waste Storage Tank ........................................... 9

2. Type II Waste Storage Tank ......................................... 10

3. Type IV Waste Storage Tank .......................................... 11

4. Type III Waste Storage Tank ......................................... 12 
SRR-STI-2010-00285

Annual Radioactive Waste Tank

This page intentionally left blank. 
SRR-STI-2011-00285

Annual Radioactive Waste Tank

Inspection Program - 2010

Acronyms and Abbreviations

\section{Acronyms and Abbreviations}

\begin{tabular}{|c|c|}
\hline A & Annulus \\
\hline ADMP & Advanced Design Mixer Pump \\
\hline ASME & American Society of Mechanical Engineers \\
\hline BFV & Back Flush Valve \\
\hline CCTV & Closed Circuit Television \\
\hline CCWS & Chromate Cooling Water System \\
\hline COP & Clean Out Port \\
\hline DB & Diversion Box \\
\hline DOE-SR & Department of Energy-Savannah River \\
\hline DP & Direct Photography \\
\hline DSP & Digital Still Photography \\
\hline DWPF & Defense Waste Processing Facility \\
\hline ETF & Effluent Treatment Facility \\
\hline EVAP & Evaporator \\
\hline FLWB & Flush Water Valve Box \\
\hline GDL & Gravity Drain Line \\
\hline HLLCP & High Liquid Level Conductivity Probe \\
\hline HPFP & High Point Flush Pit \\
\hline I & Interior \\
\hline IAL & Inter-Area Line \\
\hline ISI & In-Service Inspection \\
\hline JB & Junction Box \\
\hline LDB & Leak Detection Box \\
\hline LPPP & Low Point Pump Pit \\
\hline LPS & Leak Probe Sleeve \\
\hline MLDB & Modified Leak Detection Box \\
\hline OD & Outside Diameter \\
\hline PP & Pump Pit \\
\hline psig & pounds per square inch gauge \\
\hline PT & Pump Tank \\
\hline RCP & Reinforced Concrete Pipe \\
\hline SRR & Savannah River Remediation \\
\hline SRS & Savannah River Site \\
\hline STE & Shift Technical Engineer \\
\hline SWS & Storm Water Sewer \\
\hline TTJ & Telescopic Transfer Jet \\
\hline ТTP & Telescopic Transfer Pump \\
\hline UT & Ultrasonic Nondestructive Examination \\
\hline VB & Valve Box \\
\hline WAP & Wide-Angle Photography \\
\hline WLE & Waste Line Encasement \\
\hline WSRC & Washington Savannah River Company \\
\hline WT & Waste Transfer Line \\
\hline
\end{tabular}


SRR-STI-2011-00285

Annual Radioactive Waste Tank

This page intentionally left blank. 
SRR-STI-2011-00285

Annual Radioactive Waste Tank

Inspection Program - 2010

Introduction

\section{Introduction}

Aqueous radioactive wastes from Savannah River Site (SRS) separations and vitrification processes are contained in large underground carbon steel tanks. Inspections made during 2010 to evaluate these vessels and other waste handling facilities along with evaluations based on data from previous inspections are the subject of this report. 
SRR-STI-2011-00285

Annual Radioactive Waste Tank

Introduction

Inspection Program - 2010

This page intentionally left blank. 
SRR-STI-2011-00285

Annual Radioactive Waste Tank

Inspection Program - 2010

Summary

\section{Summary}

The 2010 inspection program revealed that the structural integrity and waste confinement capability of the Savannah River Site waste tanks were maintained. All inspections scheduled per SRR-LWE-2009-00138, HLW Tank Farm Inspection Plan for 2010, were completed. Ultrasonic measurements (UT) performed in 2010 met the requirements of C-ESG-00006, In-Service Inspection Program for High Level Waste Tanks, Rev. 3, and WSRC-TR-2002-00061, Rev.6. UT inspections were performed on Tanks 30, 31 and 32 and the findings are documented in SRNL-STI-2010-00533, Tank Inspection NDE Results for Fiscal Year 2010, Waste Tanks 30, 31 and 32 .

A total of 5824 photographs were made and 1087 visual and video inspections were performed during 2010. Ten new leaksites at Tank 5 were identified in 2010. The locations of these leaksites are documented in C-ESR-G-00003, SRS High Level Waste Tank Leaksite Information, Rev.5.

Ten leaksites at Tank 5 were documented during tank wall/annulus cleaning activities. None of these new leaksites resulted in a release to the environment. The leaksites were documented during wall cleaning activities and the waste nodules associated with the leaksites were washed away.

Previously documented leaksites were reactivated at Tank 12 during waste removal activities. 
SRR-STI-2011-00285 Annual Radioactive Waste Tank

This page intentionally left blank 


\section{Inspection Program}

\section{Background}

Alkaline aqueous radioactive wastes produced at the Savannah River Site are received and managed in large underground tanks. The waste came primarily from dissolving nuclear targets and nuclear fuel reprocessing operations in the separations areas $(\mathrm{F}$ and $\mathrm{H})$ and contains most of the radioactive fission products from SRS operations. In addition, $\mathrm{H}$ tank farm receives recycle waste from the DWPF vitrification process. Some of this waste has been transferred to F Area waste tanks from $\mathrm{H}$ tank farm. The waste stored in the tanks is present in three phases: sludge, supernate, and salt formed by supernate evaporation and cooling. The supernate and salt phases consist primarily of $\mathrm{NaNO} 3, \mathrm{NaOH}$ and NaNO2. The sludge consists primarily of $\mathrm{MnO} 2, \mathrm{Al}(\mathrm{OH}) 3$ and $\mathrm{Fe}(\mathrm{OH}) 3$.

Waste tank leak detection capabilities are essential to meet the primary objective of the SRS radioactive waste management program to manage the waste in such a manner as to minimize the radiation exposure and associated risk to man and his environment over the lifetime of the radio nuclides.

The waste tanks have differing types of containment, leak detection and/or leakage. The first 24 old style (Types I, II and IV) tanks do not meet current standards for secondary containment and/or leak detection or have leaked. All other waste tanks are compliant.

The detection of leaked waste is based on two principles: disappearance of material from its primary location and appearance of material in a secondary location. At SRS, primary reliance is on the latter because the quantity of the waste detectable in an improper location is much less than that detectable by inventory change in a large tank. Capacity of SRS tanks is 0.75 to 1.3 million gallons per tank. Although rigorous tank inventory surveillance is practiced, primary leak detection methods rely on automatic surveillance of those areas into which the leaked waste is most likely to migrate.

The annulus of each double-wall tank in operation is equipped with at least two single-point conductivity probes for leak detection. These probes are located at the bottom of the annulus and on opposite sides of the tank where possible. The single-wall tanks are built on slabs with a network of leak collection channels that drain to a common sump. Sump levels are continuously monitored with alarm capability in control rooms. Besides the automatic surveillance, routine direct visual surveys are made in the annular spaces, and nonroutine direct visual surveys are made in primary tanks through opened access risers and/or inspection ports in the roof.

In 1961-62, following leakage of waste into the annuli of Tanks 9, 10, 14, and 16, the first remote imaging inspections were made of some tanks using a periscope. Random inspections continued through 1970. A program was initiated in November 1971 to periodically inspect all waste tanks, using remote visual imagery techniques to monitor for corrosion and other degradation, waste leakage, anomalies of any type, and to investigate process or equipment concerns.

Steel thickness measurements have been made periodically of waste tanks using ultrasonic techniques to monitor for general corrosion. An analog-type instrument was used in 1967 and 1969 to measure the thickness of the primary wall of selected double-wall tanks. In 1972, a more precise instrument was put in service. About 24,000 measurements made over a period of 14 
SRR-STI-2011-00285

Annual Radioactive Waste Tank

years (1972 through 1985) indicated that no general thinning trends of SRS tanks had occurred. Steel thickness measurements were resumed in 1994 using an updated ultrasonic testing (UT) system. The system was updated again in 2002 using improved technology to detect thinning, pitting and cracks.

To date, the only visually observed serviceinduced corrosion was in Tank 23, a tank with a unique service history. The upper wall interior surfaces show general corrosion with mild pitting. The pitting is broad but shallow. Evaluation of this condition is documented in DPSP-85-11-4. This tank was used to receive contaminated water from 244-H, the Receiving Basin for Off-Site Fuels, and 245-H, the Resin Regeneration Facility. No increase in the pitting or general corrosion has been observed. The $244-\mathrm{H}$ and $245-\mathrm{H}$ facilities are out of service.

Inspections of waste tanks are complicated by factors such as radiation and radioactive contamination, remote operation as far as 40 feet below grade, and insertion of equipment through small (generally 5 to 8 -inchdiameter) access openings. Inspection techniques to circumvent these difficulties have been developed, and they yield quality visual images (photographic) and/or volumetric measurements (UT). The techniques include photographic systems, closed circuit television systems, and ultrasonic systems to measure steel thickness, cracking and pitting.
Waste tank inspection has been important in leak detection. The leaksites in ten of thirteen tanks with documented leaksites have been discovered by direct visual inspection or by one of the remote inspection techniques. Since the inspection program was initiated in 1971, eight tanks were found to have leaksites that were not identified by the installed leak detection equipment. The waste evaporated to dryness, sealing the leaksites before any liquid reached a leak detection probe. The remote inspections identified the dry deposits of salt in the annuli and/or on the walls of these tanks.

The waste tank Visual Inspection Program and the ISI (UT) programs are ongoing programs. This report gives results of 2010 visual inspections and "limited" UT data and summarizes significant findings of previous UT and visual inspections for each waste tank.

\section{Tank Description}

SRS has subsurface storage tanks of four principal types of design. All of the tanks are constructed of carbon steel and reinforced concrete. They serve as containment vessels for storage and processing of radioactive wastes. Appendix A lists tank location, design type, project number, and construction period. A brief description of the different tank designs is given in the following paragraphs. 
SRR-STI-2011-00285

Annual Radioactive Waste Tank

Inspection Program

\section{Type I Tanks}

The 12 original storage tanks constructed between 1951 and 1953 are designated Type I tanks. Tanks 1 through 8 are in F Area and Tanks 9 through 12 are in $\mathrm{H}$ Area. Each primary tank has a capacity of 750,000 gallons. Figure 1 shows the general features of Type I tanks, including the primary tank, the secondary pan, and the concrete support structure.

A 9-foot layer of earth was placed over the tanks for radiation shielding. Cooling for each Type I tank is provided by 36 parallel (water pipe) cooling coils.

A dehumidification duct in the annulus of each tank is routed from the tank top to the bottom of the annulus where it encircles all but 8 feet of the tank. The duct has distribution outlets and its cross-sectional area decreases as the distance from the air supply increases. Access to the tank interior is

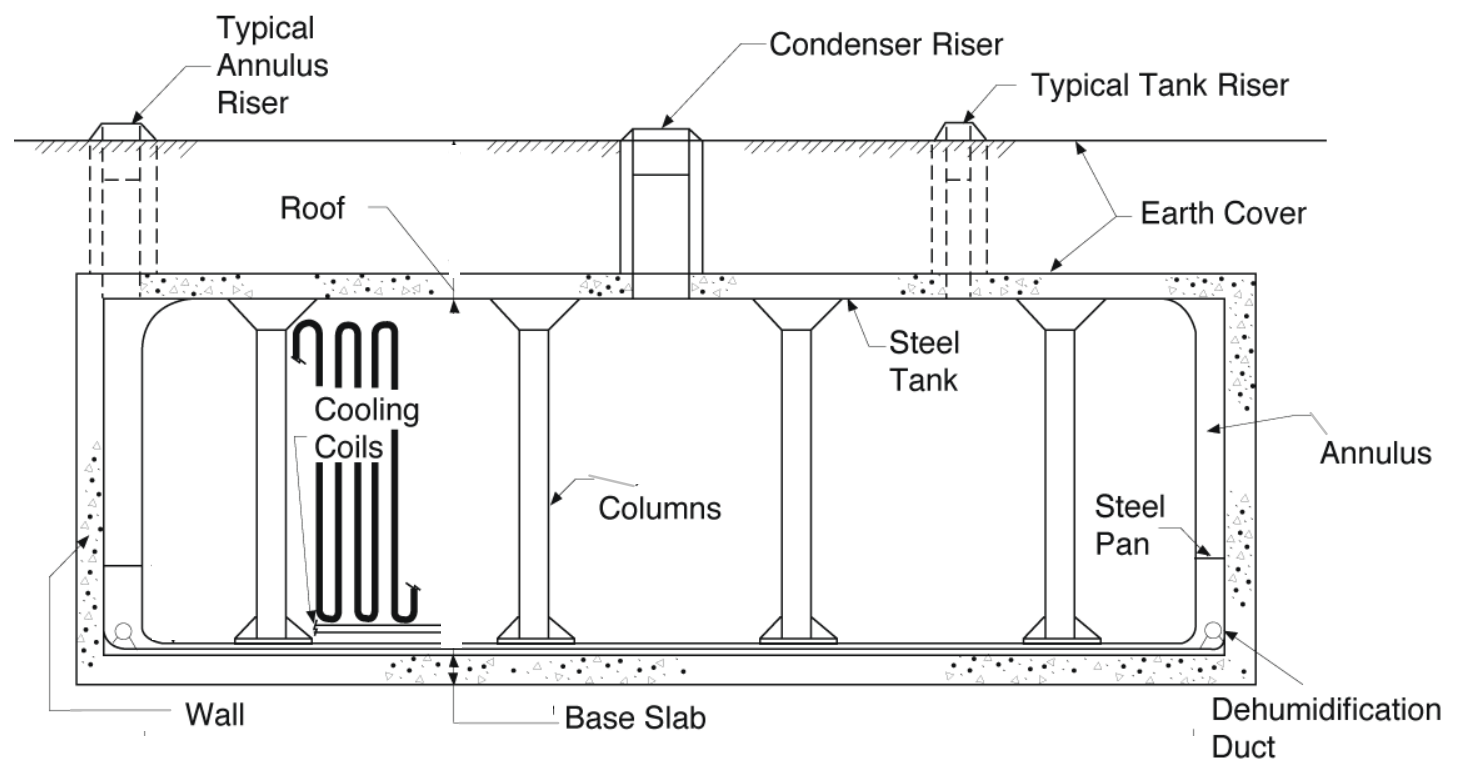

provided at eight locations, and to the annular space at four locations, through riser pipes. Each of the 12 riser pipes is capped at the top with a concrete plug. Each plug is provided with two 5-inch-diameter ports equipped with removable plugs unless equipment has been installed to support waste removal or tank closure activities. The center plug port may provide access through three 4 to 8 inch diameter ports. Some of these ports provide access for inspections.

All welds in the pan and primary tank were radiographically inspected, defects were corrected, and the welds were rechecked radiographically. The welds in the flat bottoms of both the pan and the tank were vacuum-tested for leaks. Additionally, both vessels were hydrostatically tested. The water was maintained at full height in the tank for 24 hours before inspection for leaks was made. Cooling water piping was hydrostatically tested at 300 psig and then leak-tested with $100 \mathrm{psig}$ air pressure in the piping.

Figure 1. Cooled Waste Storage Tank, Type I (Original 750,000 Gallons). 
SRR-STI-2011-00285

Annual Radioactive Waste Tank

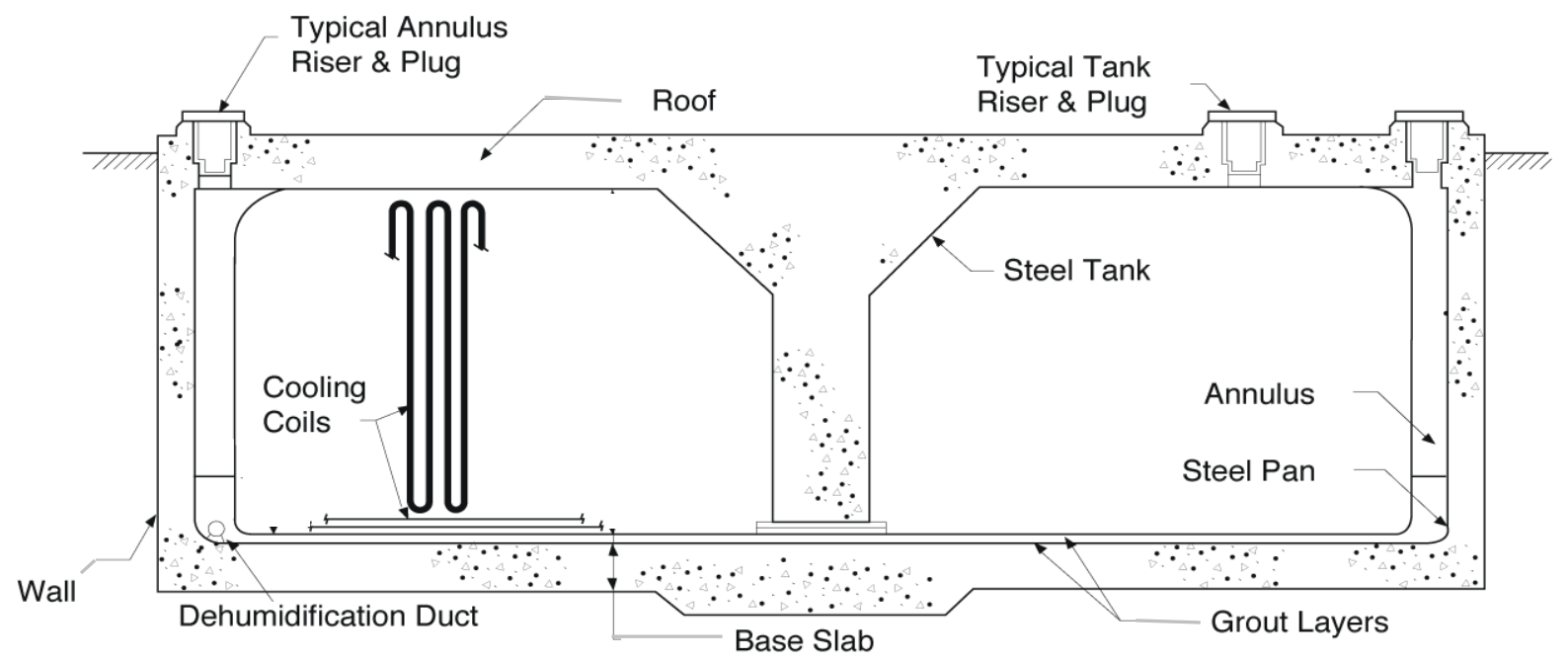

Figure 2. Cooled Waste Storage Tank, Type II (Original 1,030,000 Gallons).

\section{Type II Tanks}

Tanks 13 through 16, constructed in H Area in 1955 and 1956, are designated Type II tanks.

Figure 2 is a cross section of this type of tank. Each primary tank has a capacity of $1,030,000$ gallons.

The primary container for Type II tanks consists of two concentric steel cylinders assembled with a flat bottom and a flat top into a form somewhat like a doughnut. The top and bottom are joined to the outer cylinder by rings of curved knuckle plates. The inner cylinder is flared at the top to accommodate the roof support column. This cylinder is joined to the flat steel top with a continuous butt weld and to a base fastened to the bottom with a continuous T-weld.

The primary tank is set on a 1-inch sand bed within a circular pan of 1/2-inch thick steel plate, 5 feet deep and 5 feet larger in diameter than the primary tank, thus forming an annular space $21 / 2$ feet wide. The tank and pan assembly are surrounded by a cylindrical reinforced concrete enclosure and a flat concrete roof. The tank and pan assembly and the surrounding wall are set on a foundation slab that is 42 inches thick. The roof is supported by both the wall and a central concrete column that fits within the inner cylinder of the vessel. The concrete roof provides radiation shielding; therefore, no earth overburden is required.

Cooling for each Type II tank is provided by 44 parallel (water pipe) cooling coils.

Access to the tank interior is provided at eight locations, and to the annular space at four locations, through riser pipes. Each of the 12 riser pipes is capped at the top with a concrete plug. Each plug is provided with two 5-inch-diameter ports equipped with removable plugs. The ports provide access for inspection. In addition to the four annulus risers, other access openings (10 to 14 additional openings per tank) have been drilled into the annulus of each of these tanks to permit inspection of seventy-three to ninety-six percent of the exterior walls of the primary vessels.

A dehumidification duct in the annulus of each tank is routed from the tank top to the bottom of the annulus where it encircles all but 14 feet of the tank. The duct has distribution outlets, and its cross-sectional 
SRR-STI-2011-00285

Annual Radioactive Waste Tank

area decreases as the distance from the air supply increases.

All welds in the primary tanks were radiographically inspected, defects were corrected, and the welds were rechecked radiographically. However, the annulus pans were not inspected radiographically. The welds in the flat bottoms of these pans and the primary tanks were vacuum-tested for leaks, and the primary and secondary vessels were hydrostatically tested. Cooling water piping was hydrostatically tested at 300 psig and then leak-tested, with 100 psig air pressure in the piping.

\section{Type IV Tanks}

Tanks 17 through 24 are single-walluncooled tanks. These tanks were designed for storage of waste that does not require auxiliary cooling. Tanks 17 through 20 were constructed in F Area in 1956 and Tanks 21 through 24 were constructed in $\mathrm{H}$ Area in 1960. Each tank has a capacity of 1,300,000 gallons. Figure 3 shows the general features of Type IV tanks. Each Type IV tank is basically a steel-lined, prestressed-concrete tank in the form of a vertical cylinder with a domed roof. Carbon steel plates were used to form the cylindrical sides and flat bottom portion of the steel liners. Concrete was built up around the steel vessel by the "shotcrete" technique.

Access to the interior of the tank is provided at six locations through riser pipes. Each riser pipe is capped at the top with a concrete plug. Some of these risers provide access for inspection.

All welds in the steel liners were radiographically inspected. All of the welded tank-bottom seams and the upper seams of the knuckle rings were vacuum leak-tested. Prior to the back-filling operation, each tank was hydrostatically tested by filling with water to the normal fill line. The tank was allowed to remain filled until it was to be placed in use for waste storage.

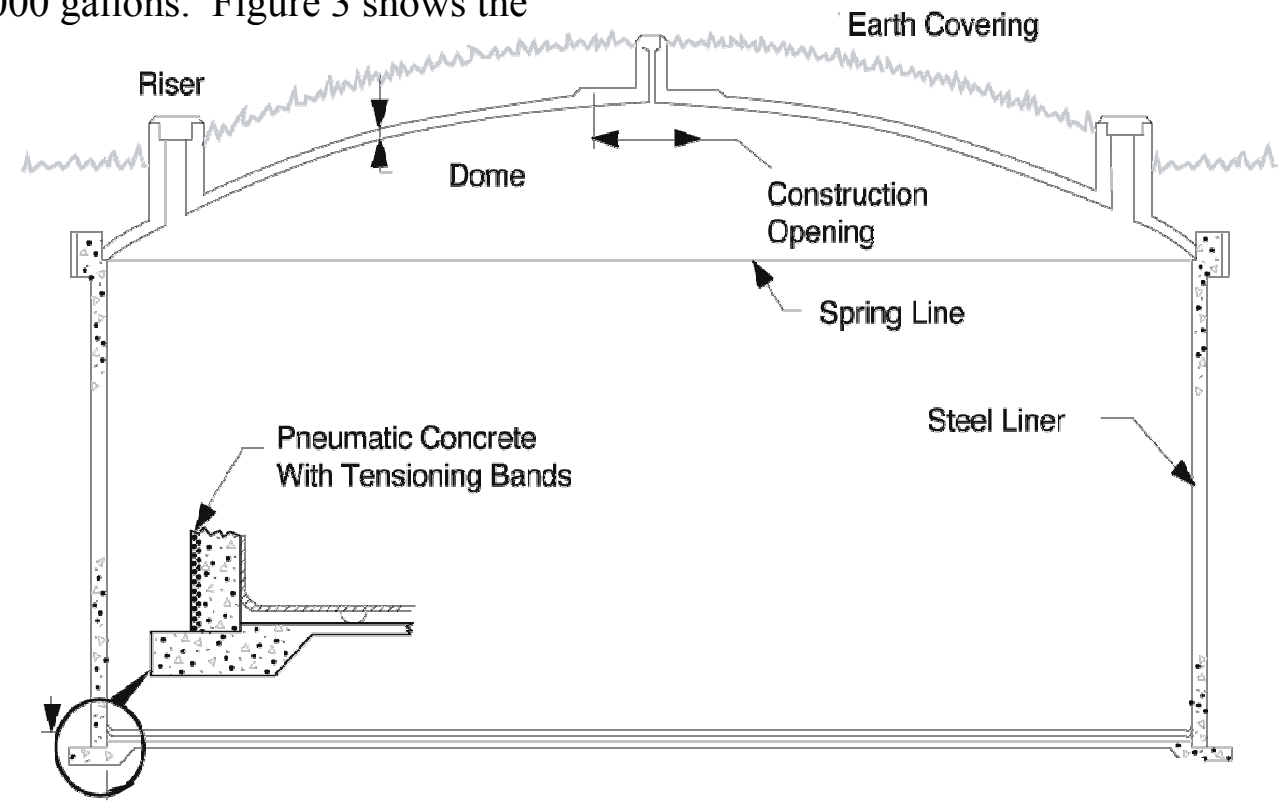

Figure 3. Uncooled Waste Storage Tank, Type IV (Prestressed Concrete Walls, 1,300,000 Gallons). 
SRR-STI-2011-00285

Annual Radioactive Waste Tank

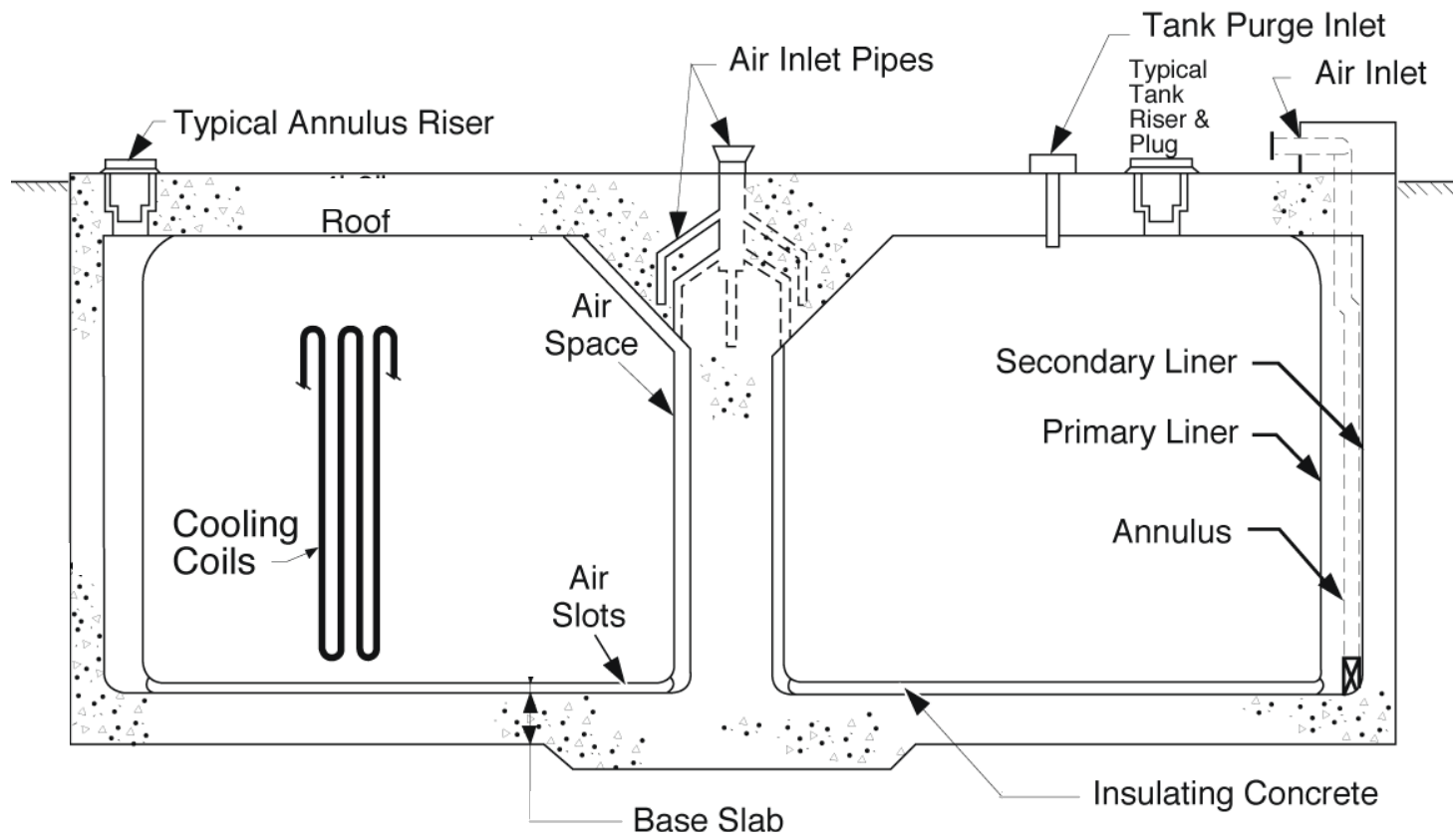

Figure 4. Cooled Waste Storage Tank, Type III (Stress Relieved Primary Liner, 1,300,000 Gallons).

\section{Type III Tanks}

The most recently constructed tanks are designated as Type III tanks (Figure 4). Twenty-seven tanks were built between 1966 and 1981. Figure 4 shows the general features of the Type III tanks. Type III tanks are designated as compliant. The Type III tank design was developed after an investigation into the causes of the leaks from the primary vessel of the Type I and Type II tanks. The study concluded that the leak-producing mechanism was nitrateinduced, stress-corrosion cracking at sites in or near the weld seams, and that stress relieving after fabrication should eliminate the cracking. For the Type III tanks, means were provided for heating each finished tank to relieve the stresses generated during fabrication. In addition, some stress patterns were avoided, or minimized, by mounting the roof supporting column on the foundation pad rather than on the bottom of the primary tank (as in Types I and II), and by providing an annular clearance around the roof supporting column. Each primary tank holds 1,300,000 gallons.

Type III tanks are similar to the doughnutlike design of Type II tanks. Each primary vessel is made of two concentric cylinders joined to washer-shaped top and bottom plates by curved knuckle plates.

The primary tank is set on a 6-inch bed of insulating concrete within the secondary containment vessel. The concrete bed is grooved radially so that ventilating air can flow from the inner to the outer annulus. If any waste were to leak from the tank bottom or center annulus wall, liquid would move through the grooves, facilitating detection in the outer annulus.

The secondary vessel is 5 feet larger in diameter than the tank, thus providing an 
outer annulus $21 / 2$ feet wide. Its sidewalls rise to the full height of the primary tank.

The nested two-vessel assembly is surrounded by a cylindrical reinforced concrete wall. The enclosure has a 48 -inchthick flat reinforced concrete roof that is supported by the concrete wall and a central column that fits within the inner cylinder of the vessel.

Cooling for the Type III tanks is provided by either deployable (water pipe) cooling coil bundles installed through risers in the tank top, or 23 parallel (water pipe) cooling coils distributed throughout the tank.

A dehumidification duct in the annulus of each tank is routed from the tank top to the bottom of the annulus where it encircles the tank. The duct has distribution outlets and its cross-sectional area decreases as distance from the air supply increases. In these tanks, additional airflow is directed through the inner annulus, passing beneath the primary tank through radial grooves in the concrete base slab, and is exhausted into the outer annulus.

Tanks 29 through 34 were placed in service prior to 1976. These tanks were constructed with annulus riser pipes at four locations providing inspection access through 5 -inchdiameter ports. All other Type III tanks were placed in service after 1976 and have annulus riser pipes at 18 locations that are 8inches in diameter. These ports are equidistant around the tank and provide for inspection of the entire exterior wall of the primary vessel. In 1982, fourteen to sixteen additional 8-inch diameter ports per tank were drilled in the tops of Tanks 29 through 34 to provide adequate access ports for inspection of the entire exterior wall of their primary vessels. All Type III tanks have interior riser pipes at various locations that provide inspection access through ports with diameters ranging from 4 to 8 inches. All inspection access ports are equipped with removable plugs.

All butt welds on the primary tanks were radiographically inspected, except welds on the horizontal roof surface. On the secondary vessels of Tanks 29 through 34 , all butt welds joining bottom plates, knuckle plates, and the lowest courses of centercolumn and outer-wall plates, were radiographically inspected. On all other Type III tanks, all plate welds in the secondary tanks were radiographically inspected. All defects were corrected and the welds were rechecked radiographically.

The Quality Assurance Program included inspection of all radiographs by two independent groups of certified weld inspectors, and all radiographs were permanently stored for future reference. All spots on the inside or outside of the primary tanks and the inside of the secondary tanks, where clips or lugs were removed and where other excisions were made, were examined by magnetic particle or liquid penetrant techniques, and any defects were repaired.

All butt welds on the secondary tanks were vacuum leak-tested. All welds in the bottom assemblies of the primary tanks, including knuckle rings and lowest course welds, were vacuum leak-tested before each bottom assembly was lowered into final position, and then tested a second time after the stress-relieving operation. A full hydrostatic test, the filling of each primary tank to a depth of 32 feet and allowing it to stand 48 hours, was conducted after stress relieving. No leaks were found by the hydrostatic tests. All circumferential welds in the pipe loops of the deployable cooling coil bundles below the $1 / 2$-inch-thick plate at the base of the riser plug were radiographed. The assembled cooler piping was tested hydrostatically to $500 \mathrm{psig}$ and halide leaktested at 300 psig. Welds in the distributed cooling coils were radiographed and 
SRR-STI-2011-00285

Annual Radioactive Waste Tank

similarly leak-tested.

The primary tank was Post Weld Heat Treated (PWHT) in place after all high temperature work (other than roof attachments) had been completed. PWHT was accomplished in accordance with the general requirements of the ASME Boiler and Pressure Vessel code.

\section{Inspection Methods}

Techniques have been developed for remote examination and evaluation of the waste tanks and waste tank ancillaries. For visual imaging, direct photography systems developed at SRS were the primary method used. Closed circuit television systems were also used where direct photography was not possible or where these systems provided a more comprehensive examination. Only the direct photography systems will be described since the video systems are similar to systems used widely in industry.

In 2007 a conversion was made from film to digital photography. This change was made due to the significant improvements and advantages of digital photography.

Wide-angle direct photography was used for general inspections of double-wall tank annuli and the primary vessels of both double-wall tanks and single-wall tanks. This technique surveys a large area of the tank and annulus floor in a single photograph. The camera used for wideangle photography was a Nikon D50 camera body, with a Voigtlander aspherical $12 \mathrm{~mm}$, f5.6 aperture lens. This lens is distortion free with a field of view of approximately 120 degrees. A bank of four electronic flash units was synchronized with this camera to provide illumination.

Another direct photography technique was used for detailed inspections. This technique provides detailed views of the tank in a series of photographs. The camera used was either a Nikon D50, D80 or D90 camera body, with a Voigtlander aspherical $12 \mathrm{~mm}$, f5.6 aperture lens, the same as used for the wide-angle direct photography. Illumination is provided by a single electronic flash unit. 


\section{Program Implementation}

\section{Visual Imagery}

The 2010 inspection program used two visual imagery techniques: photography and closed circuit television. The primary inspection methods were direct photography techniques; e.g., making a series of photographs providing detailed views of the tank and wide-angle photography for obtaining overviews of large areas. Closed circuit television systems were generally used to further investigate conditions found during scheduled inspections and to document conditions and troubleshoot process problems in tanks and ancillaries.

The inspection program objective to continuously evaluate the waste tanks was satisfied in 2010 by photographic and videotape documentation. Inspections were made through all accessible annulus risers of the double-wall tanks and at least one inspection was made in the interior of each single-wall tank.

For Tanks 1 through 12, inspections are limited to no more than $25 \%$ of the exterior of the primary vessel wall and the annular space due to limited annulus access. These tanks are monitored for leakage by instrumentation or cameras installed in their annuli.

Additionally, for those tanks that have known leaksites in the primary vessel and are not in waste removal, the supernate phase has been removed, minimized, or the level lowered below the level of known leaksites. Inspections revealing no changes on these tanks are denoted as "Remote visual tank wall inspection revealed no changes since last evaluated."

\section{Inspection Results}

The 2010 inspection program was successfully completed. The annuli of all double-wall tanks were inspected via all accessible risers and the interiors of singlewall tanks remaining in service were inspected. Other inspections of waste tanks and ancillaries were performed as required by operating conditions and equipment performance requirements.

Ultrasonic nondestructive examinations were performed in Tanks 30, 31 and 32. The findings are documented in SRNL-STI2010-00533, Tank Inspection NDE Results for Fiscal Year 2010, Waste Tanks 30, 31 and 32 .

During cleaning of the remaining $25 \%$ of the exterior of the tank wall at Tank 5, using a magnetically mounted wall crawler, ten new leaksites were documented. These new leaksites and all previously identified leaksites were cleaned.

During waste removal activities at Tank 12, some previously identified leaksites were reactivated.

Rainwater continued to leak into the annulus of some tanks. Inleakage was evidenced primarily by surface stains, and occasionally by calciferous deposits, changed configuration of salt deposits in the annulus, and mild surface corrosion.

Except as noted above, the conditions of the tanks remained essentially unchanged from the conditions reported in 2009. Details and results for inspections of the tanks and ancillaries performed in 2010 are listed in Appendix B. 
SRR-STI-2011-00285

Annual Radioactive Waste Tank

\section{Summary of Inspection Results}

The following is a brief description of tank conditions as revealed by inspections and examinations made through 2010. [NOTE: When a tank is "removed from active service", no waste transfers into or out of that tank are allowed.] The statuses of the old style (Type I, II and IV) tanks are reported in SRR-CES-201100002, CY2010 Annual Report Status of F/H Area Radioactive Waste Tanks Being Removed from Service.

\section{Tank 1}

Tank 1 was placed in service in 1954. A small amount of dry waste was observed on the annulus floor in 1969. Subsequent inspections have revealed no additional leakage. Inspection of the exterior wall of the primary vessel is limited to $25 \%$ using existing inspection techniques through the four risers that provide access to the annulus. Visual examinations of the observable portion of the tank wall have not revealed the location of the leak(s). Inspection photographs of the steel surface of the tank and the annulus have shown no significant surface corrosion or other anomalies. Ultrasonic measurements made in 1978, 1979, 1981, 1983, and 1985 showed that no detectable thinning of the tank wall had occurred.

\section{Tank 2}

Tank 2 was placed in service in 1955. Visual examinations of the observable portion $(25 \%)$ of the exterior of the primary vessel wall and the annulus have shown no leakage, significant surface corrosion or other anomalies. Ultrasonic measurements made in 1967, 1972, 1973, 1977, 1981, and 1985 showed no detectable thinning of the tank wall.

\section{Tank 3}

Tank 3 was placed in service in 1956. Visual examinations of the observable portion $(25 \%)$ of the exterior of the primary vessel wall and the annulus have shown no leakage, significant surface corrosion or other anomalies. Ultrasonic measurements made in 1973, 1977, 1981, and 1985 showed no detectable thinning of the tank wall.

\section{Tank 4}

Tank 4 was placed in service in 1961. Visual examinations of the observable portion $(25 \%)$ of the exterior of the primary vessel wall and the annulus have shown no leakage, significant surface corrosion or other anomalies. Ultrasonic measurements made in 1973, 1977, 1981, and 1985 showed no detectable thinning of the tank wall.

\section{Tank 5}

Tank 5 was placed in service in 1959. Tank 5 was removed from active service in November 1990. Visual examinations of the observable portions $(25 \%)$ of the exterior of the primary vessel wall and the annulus through calendar year 2000 had shown no leakage, significant surface corrosion, or other anomalies. The tank was returned to active service in 2000 to support tank closure activities. Several months after liquid was added to the tank in 2001, a magnetically mounted wall crawler with a video camera attached was deployed which enabled an additional $50 \%$ of the primary vessel wall to be inspected. These inspections revealed 15 leaksites. Less than 5 gallons of waste had reached the annulus floor. Waste was removed from the tank to a level below the lowest known leaksite. During waste removal activities initiated in 2005, three new leaksites were discovered. 
One new leaksite was documented in 2008 at 70 inches above the tank bottom. All leaksites were adjacent to welds and attributed to stress corrosion cracking. In $2009,75 \%$ of the tank wall was inspected and cleaned using a magnetically mounted wall crawler with washing capabilities. Fifteen new leaksites were documented. In 2010 during cleaning of the remaining $25 \%$ of the exterior of the tank wall at Tank 5, using a magnetically mounted wall crawler, ten new leaksites were documented. Ultrasonic measurements made in 1973 , 1977, 1981, and 1985 showed no detectable thinning of the tank wall. Suspension of further waste removal efforts in Tank 5 has been approved by the regulators pending sampling and analysis results.

\section{Tank 6}

Tank 6 was placed in service in 1964. Tank 6 was removed from active service in October 1990. Visual examinations of the observable portions $(25 \%)$ of the exterior of the primary vessel wall and the annulus through calendar year 2000 had shown no leakage, significant surface corrosion, or other anomalies. The tank was returned to active service in 2000 to support tank closure activities. The first indication of leakage from the tank was in January 2001 when an annulus conductivity probe alarm was received. Liquid was observed on the annulus floor; however, no leaksites could be located from the four risers used to inspect the tank. In February 2001, a magnetically mounted wall crawler with a video camera attached enabled an additional $48 \%$ of the primary vessel wall to be examined. These inspections revealed 6 leaksites. Approximately 92 gallons of waste reached the annulus floor. Waste was removed from the tank to a level below the lowest known leaksite. All leaksites were adjacent to welds and attributed to stress corrosion cracking. In 2009, $100 \%$ of the tank wall was inspected and cleaned using a magnetically mounted wall crawler with washing capabilities. Five new leaksites were documented. Ultrasonic measurements made in 1974, 1977, 1978, 1979, 1981, 1985 and 2008 showed no detectable thinning of the tank wall. Post chemical cleaning UT measurements were made and the results are documented in SRNL-STI-2009-00560, Tank Inspection NDE Results Tank 6, Including Summary of Waste Removal Support Activities in Tanks 5 and 6. Suspension of further waste removal efforts in Tank 6 has been approved by the regulators pending sampling and analysis results.

\section{Tank 7}

Tank 7 was placed in service in 1954. Tank 7 was removed from active service in November 1989. Visual examinations of the observable portion (19\%) of the exterior of the primary vessel wall and the annulus have shown no leakage, significant surface corrosion or other anomalies. Ultrasonic measurements made in 1974, 1979, 1981, 1983, and 1985 showed no detectable thinning of the tank wall. Tank 7 was returned to active service in 2002 to support waste removal activities.

\section{Tank 8}

Tank 8 was placed in service in 1956. Tank 8 was removed from active service in September 1992. Tank 8 was returned to active service in 2001 to support waste removal activities. Visual examinations of the observable portion $(25 \%)$ of the exterior of the primary vessel wall and the annulus have shown no leakage, significant surface corrosion or other anomalies. A magnetically mounted wall crawler with a video camera attached enabled inspection of 
SRR-STI-2011-00285

Annual Radioactive Waste Tank

an additional $34 \%$ of the primary vessel wall and annulus. No leakage, significant surface corrosion, or other anomalies were observed. Ultrasonic measurements made in 1973, 1977, 1981, and 1985 showed no detectable thinning of the tank wall.

\section{Tank 9}

Tank 9 was placed in service in 1955. Liquid waste was observed in the annulus pan in 1957. Currently, the annulus pan contains 8 to 10 inches of salt deposits. Visual examinations of the observable portion $(13 \%)$ of the exterior of the primary vessel wall have shown three leaksites high on the tank wall; 269, 271, and 276 inches above the tank bottom. None of these leaksites are the source of the leaked waste in the annulus pan. The waste leaked at these sites was only enough to form localized salt nodules. The leak(s) that are the source of the waste in the annulus pan have not been observed. Inspections have shown no significant surface corrosion, and the ultrasonic measurements made in 1979 and 1983 showed no detectable thinning of the tank wall.

\section{Tank 10}

Tank 10 was placed in service in 1955 . The first indication that Tank 10 had leaked was in 1959 when dry waste was discovered in the annulus pan during a visual inspection. Currently, the annulus pan contains about 2 3 inches of salt deposits. Visual examinations of the observable portion $(19 \%)$ of the exterior of the primary vessel wall have not shown the source of the leaked waste or any other leaksite(s). Inspections have shown no significant surface corrosion, and the ultrasonic measurements made in 1979 and 1983 showed no detectable thinning of the tank wall.

\section{Tank 11}

Tank 11 was placed in service in 1955. Tank 11 was removed from active service in July 1989. Inspections performed in 1974 revealed two leaksites. The leaksites are 189 and 235 inches above the tank bottom. Visual examinations of the observable portions $(25 \%)$ of the exterior of the primary vessel wall have shown no significant surface corrosion, and ultrasonic measurements made in 1973, 1977, 1981, and 1985 showed no detectable thinning of the tank wall. The tank was returned to service in 2004 for waste removal activities.

\section{Tank 12}

Tank 12 was placed in service in 1956. Tank 12 was removed from active service in July 1990. Inspections in 1974 and 1984 revealed two leaksites. The leaksites are 93 and 105 inches above the tank bottom. Inspections in 2004 revealed a new leaksite at 95 inches above the tank bottom. Water additions were made in 2005 to re-wet the dry sludge in preparation of waste removal. Inspections in 2005 revealed two new leaksites at 70 and 129 inches above the tank bottom. A small amount of seepage was observed on the tank wall beneath the leaksite located at 70 inches above the tank bottom in 2007. Deposits observed on the annulus floor in 2008 indicated that a new leaksite was present. These deposits are located in an area where no leaksites have been identified. The deposits were observed between the North and East risers. The exact location of the leaksite is unknown. During waste removal activities in 2009 and 2010 several leaksites were reactivated. A small quanitity of waste leaked into the annulus. Visual examinations of the observable portions $(25 \%)$ of the exterior of the primary vessel wall have shown no significant surface corrosion, and ultrasonic measurements made in 1972, 1973, 1977, 
SRR-STI-2011-00285

Annual Radioactive Waste Tank

1981, 1983, and 1985 showed no detectable thinning of the tank wall. The tank was returned to service in 2004 for waste removal activities.

\section{Tank 13}

Tank 13 was placed in service in 1956. Ninety percent of the exterior of the primary vessel wall is observable via the 13 risers that provide access to the annulus. Inspections in 1977 revealed a leaksite 279 inches above the tank bottom. In 1980, another leaksite was discovered 269 inches above the tank bottom. Visual examinations have shown no significant surface corrosion, and ultrasonic measurements made in 1974, 1979, 1985 and 2000 showed no detectable thinning of the tank wall.

\section{Tank 14}

Tank 14 was placed in service in 1957. The first indication that Tank 14 had leaked was in 1959 when dry leaked waste was observed in the annulus pan. Currently, the annulus pan contains 12 to 13 inches of salt deposits. Eighty-nine percent of the exterior of the primary vessel wall is observable via the 18 risers that provide access to the annulus. Inspections have documented 33 leaksites, and it is estimated that there are about 50 leaksites in this tank. All of the documented leaksites are near the bottom circumferential weld that is 2.5 feet above the tank bottom, except for one leaksite that was observed approximately 288 inches above the tank bottom. Visual examinations have shown no significant surface corrosion, and ultrasonic measurements made in 1979 and 1983 showed no detectable thinning of the tank wall.

\section{Tank 15}

Tank 15 was placed in service in 1960.
Inspections in 1972 below one of the four risers providing access to the annulus documented two leaksites near the bottom circumferential weld about 2.5 feet above the tank bottom. Twelve additional risers were installed, increasing the observable portion of the primary vessel wall from $25 \%$ to $96 \%$. Inspections in 1973, via the additional risers, revealed eleven other leaksites. Later inspections revealed five other sites where cracks penetrated the steel wall, one was observed in 1994, two were observed in 1997 and two were observed in 2000. Inspections in 2005 revealed an additional leaksite near the bottom circumferential weld. Ultrasonic measurements made in 1972, 1977, 1980, 1984, 2002 and 2007 showed no reportable thinning of the tank wall. UT Inspections in 2002 revealed a leaksite at 129 inches on the middle circumferential weld. A total of 20 leaksites have been documented. Visual examinations have shown mild corrosion of the steel surfaces in the tank annulus. Using new equipment capable of detecting cracks and pitting, four partial through-wall crack indications and one complete through-wall crack were documented during UT mapping in 2002 that were previously unknown. In 2007 UT examinations revealed no reportable thinning or pitting areas on the tank wall. Details of this inspection are documented in WSRC-TR-2007-00064. The ten cracks reported in 2002 were reexamined for crack growth. These examinations revealed that four cracks had grown. Evaluation of the cracks is documented in WSRC-TR-2002-00590, Rev. 1 (U). 
SRR-STI-2011-00285

Annual Radioactive Waste Tank

\section{Tank 16}

Tank 16 was placed in service in 1959. Tank 16 was removed from active service in February 1979. Liquid waste was detected in the annulus pan in 1959. Seventy-three percent of the exterior wall of the primary vessel is observable via the sixteen risers that provide access to the annulus. Inspections in 1961 and 1962, through 13 risers, revealed about 175 leaksites in the tank wall. In October 1961 and March 1962, two 5 3/4-inch-diameter samples were cut from the top horizontal circumferential weld of the tank wall about 40 feet apart. Metallurgical examination indicated the cause of the cracks was nitrate-induced stress corrosion. Extensive inspection performed since 1972 indicated that the primary vessel wall has 300 to 350 leaksites. In $1978,70 \%$ of the leaked waste in the annulus pan was removed, leaving an heel containing approximately 30,000 curies Cs137. Waste removal from the interior of the primary vessel was completed in 1980, and the tank status changed to "out of service". In 2007 a magnetic video wall crawler was used to document conditions and quantify the amount of waste remaining in the annulus. The inspection covered $100 \%$ of the annulus floor. Details of this inspection are documented in LWO-LWE-2007-00085. Visual examinations have shown no significant surface corrosion. No ultrasonic steel thickness measurements of the tank were made because of the number of leaksites and the presence of salt nodules on the primary vessel exterior. Annual photographic inspections were eliminated in 2007. No significant changes have been observed in the waste in the annulus and the primary tank is empty. Inspections will be performed on an "as needed" basis and periodically during annulus waste removal activities.

\section{Tank 17}

Tank 17 was placed in service in 1961 . Visual examinations of the steel liner revealed no evidence of failure, significant surface corrosion or other anomalies. Tank 17 was removed from service and closed December 15, 1997. Inspections have been discontinued.

\section{Tank 18}

Tank 18 was placed in service in 1959. Visual examinations of the steel liner have shown no evidence of failure, significant surface corrosion or other anomalies. Ultrasonic measurements made in 1977, 1980, and 1983 showed no detectable thinning of the liner bottom. Activities to remove all waste from the tank began in 2001. The tank was removed from service in 2003. Suspension of further waste removal efforts in Tank 18 has been approved by the regulators pending sampling and analysis results.

\section{Tank 19}

Tank 19 was placed in service in 1961 and emptied in 1981. Visual examinations through 2008 of the steel liner have revealed two failures; i.e. sites where inleakage had occurred. The failures are in the wall of the steel liner at heights of 317 inches and 330 inches. Inspection records photographically document that these leaksites existed before 1994. However, inspections made from the interior of this single-wall (visual inspection of the exterior is not possible) had to track changes in artifacts at the sites by periodic observation to judge that inleakage had occurred. In 2009 two leaksites were documented on the NE wall. These leaksites are approximately 25 inches above the tank bottom. Further evaluation of these deposits observed on the tank wall determined that 
the deposits are most likely residual Zeolite. The evaluation is documented in Evaluation of Residual Nodules in Tank 19, SRR-STI2010-00553. Ultrasonic measurements made in 1982 and 1985 showed no detectable thinning of the liner bottom. Activities to remove all waste from the tank began in 2000. The tank was removed from service in 2003. Suspension of further waste removal efforts in Tank 19 has been approved by the regulators pending sampling and analysis results.

\section{Tank 20}

Tank 20 was placed in service in 1960. Visual examinations of the steel liner revealed four failure sites. In 1983, leaksites were observed in the wall of the steel liner at heights of 22, 24.5, and 26.5 feet. In 1990, a leaksite was confirmed in the liner wall at a height of 26.25 feet. This site had been suspect since 1984. This is a single-wall tank with no annulus. The leaksites in the steel liner were detected by inspections made from the tank interior, since inspection of the exterior was not possible. Artifacts observed on the interior wall indicated water had leaked through the steel liner into the tank. Tank 20 was removed from service and closed July 31, 1997. Inspections have been discontinued.

\section{Tank 21}

Tank 21 was placed in service in 1961. Visual examinations of the steel liner have shown no evidence of failure, significant surface corrosion or other anomalies. Ultrasonic measurements made in 1973, 1977, 1980, and 1983 showed no detectable thinning of the liner bottom.

\section{Tank 22}

Tank 22 was placed in service in 1965.
Visual examinations of the steel liner have shown no evidence of failure, significant surface corrosion or other anomalies. Water inleakage penetrating the concrete roof was investigated in 1994. This water intrusion was attributed to the presence of perched water on top of the dome (PEC-SMS-960084).

Inspections performed in 2004 showed that the water intrusion through the concrete dome at the NW riser had increased. An Inspection Plan (PDCS-SEG-2005-00032 [7]) was developed for excavation and inspection to assess the structural integrity of the concrete dome, ring girder and to determine the source of the inleakage. In 2006, excavation of the tank overburden and subsequent visual and UT inspections showed the condition of the dome and ring girder to be structurally sound. The source of the inleakage was identified as a cracked 10 " concrete encasement, containing the purge ventilation condensate drain line, allowing perched water to leak through the concrete dome. The area was repaired and a waterproofing material was added. Subsequent leak checks showed no inleakage of water. The rework of this area eliminated the source of in-leakage into the tank. Details of these findings can be found in Tank -22H Structural Integrity Inspection Report at Northwest Riser (WSRC-TR2006-00355).

Ultrasonic measurements made in 1974, 1977, 1980, and 1983 showed no detectable thinning of the liner bottom.

\section{Tank 23}

Tank 23 was placed in service in 1964. Visual examinations of the steel liner have revealed corrosion but no evidence of failure. Ultrasonic measurements made in 1973, 1977, 1980, and 1983 showed no detectable thinning of the liner bottom. Examinations of the steel liner have shown 
SRR-STI-2011-00285

Annual Radioactive Waste Tank

rust and tubercles on the surface of the upper portion. This tank served as a receiver tank for inhibited contaminated water from Buildings 244-H, the Receiving Basin for Off-Site Fuels, and 245-H, the Resin Regeneration Facility. This mode of operation exposed only the lower half of the tank to the inhibited contents and exposed the upper half of the tank to a warm humid atmosphere. In 1984, rust and tubercles were cleaned from two small areas, exposing the steel surface. The cleaned liner surface was generally corroded with mild pitting. The pits were broad and shallow. In 1999, cracked or crushed concrete was noted in the tank dome, spanning about fifteen feet immediately above the tank wall. The structural integrity of the dome was evaluated as acceptable per (T-CLC-H00444 and T-CLC-H-00447). The dome meets AC1 318-95 code requirements and will continue to be monitored.

\section{Tank 24}

Tank 24 was placed in service in 1963. Visual examinations of the steel liner have shown no evidence of failure, significant surface corrosion or other anomalies. Ultrasonic measurements made in 1984 showed no detectable thinning of the liner.

\section{Tank 25}

Tank 25 was placed in service in 1980 . Visual examinations of $100 \%$ of the exterior of the primary vessel wall and the annulus have shown no leakage, significant surface corrosion or other anomalies. UT measurements made in 1979 and 1983 showed no detectable thinning of the tank wall. UT measurements made in 2004 showed no reportable thinning, pitting or stress corrosion cracking or evidence of service induced tank wall thinning on the primary tank wall. Details of this inspection are documented in WSRC-TR-2004-00166.

\section{Tank 26}

Tank 26 was placed in service in 1980. Visual examinations of $100 \%$ of the exterior of the primary vessel wall and the annulus have shown no leakage, significant surface corrosion or other anomalies. UT measurements made in 1979 and 1983 showed no detectable thinning of the primary tank wall. UT measurements made in 2003 showed no reportable thinning, pitting or stress corrosion cracking or evidence of service induced tank wall thinning on the primary tank wall. Details of this inspection are documented in WSRCTR-2004-00166.

\section{Tank 27}

Tank 27 was placed in service in 1980 . Visual examinations of $100 \%$ of the exterior of the primary vessel wall and the annulus have shown no leakage, significant surface corrosion or other anomalies. UT measurements made in 1979 and 1983 showed no detectable thinning of the tank wall. UT measurements made in 2005 showed no reportable thinning, pitting or stress corrosion cracking or evidence of service induced tank wall thinning on the primary tank wall. Details of this inspection are documented in WSRC-TR-2006-00002.

\section{Tank 28}

Tank 28 was placed in service in 1980. Visual examinations of $100 \%$ of the exterior of the primary vessel wall and the annulus have shown no leakage, significant surface corrosion or other anomalies. UT measurements made in 1979 and 1983 showed no detectable thinning of the tank wall. UT measurements made in 2005 showed no reportable thinning, pitting or stress corrosion cracking in the primary vessel wall. Several small areas of 
reportable thickness in secondary wall plates 1, 2 and 3 were identified. Local thinning was noted at $10 \%$ below nominal thickness in the first secondary wall plate. Details of this inspection are documented in WSRCTR-2005-00039.

\section{Tank 29}

Tank 29 was placed in service in 1971. Visual examinations of $100 \%$ of the exterior of the primary vessel wall and the annulus have shown no leakage, significant surface corrosion or other anomalies. UT measurements made in 1973 and 1974 showed no detectable thinning of the tank wall. UT measurements made in 2006 showed no reportable thinning, pitting, stress corrosion cracking, or evidence of service induced thinning on the primary tank wall. Reportable thickness was detected on one plate of the secondary wall. Reportable thickness was detected on the top plate of the primary tank wall but was attributed to fabrication artifacts. Incipient pitting was detected in the lower plate of the primary tank wall beneath riser P-02. Details of this inspection are documented in WSRC-TR2006-00002. UT measurements made in 2009 under every riser (18) showed no reportable thinning, pitting, stress corrosion cracking, or evidence of service induced thinning on the primary tank wall. Reportable thickness was detected on the top plate of the primary tank wall, but was attributed to fabrication artifacts such as grinding areas. No crack-like indications were detected. Incipient pitting was detected in several locations, with the deepest pit measuring 0.063 " deep. Details of this inspection are documented in SRNL-STI2009-00559.

\section{Tank 30}

Tank 30 was placed in service in 1974.
Visual examinations of $100 \%$ of the exterior of the primary vessel wall and the annulus have shown no leakage, significant surface corrosion or other anomalies. UT measurements made in 1975 showed no detectable thinning of the tank wall. UT measurements made in 2003 showed no reportable thinning, pitting or stress corrosion cracking or evidence of service induced tank wall thinning on the primary tank wall. Details of this inspection are documented in WSRC-TR-2003-00370. UT measurements made in 2010 showed no reportable thinning, pitting or stress corrosion cracking or evidence of service induced tank wall thinning on the primary tank wall. Ten incipient pits were documented however all of the pits are consistent with pre-service pitting with no evidence of active corrosion or growth. Details of this inspection are documented in SRNL-STI-2010-00533.

\section{Tank 31}

Tank 31 was placed in service in 1972. Visual examinations of $100 \%$ of the exterior of the primary vessel wall and the annulus have shown no leakage, significant surface corrosion or other anomalies. UT measurements made in 2003 showed no reportable thinning, pitting or stress corrosion cracking or evidence of service induced tank wall thinning on the primary tank wall. Details of this inspection are documented in WSRC-TR-2003-00370. UT measurements made in 2010 showed no reportable thinning, pitting or stress corrosion cracking or evidence of service induced tank wall thinning on the primary tank wall. Nine incipient pits were documented however all of the pits are consistent with pre-service pitting with no evidence of active corrosion or growth. Details of this inspection are documented in SRNL-STI-2010-00533. 
SRR-STI-2011-00285

Annual Radioactive Waste Tank

\section{Tank 32}

Tank 32 was placed in service in 1971. Visual examinations of $100 \%$ of the exterior of the primary vessel wall and the annulus have shown no leakage, significant surface corrosion or other anomalies. UT measurements made in 2003 showed no reportable thinning, pitting or stress corrosion cracking or evidence of service induced tank wall thinning on the primary tank wall. Details of this inspection are documented in WSRC-TR-2003-00370. UT measurements made in 2010 showed no reportable thinning, pitting or stress corrosion cracking or evidence of service induced tank wall thinning on the primary tank wall. Nine incipient pits were documented however all of the pits are consistent with pre-service pitting with no evidence of active corrosion or growth. Details of this inspection are documented in SRNL-STI-2010-00533.

\section{Tank 33}

Tank 33 was placed in service in 1969. Visual examinations of $100 \%$ of the exterior of the primary vessel wall and the annulus have shown no leakage, significant surface corrosion or other anomalies. UT measurements made in 2005 showed no reportable thinning, pitting or stress corrosion cracking or evidence of service induced tank wall thinning on the primary tank wall. Details of this inspection are documented in WSRC-TR-2006-00002.

\section{Tank 34}

Tank 34 was placed in service in 1972. Visual examinations of $100 \%$ of the exterior of the primary vessel wall and the annulus have shown no leakage, significant surface corrosion or other anomalies. UT measurements made in 2003 showed no reportable thinning, pitting or stress corrosion cracking or evidence of service induced tank wall thinning on the primary tank wall. Details of this inspection are documented in WSRC-TR-2003-00370.

\section{Tank 35}

Tank 35 was placed in service in 1977. Visual examinations of $100 \%$ of the exterior of the primary vessel wall and the annulus have shown no leakage, significant surface corrosion or other anomalies. UT measurements made in 1977, 1981, and 1985 showed no detectable thinning of the tank wall. UT measurements made in 2006 showed no reportable thinning, pitting, stress corrosion cracking, or evidence of service induced thinning on the primary tank wall. Reportable thicknesses were detected in the top plate of the primary vessel, but are attributed to fabrication artifacts.

Reportable thicknesses were detected in one of four secondary wall plates as well as the annulus floor. Details of this inspection are documented in WSRC-TR-2007-00064.

\section{Tank 36}

Tank 36 was placed in service in 1977. Visual examinations of $100 \%$ of the exterior of the primary vessel wall and the annulus have shown no leakage, significant surface corrosion or other anomalies. UT measurements made in 1977, 1981, and 1985 showed no detectable thinning of the tank wall. UT measurements made in 2007 showed no reportable thinning, pitting, stress corrosion cracking, or evidence of service induced thinning on the primary or secondary tank wall. Reportable areas were observed in annulus floor. Details of this inspection are documented in WSRC-TR2007-00064. 


\section{Tank 37}

Tank 37 was placed in service in 1978. Visual examinations of $100 \%$ of the exterior of the primary vessel wall and the annulus have shown no leakage, significant surface corrosion or other anomalies. UT measurements made in 1977, 1981, and 1985 showed no detectable thinning of the tank wall. UT measurements made in 2007 showed no reportable thinning, pitting, stress corrosion cracking, or evidence of service induced thinning on the primary or secondary tank wall. Reportable areas were observed in annulus floor. Details of this inspection are documented in WSRC-TR2007-00064.

\section{Tank 38}

Tank 38 was placed in service in 1981. Visual examinations of $100 \%$ of the exterior of the primary vessel wall and the annulus have shown no leakage, significant surface corrosion or other anomalies. UT measurements made in 1980, 1981, and 1984 showed no detectable thinning of the tank wall. UT measurements made in 2007 showed no reportable thinning, pitting, stress corrosion cracking, or evidence of service induced thinning on the primary tank wall. Reportable areas were observed in one plate of the secondary wall and the annulus floor. Details of this inspection are documented in WSRC-TR-2007-00064.

\section{Tank 39}

Tank 39 was placed in service in 1982. Visual examinations of $100 \%$ of the exterior of the primary vessel wall and the annulus have shown no leakage, significant surface corrosion or other anomalies. UT measurements made in 1980, 1981, 1984, and 1985 showed no detectable thinning of the tank wall. UT measurements made in
2005 showed no reportable thinning, pitting or stress corrosion cracking or evidence of service induced tank wall thinning on the primary tank wall. Several grinding areas in the upper plate of the primary vessel wall had areas below the $10 \%$ reporting criteria. Several small areas of reportable thickness were detected in secondary wall plates 1,2 and 4. Details of this inspection are documented in WSRC-TR-2006-00002.

\section{Tank 40}

Tank 40 was placed in service in 1986. Visual examinations of $100 \%$ of the exterior of the primary vessel wall and the annulus have shown no leakage, significant surface corrosion or other anomalies. UT measurements were made in 1980, 1981, and 1984. Thickness mapping was performed in 1996 using the P-scan System to provide reference measurements for the future. UT measurements made in 2006 showed no reportable pitting, stress corrosion cracking, or evidence of service induced thinning on the primary tank wall. Reportable thicknesses were detected in the top plate of the primary tank wall but were attributed to fabrication artifacts. Reportable thicknesses were detected in 2 of 4 secondary wall plates. Reportable thicknesses were detected on the annulus floor, but were attributed to pre-service pitting. Details of this inspection are documented in WSRC-TR-2006-00002.

\section{Tank 41}

Tank 41 was placed in service in 1982. Visual examinations of $100 \%$ of the exterior of the primary vessel wall and the annulus have shown no leakage, significant surface corrosion or other anomalies. UT measurements made in 1980, 1981, and 1984 showed no detectable thinning of the tank wall. UT measurements made in 2006 
SRR-STI-2011-00285

Annual Radioactive Waste Tank

showed no reportable pitting, stress corrosion cracking, or evidence of service induced thinning on the primary tank wall. Reportable thicknesses were detected in the top knuckle and plate of the primary tank and in one plate on the secondary wall. Reportable thicknesses were detected on the annulus floor but were attributed to preservice pitting. Details of this inspection are documented in WSRC-TR-2006-00002.

\section{Tank 42}

Tank 42 was placed in service in 1982. Visual examinations of $100 \%$ of the exterior of the primary vessel wall and the annulus have shown no leakage, significant surface corrosion or other anomalies. Ultrasonic thickness measurements were made in 1980 , 1981, 1984, 1985 and 1990. Thickness mapping was performed in 1995 and 1996 using the P-scan System to provide reference measurements for the future. UT measurements made in 2004 showed no reportable thinning, pitting or stress corrosion cracking or evidence of service induced tank wall thinning on the primary tank wall. A few small areas of reportable thickness were detected on the secondary tank wall with the minimum thickness being 0.338 inches on plate one, 0.336 inches on plate two, and 0.332 inches on plate three. Details of this inspection are documented in WSRC-TR-2005-00039.

\section{Tank 43}

Tank 43 was placed in service in 1982. Visual examinations of $100 \%$ of the exterior of the primary vessel wall and the annulus have shown no leakage, significant surface corrosion or other anomalies. UT measurements made in 1980, 1981, 1984, and 1985 showed no detectable thinning of the tank wall. UT measurements made in 2006 showed no reportable thinning, pitting, stress corrosion cracking, or evidence of service induced thinning on the primary tank wall. Reportable thicknesses were detected in the top and middle plates of the primary vessel, but are attributed to fabrication artifacts. Reportable thicknesses were detected in two of four secondary wall plates as well as the annulus floor. Grinding areas were observed in all plates. Details of this inspection are documented in WSRC-TR2006-00002.

\section{Tank 44}

Tank 44 was placed in service in 1982.

Visual examinations of $100 \%$ of the exterior of the primary vessel wall and the annulus have shown no leakage, significant surface corrosion or other anomalies. UT measurements made in 1980, 1981, and 1984 showed no detectable thinning of the tank wall. UT measurements made in 2005 showed no reportable thinning, pitting or stress corrosion cracking or evidence of service induced tank wall thinning on the primary tank wall. Several small areas of reportable thickness in secondary wall plates 1, 2 and 4 were detected. Details of this inspection are documented in WSRC-TR2005-00039.

\section{Tank 45}

Tank 45 was placed in service in 1982. Visual examinations of $100 \%$ of the exterior of the primary vessel wall and the annulus have shown no leakage, significant surface corrosion or other anomalies. UT measurements made in 1980,1981 , and 1984 showed no detectable thinning of the tank wall. UT measurements made in 2005 showed no reportable thinning, pitting or stress corrosion cracking or evidence of service induced tank wall thinning on the primary tank wall. One small area of reportable thickness was detected in the second wall plate on the secondary liner. Details of this inspection are documented in 
SRR-STI-2011-00285

Annual Radioactive Waste Tank

Inspection Program - 2010

Program Implementation

WSRC-TR-2005-00039.

Tank 48

\section{Tank 46}

Tank 46 was placed in service as an emergency spare tank in 1980. It was placed in waste storage service in 1994 when it began receiving concentrate from the $2 \mathrm{~F}$ evaporator. Visual examinations of $100 \%$ of the exterior of the primary vessel wall and the annulus have shown no significant surface corrosion or other anomalies. UT measurements made in 1980, 1981, and 1984 showed no detectable thinning of the tank wall. UT measurements made in 2005 showed no reportable thinning, pitting or stress corrosion cracking or evidence of service induced tank wall thinning on the primary tank wall. One small area of reportable thickness was detected in the first wall plate on the secondary liner. Details of this inspection are documented in WSRC-TR-2005-00039.

\section{Tank 47}

Tank 47 was placed in service in 1980 . Visual examinations of $100 \%$ of the exterior of the primary vessel wall and the annulus have shown no leakage, significant surface corrosion or other anomalies. UT measurements made in 1980, 1981, and 1984 showed no detectable thinning of the tank wall. UT measurements made in 2005 showed no reportable thinning, pitting or stress corrosion cracking or evidence of service induced tank wall thinning on the primary tank wall. Two small areas of reportable thickness were detected in the fourth wall plate on the secondary liner. An incipient pit was noted in the lower plate of the primary vessel wall. Details of this inspection are documented in WSRC-TR2005-00039.

Tank 48 was placed in service in 1983. Visual examinations of $100 \%$ of the exterior of the primary vessel wall and the annulus have shown no leakage, significant surface corrosion or other anomalies. UT measurements were made in 1982 prior to placing the tank in service. Thickness mapping was performed in 1994, 1995, 1996, and 1997 using the P-scan System to provide reference measurements for the future. UT measurements made in 2004 showed no reportable thinning, pitting or stress corrosion cracking or evidence of service induced tank wall thinning on the primary tank wall. Details of this inspection are documented in WSRC-TR-2004-00166.

\section{Tank 49}

Tank 49 was placed in service in 1983. Visual examinations of $100 \%$ of the exterior of the primary vessel wall and the annulus have shown no leakage, significant surface corrosion or other anomalies. UT measurements were made in 1982 prior to placing the tank in service. Thickness mapping was performed in 1995 using the P-scan System to provide reference measurements for the future. UT measurements made in 2004 showed no reportable thinning, pitting or stress corrosion cracking or evidence of service induced tank wall thinning on the primary tank wall. Details of this inspection are documented in WSRC-TR-2005-00039. Two cooling coils were identified as failed in 2007 when inspections revealed the presence of chromate deposits on the primary vessel wall.

\section{Tank 50}

Tank 50 was placed in service in 1983. Visual examinations of $100 \%$ of the exterior 
SRR-STI-2011-00285

Annual Radioactive Waste Tank

of the primary vessel wall and the annulus

have shown no leakage, significant surface corrosion or other anomalies. UT

measurements were made in 1982 prior to placing the tank in service. Thickness mapping was performed in 1994 and 1995 using the P-scan System to provide reference measurements for the future. UT measurements made in 2004 showed no reportable thinning, pitting or stress corrosion cracking or evidence of service induced tank wall thinning on the primary tank wall. Details of this inspection are documented in WSRC-TR-2004-00166.

\section{Tank 51}

Tank 51 was placed in service in 1986.

Visual examinations of $100 \%$ of the exterior of the primary vessel wall and the annulus have shown no leakage, significant surface corrosion or other anomalies. UT measurements were made in 1982 prior to placing the tank in service. Thickness mapping was performed in 1996 and 1997 using the P-scan System to provide reference measurements for the future. UT measurements made in 2004 showed no reportable thinning, pitting or stress corrosion cracking or evidence of service induced tank wall thinning on the primary tank wall. A few small areas of reportable thickness were detected on the secondary tank wall with the minimum thickness being 0.332 inches on plate one and 0.336 inches on plate two. Details of this inspection are documented in WSRC-TR-2005-00039. One cooling coil was identified as failed in 2007 when inspections revealed the presence of chromate deposits on the primary vessel wall. 
SRR-STI-2011-00285

Annual Radioactive Waste Tank

\section{Appendix A-Waste Tanks at SRS}

\section{SRS Waste Tank Specifications}

\begin{tabular}{|c|c|c|c|c|}
\hline Number & Type & $\begin{array}{l}\text { Project } \\
\text { Number }\end{array}$ & $\begin{array}{c}\text { Construction } \\
\text { Period }\end{array}$ & $\begin{array}{c}\text { Type of* } \\
\text { Construction }\end{array}$ \\
\hline $1-8$ & I & 8980 & $1951-1953$ & $\begin{array}{l}\text { Double wall- } \\
\text { cooled }\end{array}$ \\
\hline $9-12$ & I & 8980 & $1951-1953$ & $\begin{array}{l}\text { Double wall- } \\
\text { cooled }\end{array}$ \\
\hline $13-16$ & II & $\begin{array}{l}8980 \\
\text { P. W. O }\end{array}$ & $1955-1956$ & $\begin{array}{l}\text { Double wall- } \\
\text { cooled }\end{array}$ \\
\hline $17-20$ & IV & 981030 & 1956 & $\begin{array}{l}\text { Single wall- } \\
\text { uncooled }\end{array}$ \\
\hline $21-24$ & IV & 981089 & 1960 & $\begin{array}{l}\text { Single wall- } \\
\text { uncooled }\end{array}$ \\
\hline $25-28$ & IIIA & $\begin{array}{l}9 \mathrm{~S} 1493 \\
(75-1-\mathrm{a})\end{array}$ & $1975-1978$ & $\begin{array}{l}\text { Double wall- } \\
\text { cooled }\end{array}$ \\
\hline $29-32$ & III & 981232 & $1966-1970$ & $\begin{array}{l}\text { Double wall- } \\
\text { cooled }\end{array}$ \\
\hline $33-34$ & III & 9S0974 & $1969-1972$ & $\begin{array}{l}\text { Double wall- } \\
\text { cooled }\end{array}$ \\
\hline $35-37$ & IIIA & $\begin{array}{l}9 \mathrm{~S} 1463 \\
(74-1-a)\end{array}$ & 1974-1977 & $\begin{array}{l}\text { Double wall- } \\
\text { cooled }\end{array}$ \\
\hline $38-43$ & IIIA & $\begin{array}{l}\text { 9S1618 } \\
(76-8-A)\end{array}$ & $1976-1980$ & $\begin{array}{l}\text { Double wall- } \\
\text { cooled }\end{array}$ \\
\hline $44-47$ & IIIA & 9S1747 & $1977-1980$ & $\begin{array}{l}\text { Double wall- } \\
\text { cooled }\end{array}$ \\
\hline $48-51$ & IIIA & $\begin{array}{l}9 \mathrm{~S} 1828 \\
(78-18-\mathrm{b})\end{array}$ & $1978-1981$ & $\begin{array}{l}\text { Double wall- } \\
\text { cooled }\end{array}$ \\
\hline
\end{tabular}

* Tanks 32 and 35 have removable, roof-supported cooling coils. Tanks 30, 33, and 34 have bottom-supported deployable cooling coils. Tanks 29 and 31 have some deployable and some close-packed cooling assemblies, all bottom supported. All other cooled tanks have permanently installed cooling coils, roof-supported in Type I and II and bottom-supported in Type III tanks. 
SRR-STI-2011-00285

Annual Radioactive Waste Tank

This page intentionally left blank 


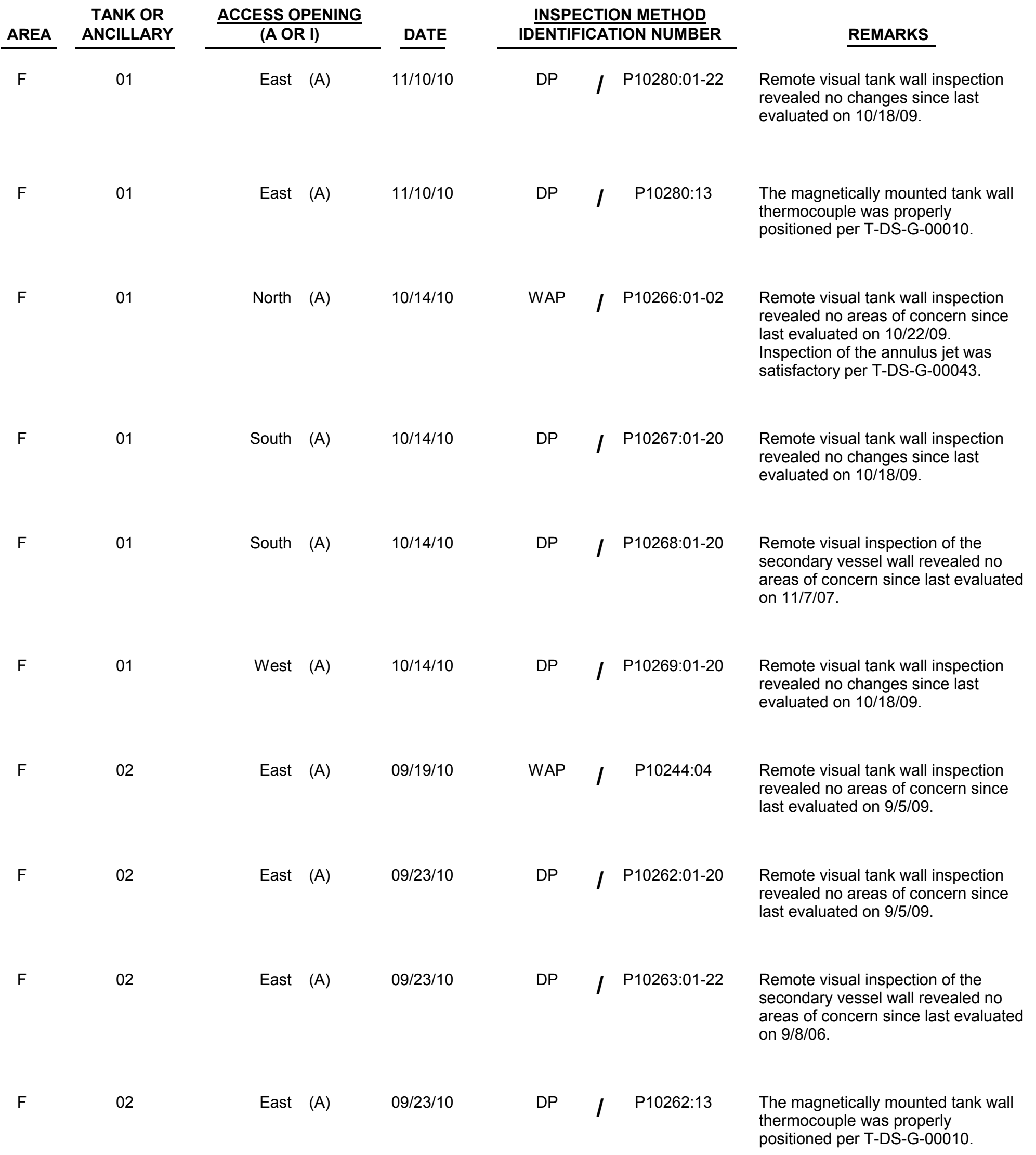




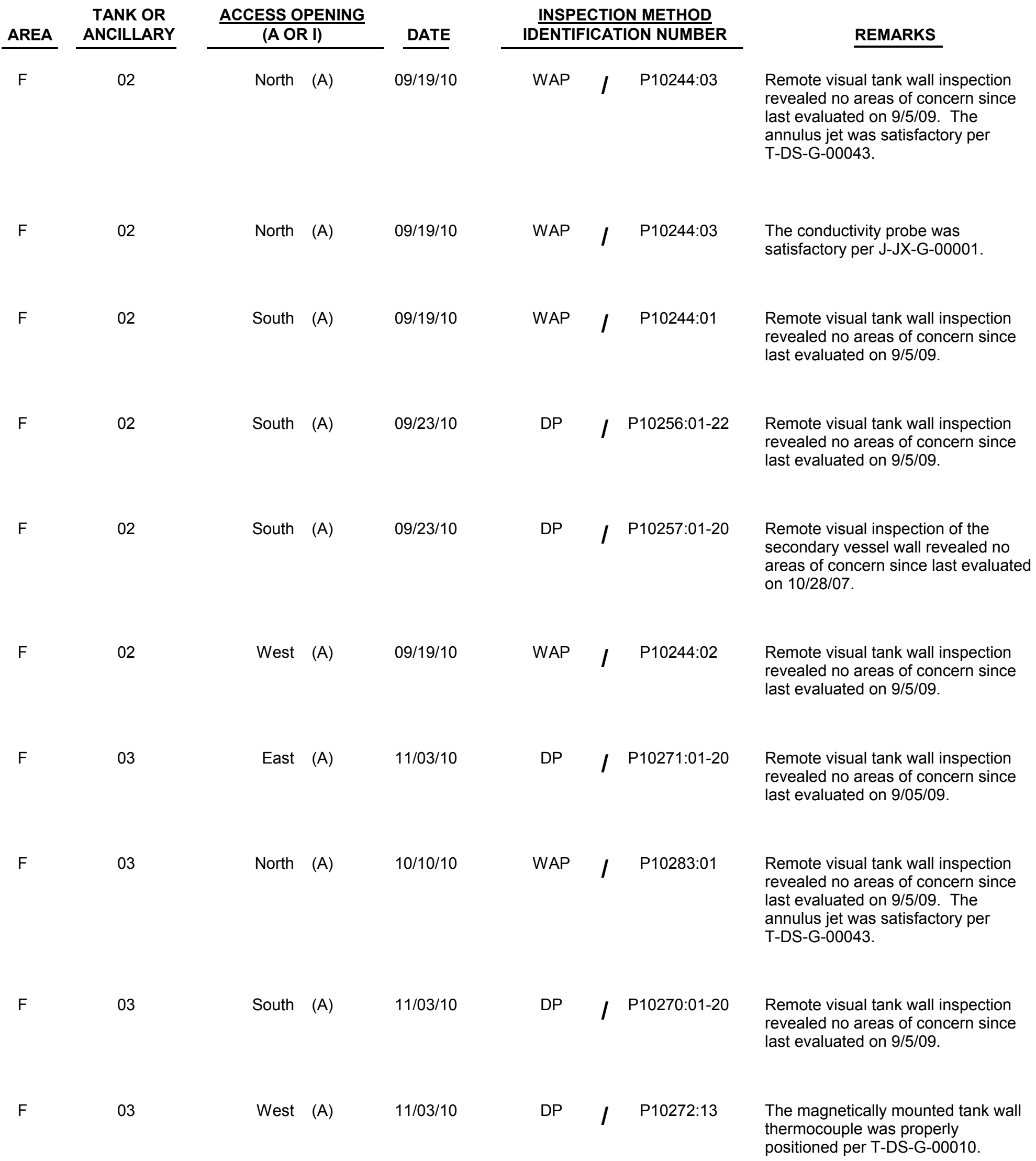


TANK OR ACCESS OPENING

AREA ANCILLARY

03

04

04

04

04

04

04

$\mathrm{F}$

$\mathrm{F}$

$\mathrm{F}$

South (A)

$09 / 25 / 10$

East (A) 09/25/10

East (A)

$09 / 25 / 10$

North

(A)

$09 / 25 / 10$

North (A)

$10 / 24 / 10$

South (A)

$09 / 25 / 10$

04

West (A)

$09 / 25 / 10$

05

05
CCTV

I

2173

DP / P10248:01-21

INSPECTION METHOD IDENTIFICATION NUMBER

DP I P10272:01-20

DP / P10273:01-20

DP / P10252:01-20

$\mathrm{DP} \quad / \quad \mathrm{P} 10252: 18$

CCTV I $\quad 2144$

The conductivity probe was properly positioned per J-JX-G-0001.

Remote visual tank wall inspection revealed no areas of concern since last evaluated on 9/25/09.

Remote visual tank wall inspection revealed no areas of concern since last evaluated on $9 / 25 / 09$. The annulus jet was satisfactory per T-DS-G-00043.

Remote visual inspection of the secondary vessel wall revealed no areas of concern since last evaluated on $10 / 30 / 07$.

Remote visual tank wall inspection revealed no areas of concern since last evaluated on 9/25/09.

Remote visual tank wall inspection revealed no changes since last evaluated on 10/21/09.

Remote visual tank wall inspection revealed no changes since last evaluated on 10/13/09. 


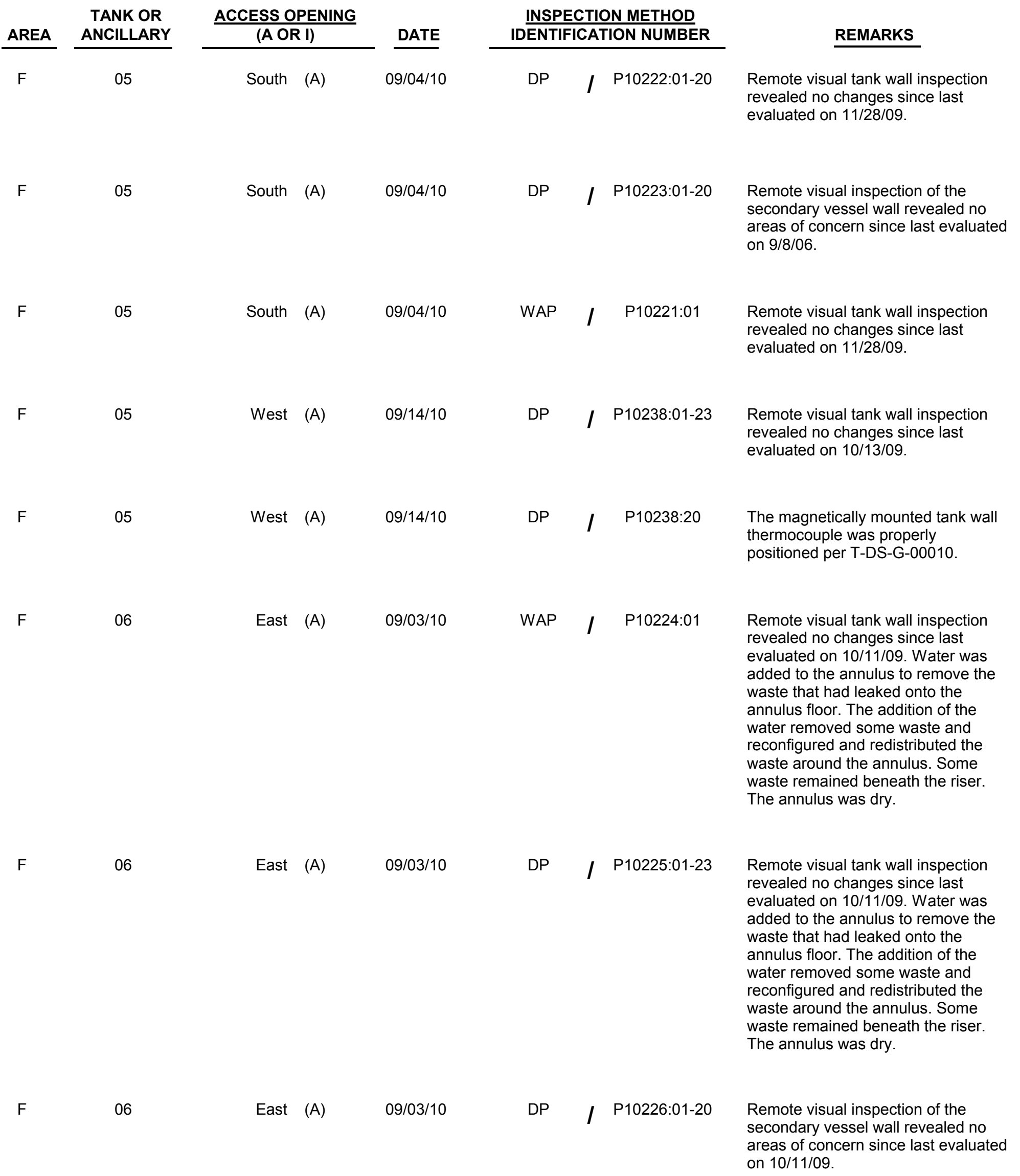




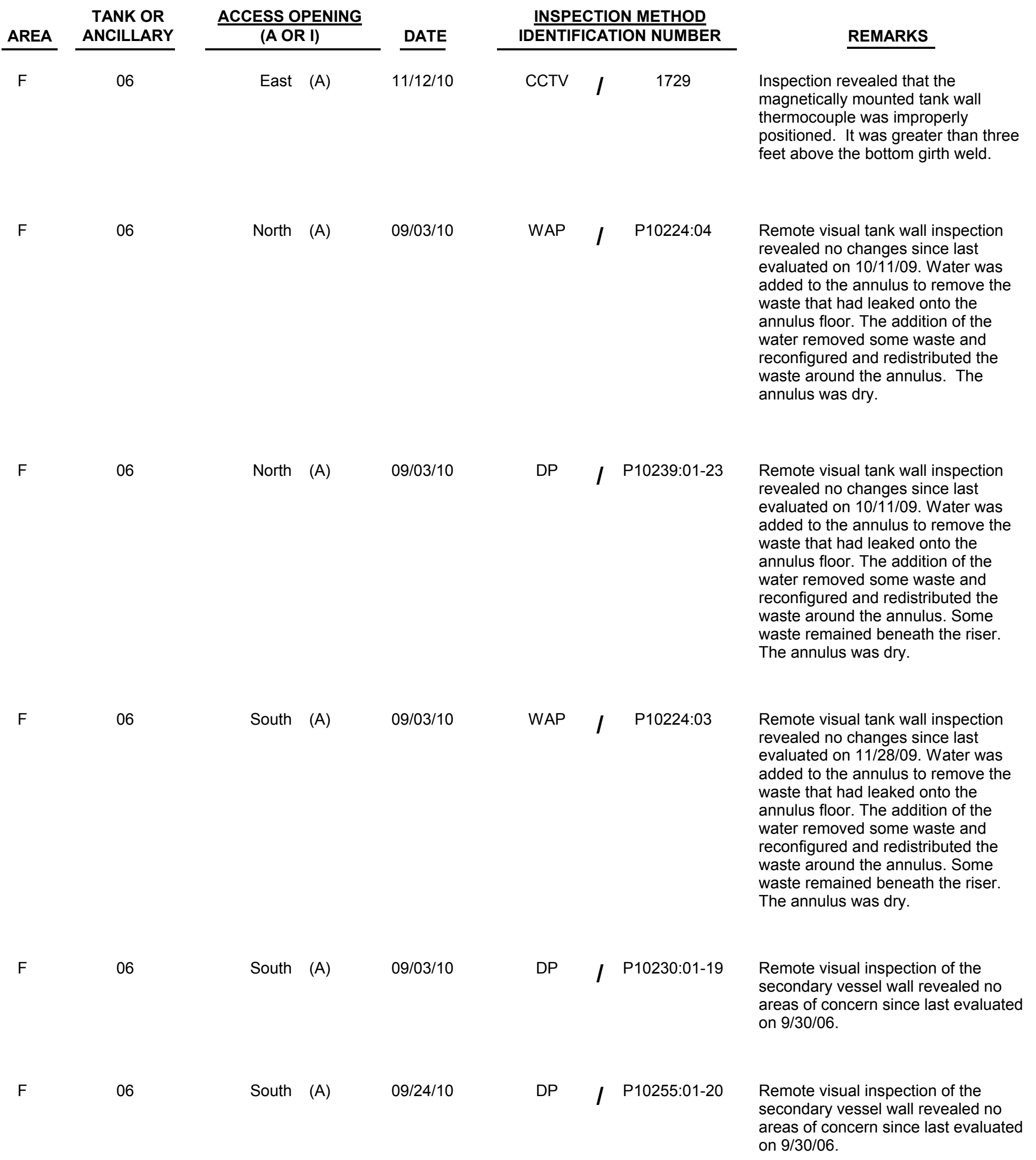


TANK OR ACCESS OPENING

AREA ANCILLARY

06

(A OR I)

South (A)
DATE

$09 / 24 / 10$

West

(A)

09/03/10

06

06

06

07

VB-01

West (A)

(A)

West (A)

09/03/10

$09 / 24 / 10$

DP

I P10253:01-21 IDENTIFICATION NUMBER

DP

WAP / P10224:02

DP / P10228:01-20
INSPECTION METHOD

I P10254:01-20

Remote visual inspection of the secondary vessel wall revealed no areas of concern since last evaluated on $9 / 23 / 08$.

Remote visual tank wall inspection revealed no areas of concern since last evaluated on 11/28/09. Water was added to the annulus to remove the waste that had leaked onto the annulus floor. The addition of the water removed some waste and reconfigured and redistributed the waste around the annulus. The annulus was dry.

Inspection of the walls, floors, jumpers, valves, piping, and conductivity probes was satisfactory per SW11.6-SVP-45, Section 7.9.

Inspection of the walls, floor, jumpers, valves, piping, and conductivity probes was satisfactory per SW11.6-SVP-45, Section 7.9. 


\begin{tabular}{|c|c|c|c|c|c|c|c|}
\hline \multirow{2}{*}{$\frac{\text { AREA }}{F}$} & \multirow{2}{*}{$\begin{array}{c}\text { TANK OR } \\
\text { ANCILLARY } \\
07\end{array}$} & $\frac{\text { ACCESS OPENING }}{(A \text { OR I) }}$ & \multirow{2}{*}{$\frac{\text { DATE }}{10 / 31 / 10}$} & \multicolumn{3}{|c|}{$\frac{\text { INSPECTION METHOD }}{\text { IDENTIFICATION NUMBER }}$} & \multirow{2}{*}{$\begin{array}{l}\text { REMARKS } \\
\text { Inspection of the walls, floor, } \\
\text { jumpers, valves, piping, and } \\
\text { conductivity probes was satisfactory } \\
\text { per SW11.6-SVP-45, Section } 7.9 \text {. }\end{array}$} \\
\hline & & VB-03 & & CCTV & l & 2186 & \\
\hline $\mathrm{F}$ & 07 & VB-04 & $10 / 31 / 10$ & CCTV & I & 2186 & $\begin{array}{l}\text { Inspection of the walls, floor, } \\
\text { jumpers, valves, piping, and } \\
\text { conductivity probes was satisfactory } \\
\text { per SW11.6-SVP-45, Section } 7.9 \text {. }\end{array}$ \\
\hline $\mathrm{F}$ & 07 & VB-05 & $10 / 30 / 10$ & CCTV & I & 2186 & $\begin{array}{l}\text { Inspection of the walls, floors, } \\
\text { jumpers, valves, piping, and } \\
\text { conductivity probes was satisfactory } \\
\text { per SW11.6-SVP-45, Section } 7.9 \text {. }\end{array}$ \\
\hline $\mathrm{F}$ & 07 & North (A) & $11 / 03 / 10$ & DP & I & P10274:01-21 & $\begin{array}{l}\text { Remote visual tank wall inspection } \\
\text { revealed no areas of concern since } \\
\text { last evaluated on } 3 / 18 / 09 \text {. }\end{array}$ \\
\hline $\mathrm{F}$ & 07 & North (A) & $11 / 03 / 10$ & DP & I & P10275:01-19 & $\begin{array}{l}\text { Remote visual inspection of the } \\
\text { secondary vessel wall revealed no } \\
\text { areas of concern since last evaluated } \\
\text { on } 3 / 18 / 09 \text {. }\end{array}$ \\
\hline $\mathrm{F}$ & 07 & South (A) & $10 / 04 / 10$ & WAP & l & P10264:01 & $\begin{array}{l}\text { Remote visual tank wall inspection } \\
\text { revealed no areas of concern since } \\
\text { last evaluated on } 9 / 28 / 09 \text {. The } \\
\text { annulus jet was satisfactory per } \\
\text { T-DS-G-00043. }\end{array}$ \\
\hline $\mathrm{F}$ & 07 & West (A) & $10 / 03 / 10$ & DP & I & P10261:11 & $\begin{array}{l}\text { The magnetically mounted tank wall } \\
\text { thermocouple was properly } \\
\text { positioned per T-DS-G-00010. }\end{array}$ \\
\hline$F$ & 07 & West (A) & $10 / 03 / 10$ & DP & I & P10261:01-20 & $\begin{array}{l}\text { Remote visual tank wall inspection } \\
\text { revealed no areas of concern since } \\
\text { last evaluated on } 3 / 18 / 09 \text {. }\end{array}$ \\
\hline $\mathrm{F}$ & 08 & LDB 17 & $12 / 29 / 10$ & CCTV & I & 2108 & $\begin{array}{l}\text { Inspection of the valves, piping, wall, } \\
\text { cover and conductivity probe was } \\
\text { satisfactory per SW11.6-SVP-45, } \\
\text { section } 7.9 \text {. }\end{array}$ \\
\hline $\mathrm{F}$ & 08 & East $(\mathrm{A})$ & $10 / 03 / 10$ & DP & I & P10258:01-20 & $\begin{array}{l}\text { Remote visual tank wall inspection } \\
\text { revealed no areas of concern since } \\
\text { last evaluated on } 9 / 4 / 09 \text {. }\end{array}$ \\
\hline
\end{tabular}


TANK OR ACCESS OPENING

AREA ANCILLARY

10

10

$\mathrm{H}$

10

$\mathrm{H}$

10

$\mathrm{H}$

$\mathrm{H}$

11

11

$\mathrm{H}$

11

11

$\mathrm{H}$

West (A)

(A) $\quad 04 / 02 / 10$

East (A)

$04 / 03 / 10$

DP / P10123:01-24

$\mathrm{DP} \quad$ / P10130:01-20

Remote visual inspection of the secondary vessel wall revealed no changes since last evaluated on 3/9/06.

Remote visual tank wall inspection revealed no changes since last evaluated on 9/9/09.

$\mathrm{DP} \quad$ / P10124:01-23

DP ～～P10125:01-21

North (A) $\quad 04 / 03 / 10$

South (A)

$04 / 03 / 10$

WAP

P10121:02
Remote visual tank wall inspection revealed no changes since last evaluated on 9/9/09.

Remote visual inspection of the secondary vessel wall revealed no areas of concern since last evaluated on $3 / 7 / 06$.

Remote visual tank wall inspection revealed no changes since last evaluated on $8 / 29 / 09$. Changes in stains observed on the annulus floor were due to water inleakage. The annulus jet was satisfactory per T-DS-G-00043.

Remote visual tank wall inspection revealed no changes since last evaluated on $8 / 29 / 09$. Water observed on the annulus floor was due to inleakage.

The magnetically mounted tank wall thermocouple was properly positioned per T-DS-G-00010. 
TANK OR ACCESS OPENING

AREA ANCILLARY

12

12

12

$\mathrm{H}$

$\mathrm{H}$

11

$\mathrm{H}$

$\mathrm{H}$

12

12

12

$\mathrm{H}$

$\mathrm{H}$

North (A)

$03 / 04 / 10$

East (A) $\quad 03 / 13 / 10$

East (A)

$03 / 13 / 10$

East (A)

$11 / 03 / 10$

North (A)

$03 / 04 / 10$

$03 / 13 / 10$

South (A)

12

West (A)

$03 / 04 / 10$

12

13
DP

/ P10085:01-22

$\mathrm{DP} \quad / \quad \mathrm{P} 10086: 01-22$

WAP

I P10088:01

DP / P10087:01-24

INSPECTION METHOD

IDENTIFICATION NUMBER

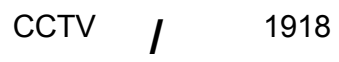

DP / P10084:01-20

$\mathrm{DP} \quad / \quad \mathrm{P} 10084: 18$

WAP / P10278:01

Remote visual tank wall inspection revealed no changes since last inspected on 8/28/09.

Remote visual tank wall inspection revealed no changes since last inspected on $8 / 28 / 09$. During waste removal activities, previously identified leaksites had been reactivated.

Remote visual inspection of the secondary vessel wall revealed no areas of concern since last evaluated on $1 / 3 / 06$.

Remote visual tank wall inspection revealed no changes since last inspected on $8 / 28 / 09$. Water observed on the annulus floor was due to inleakage.

Remote visual tank wall inspection revealed no changes since last inspected on 8/28/09.

Inspection of the transfer isolation valves and piping was satisfactory per T-DS-G-00003.

Remote visual tank wall inspection revealed no changes since last evaluated on 11/18/09. 
TANK OR ACCESS OPENING

AREA ANCILLARY

13

13

13

13

13

$\mathrm{H}$

$\mathrm{H}$

13

$\frac{\frac{\text { ACCESS OPENING }}{\text { (A OR I) }}}{}$

DATE

032 (A)

$04 / 18 / 10$

055 (A)

$04 / 18 / 10$

$071 \quad$ (A)

$11 / 08 / 10$

071 (A)

$11 / 18 / 10$

107 (A)

$04 / 18 / 10$

151 (A)

$04 / 18 / 10$

175 (A)

05/01/10

207 (A)

$04 / 17 / 10$

13

$\mathrm{H}$

$\mathrm{H}$

13

13

$\mathrm{H}$

$\mathrm{H}$
East (A)

$05 / 01 / 10$
DP

/ P10156:01-22

DP

/ P10152:01-21

WAP

/ P10183:01

INSPECTION METHOD IDENTIFICATION NUMBER

DP / P10155:01-23

DP / P10277:01-20

DP I P10276:01-20

$\mathrm{DP} \quad$ / P10153:01-25

Remote visual tank wall inspection revealed no changes since last evaluated on 11/18/09.

Remote visual tank wall inspection revealed no changes since last evaluated on 11/18/09.

WAP I P10148:02

Remote visual tank wall inspection revealed no changes since last evaluated on 11/18/09.

Remote visual tank wall inspection revealed no changes since last evaluated on 11/14/09.

Remote visual tank wall inspection revealed no changes since last evaluated on $11 / 18 / 09$. The annulus jet was satisfactory per T-DS-G-00043.

Remote visual tank wall inspection revealed no changes since last evaluated on 11/14/09. 
TANK OR ACCESS OPENING

AREA ANCILLARY

13

13

$\mathrm{H}$

13

$\mathrm{H}$

14

$\mathrm{H}$

$\mathrm{H}$

14

14

14

14

$\mathrm{H}$

$\mathrm{H}$

$\mathrm{H}$

065 (A)

$04 / 11 / 10$

065 (A)

$04 / 11 / 10$

108

(A)

$04 / 11 / 10$

14

$118 \quad(\mathrm{~A})$

$04 / 11 / 10$

14

14
DP

I P10134:01-22

WAP

/ P10131:01

INSPECTION METHOD IDENTIFICATION NUMBER

DP / P10149:26

DP / P10150:01-20

DP / P10151:01-22

WAP / P10131:06

WAP / P10131:07

DP / P10133:01-22

DP / P10132:01-22

Remote visual tank wall inspection revealed no changes since last inspected on 11/9/09.

Remote visual tank wall inspection revealed no changes since last inspected on 11/9/09.

Remote visual tank wall inspection revealed no changes since last inspected on 11/9/09.

Remote visual tank wall inspection revealed no changes since last inspected on 11/9/09.

WAP / P10131:02
Remote visual tank wall inspection revealed no changes since last inspected on 11/9/09. 
TANK OR ACCESS OPENING

AREA ANCILLARY

14

14

$\mathrm{H}$

$\mathrm{H}$

14

14

14

14

$\mathrm{H}$

$\mathrm{H}$

$\mathrm{H}$

259 (A)

$04 / 11 / 10$

207 (A) $\quad 04 / 11 / 10$

235 (A)

$04 / 11 / 10$

East (A)

$04 / 11 / 10$

North (A)

$04 / 11 / 10$

North (A)

$04 / 11 / 10$

14

$\mathrm{H}$

15

15

15

15
$010 \quad(A)$

04/09/10

032 (A)

04/07/10

$04 / 07 / 10$

055 (A)

071 (A)

04/07/10
WAP

I P10131:04

DP

I P10137:01-22

DP

I P10138:01-22

INSPECTION METHOD IDENTIFICATION NUMBER

WAP / P10131:03

DP / P10136:01-22

WAP / P10131:05

Remote visual tank wall inspection revealed no changes since last inspected on 11/9/09.

Remote visual tank wall inspection revealed no changes since last inspected on 11/13/09.

Remote visual tank wall inspection revealed no changes since last inspected on 11/13/09.

The magnetically mounted tank wall thermocouple was properly positioned per T-DS-G-00010.

Remote visual tank wall inspection revealed no changes since last evaluated on 11/21/09.

Remote visual tank wall inspection revealed no changes since last evaluated on 11/20/09.

Remote visual tank wall inspection revealed no changes since last evaluated on 11/20/09.

Remote visual tank wall inspection revealed no changes since last evaluated on 11/20/09. 
TANK OR ACCESS OPENING

AREA ANCILLARY

15

15

15

15

$\mathrm{H}$

15

$\frac{\frac{\text { ACCESS OPENING }}{(A \text { OR I) }}}{}$

DATE

$071 \quad$ (A)

$04 / 07 / 10$

107

(A)

$04 / 09 / 10$

WAP

I P10147:03

117 (A)

$08 / 16 / 10$

CCTV

1909

WAP I P10147:04

$137 \quad$ (A) $\quad 04 / 09 / 10$

171 (A)

$04 / 09 / 10$

WAP

P10147:05

182 (A)

$04 / 09 / 10$

WAP

I P10147:06

207 (A)

$04 / 07 / 10$

15

15

$\mathrm{H}$

$\mathrm{H}$

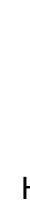

15
15

15

242 (A)

242 (A)

$04 / 09 / 10$

WAP / P10147:08
$01 / 10 / 10$

\section{REMARKS}

Remote visual inspection of the secondary vessel wall revealed no areas of concern since last evaluated on $5 / 16 / 06$.

Remote visual tank wall inspection revealed no changes since last evaluated on 11/21/09.

The conductivity probe was properly positioned per J-JX-G-0001.

Remote visual tank wall inspection revealed no changes since last evaluated on $11 / 21 / 09$.

Remote visual tank wall inspection revealed no changes since last evaluated on 11/21/09.

Remote visual tank wall inspection revealed no changes since last evaluated on 11/21/09. An increase in stains on the ventilation duct was due to water inleakage.

Remote visual tank wall inspection revealed no changes since last evaluated on 11/20/09.

Remote visual tank wall inspection revealed no changes since last evaluated on 11/20/09.

The magnetically mounted tank wall thermocouple was properly positioned per T-DS-G-00010.

Remote visual tank wall inspection revealed no changes since last evaluated on $3 / 29 / 89$.

Remote visual tank wall inspection revealed no changes since last evaluated on 11/20/09. 
TANK OR ACCESS OPENING

AREA ANCILLARY

15

15

15

$\mathrm{H}$

$\mathrm{H}$

$\mathrm{H}$

15

(A OR I)

DATE

North (A)

$04 / 07 / 10$

$\mathrm{DP} \quad$ / P10146:01-26

INSPECTION METHOD

IDENTIFICATION NUMBER

REMARKS

Remote visual tank wall inspection revealed no changes since last evaluated on 11/20/09.

South (A)

$04 / 09 / 10$

WAP

I P10147:01

08/05/10

CCTV

2090

South

(A)

West

(A)

$04 / 07 / 10$

DP

I P10145:01-27

$07 / 04 / 10$

CCTV

2123

Center (I)

I

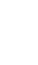

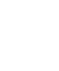

Remote visual inspection ot the tank wall and concrete dome revealed no areas of concern since last evaluated

$07 / 02 / 10$

CCTV

l

2122

$\mathrm{H}$

21

NE (I)

05/20/10

CCTV

2105

$H$

21

$\mathrm{H}$

22

NE (l)

$06 / 02 / 10$

CCTV

I

2112

SW (I)

$11 / 19 / 10$

CCTV / 2196

Remote visual inspection of the tank wall and concrete dome revealed no areas of concern since last evaluated on 09/30/09. The HLLCP was

properly positioned. on $7 / 22 / 09$.

Remote visual inspection of the tank wall and concrete dome revealed no areas of concern since last evaluated on $3 / 20 / 09$.

Remote visual inspection of the tank wall and concrete dome revealed no areas of concern since last evaluated on $9 / 4 / 09$.

Inspection of the concrete dome and tank wall revealed no areas of concern signs last evaluated on $9 / 7 / 09$. The HLLCP was properly positioned. Water was observed leaking through the concrete dome. 
TANK OR ACCESS OPENING

AREA ANCILLARY

25

COP \#20

A-01 (A)

(A) $\quad 03 / 16 / 10$

WAP

I P10180:10

A-02 (A)

$03 / 16 / 10$

25

25

$\mathrm{F}$

$\mathrm{F}$

25

25

25

$\mathrm{F}$

$\mathrm{F}$

$\mathrm{F}$

A-04 (A)

$03 / 16 / 10$

WAP

I P10180:07

P-01 (A)

$03 / 16 / 10$

P-02 (A)

$03 / 16 / 10$

WAP

WAP I P10180:09

P-03 (A)

$03 / 16 / 10$

WAP

P10180:12

$\mathrm{P}-04 \quad(\mathrm{~A})$

$03 / 16 / 10$

WAP

/ P10180:13

\section{REMARKS}

Remote visual inspection of the tank wall and concrete dome revealed no areas of concern since last evaluated on $9 / 7 / 09$. The HLLCP was properly positioned.

Inspection of the transfer lines within the cleanout port was satisfactory per T-DS-G-00001. The conductivity probe was properly positioned.

Remote visual tank wall inspection revealed no areas of concern since last evaluated on 3/31/09.

Remote visual tank wall inspection revealed no areas of concern since last evaluated on 3/31/09.

Remote visual tank wall inspection revealed no areas of concern since last evaluated on 3/31/09.

Remote visual tank wall inspection revealed no areas of concern since last evaluated on 3/31/09.

Remote visual tank wall inspection revealed no areas of concern since last evaluated on 3/2/09.

Remote visual tank wall inspection revealed no areas of concern since last evaluated on 3/2/09.

Remote visual tank wall inspection revealed no areas of concern since last evaluated on 3/31/09.

Remote visual tank wall inspection revealed no areas of concern since last evaluated on 3/31/09.

Remote visual tank wall inspection revealed no areas of concern since last evaluated on 3/31/09. 


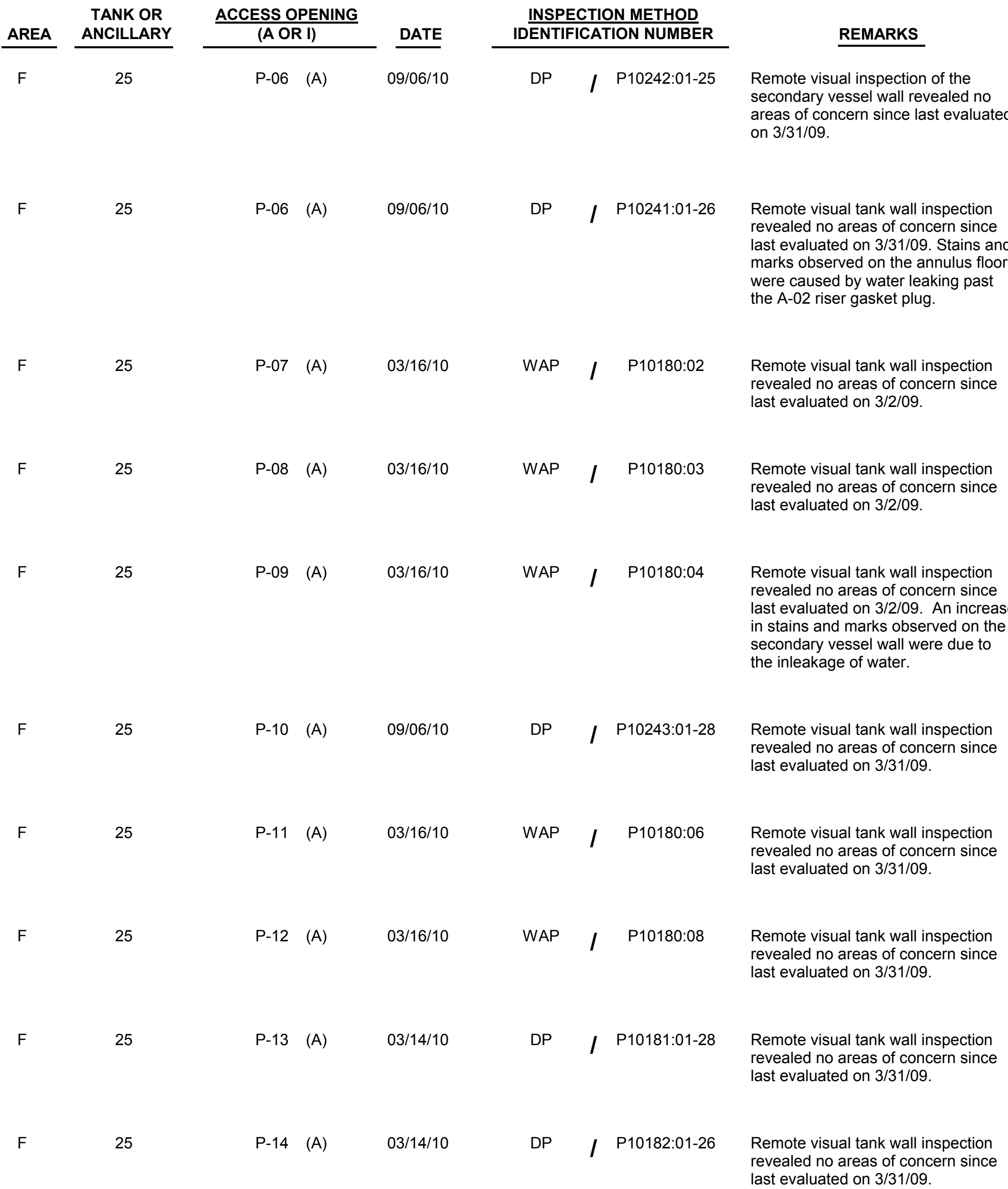




\begin{tabular}{|c|c|c|c|c|c|c|c|c|}
\hline \multirow{2}{*}{$\frac{\text { AREA }}{F}$} & \multirow{2}{*}{$\begin{array}{c}\text { TANK OR } \\
\text { ANCILLARY } \\
27\end{array}$} & \multicolumn{2}{|c|}{$\frac{\text { ACCESS OPENING }}{(A \text { OR I) }}$} & \multirow{2}{*}{$\frac{\text { DATE }}{03 / 06 / 10}$} & \multicolumn{3}{|c|}{$\frac{\text { INSPECTION METHOD }}{\text { IDENTIFICATION NUMBER }}$} & \multirow{2}{*}{$\begin{array}{l}\text { REMARKS } \\
\text { sual tank wall inspection } \\
\text { o areas of concern since } \\
\text { ted on 4/4/09. }\end{array}$} \\
\hline & & A-02 & $(\mathrm{A})$ & & WAP & l & P10193:14 & \\
\hline $\mathrm{F}$ & 27 & $A-03$ & $(\mathrm{~A})$ & 03/06/10 & WAP & l & P10193:03 & $\begin{array}{l}\text { Remote visual tank wall inspection } \\
\text { revealed no areas of concern since } \\
\text { last evaluated on } 4 / 4 / 09 \text {. }\end{array}$ \\
\hline $\mathrm{F}$ & 27 & A-04 & $(\mathrm{A})$ & 03/06/10 & WAP & l & P10193:06 & $\begin{array}{l}\text { Remote visual tank wall inspection } \\
\text { revealed no areas of concern since } \\
\text { last evaluated on } 4 / 4 / 09 \text {. }\end{array}$ \\
\hline $\mathrm{F}$ & 27 & P-01 & $(\mathrm{A})$ & $03 / 06 / 10$ & WAP & l & P10193:10 & $\begin{array}{l}\text { Remote visual tank wall inspection } \\
\text { revealed no areas of concern since } \\
\text { last evaluated on } 4 / 4 / 09 \text {. }\end{array}$ \\
\hline $\mathrm{F}$ & 27 & P-02 & (A) & 03/06/10 & WAP & l & P10193:11 & $\begin{array}{l}\text { Remote visual tank wall inspection } \\
\text { revealed no areas of concern since } \\
\text { last evaluated on } 4 / 4 / 09 \text {. }\end{array}$ \\
\hline $\mathrm{F}$ & 27 & P-03 & (A) & 03/06/10 & WAP & l & P10193:12 & $\begin{array}{l}\text { Remote visual tank wall inspection } \\
\text { revealed no areas of concern since } \\
\text { last evaluated on } 4 / 4 / 09 \text {. }\end{array}$ \\
\hline $\mathrm{F}$ & 27 & P-04 & (A) & $03 / 06 / 10$ & WAP & I & P10193:13 & $\begin{array}{l}\text { Remote visual tank wall inspection } \\
\text { revealed no areas of concern since } \\
\text { last evaluated on } 4 / 4 / 09 \text {. }\end{array}$ \\
\hline$F$ & 27 & P-05 & $(\mathrm{A})$ & $03 / 14 / 10$ & DP & I & P10194:01-25 & $\begin{array}{l}\text { Remote visual tank wall inspection } \\
\text { revealed no areas of concern since } \\
\text { last evaluated on } 4 / 4 / 09 \text {. }\end{array}$ \\
\hline$F$ & 27 & P-06 & (A) & $03 / 14 / 10$ & DP & l & P10195:01-26 & $\begin{array}{l}\text { Remote visual tank wall inspection } \\
\text { revealed no areas of concern since } \\
\text { last evaluated on 4/4/09. }\end{array}$ \\
\hline $\mathrm{F}$ & 27 & P-06 & $(\mathrm{A})$ & $03 / 14 / 10$ & DP & l & P10196:01-25 & $\begin{array}{l}\text { Remote visual inspection of the } \\
\text { secondary vessel wall revealed no } \\
\text { areas of concern since last evaluated } \\
\text { on } 4 / 4 / 09 \text {. }\end{array}$ \\
\hline $\mathrm{F}$ & 27 & P-07 & $(A)$ & $03 / 06 / 10$ & WAP & l & P09193:15 & $\begin{array}{l}\text { Remote visual tank wall inspection } \\
\text { revealed no areas of concern since } \\
\text { last evaluated on } 4 / 4 / 09 \text {. }\end{array}$ \\
\hline
\end{tabular}




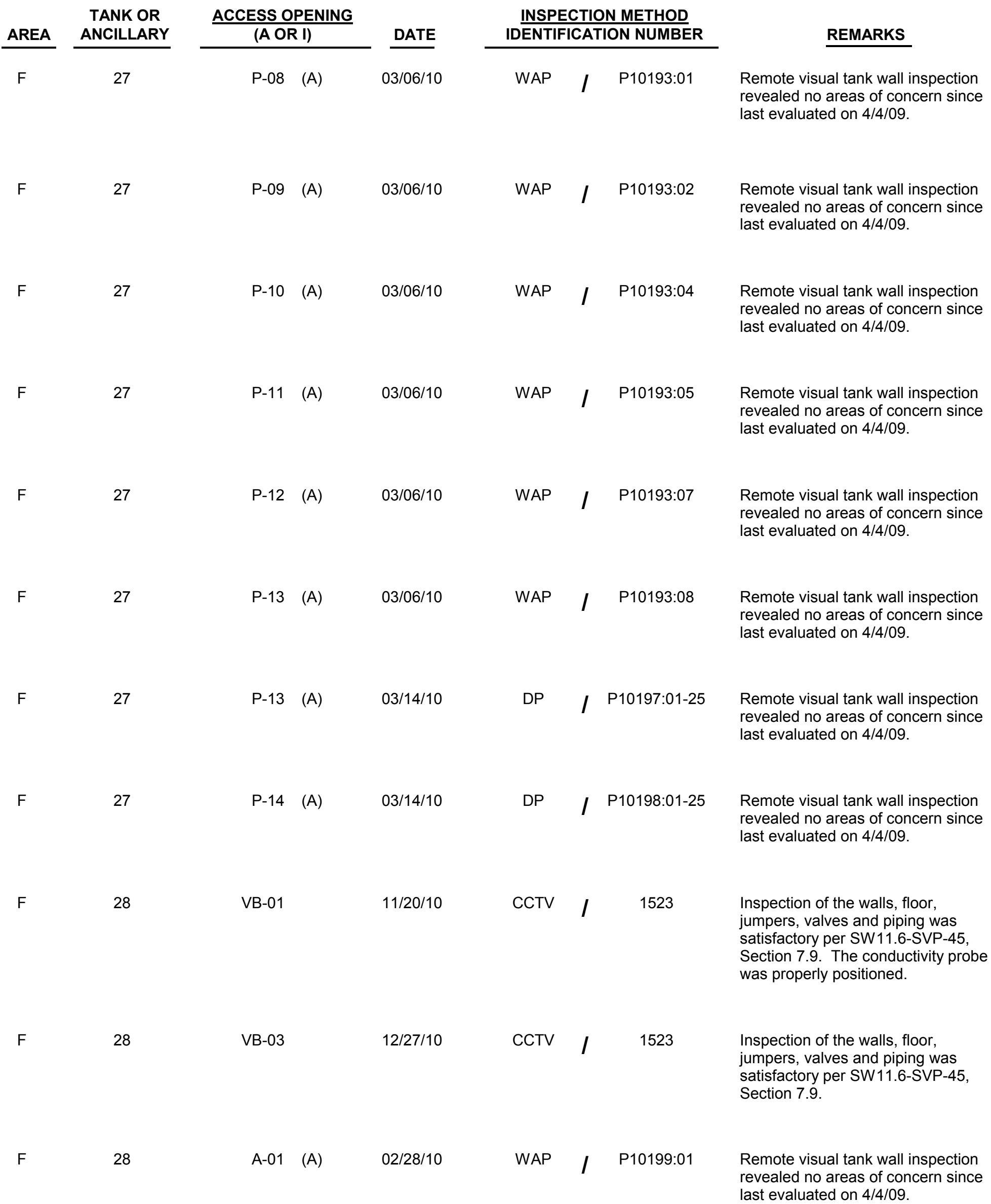




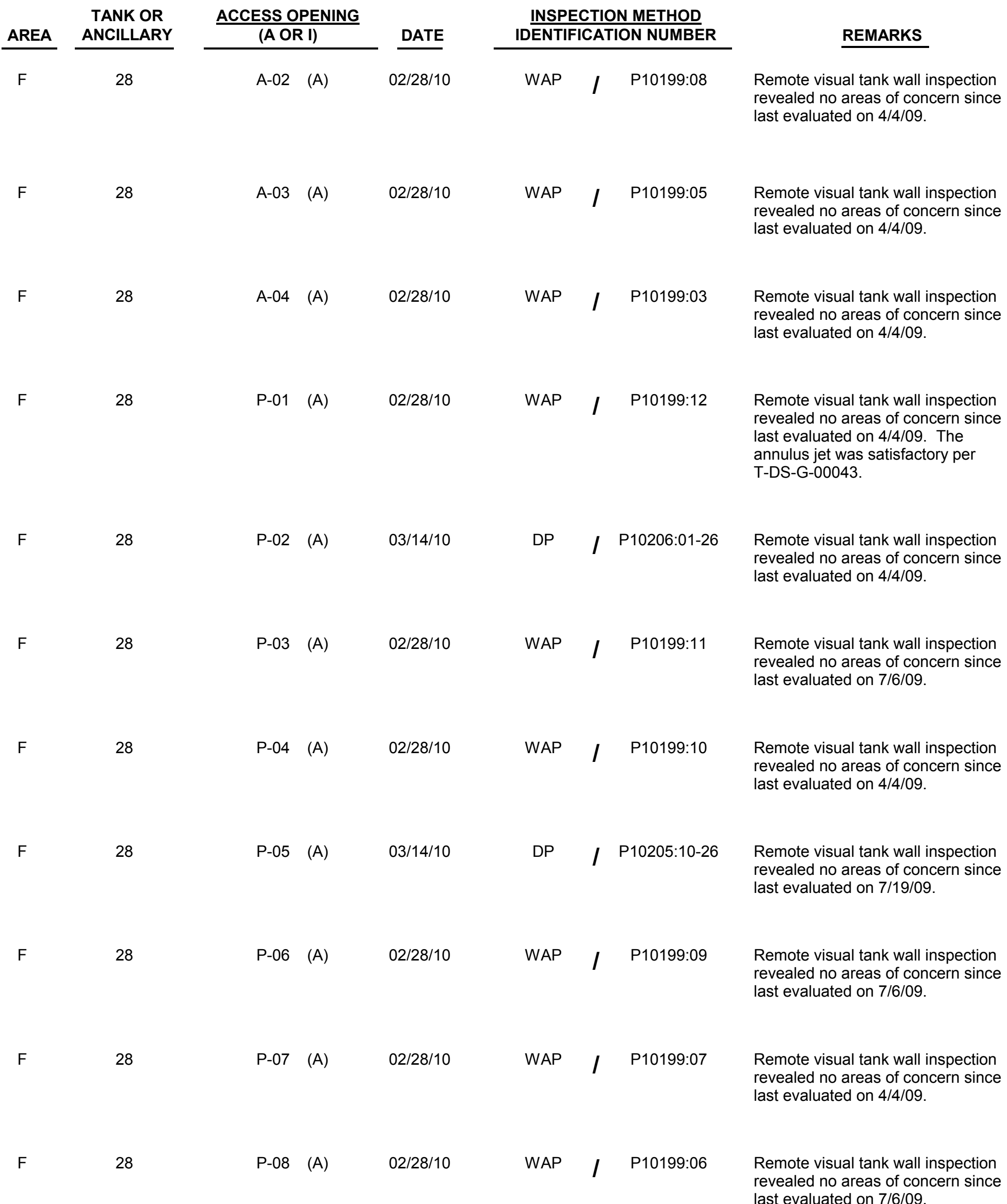
last evaluated on 7/6/09. 


\begin{tabular}{|c|c|c|c|c|c|c|c|c|}
\hline \multirow{2}{*}{$\frac{\text { AREA }}{F}$} & \multirow{2}{*}{$\begin{array}{c}\begin{array}{c}\text { TANK OR } \\
\text { ANCILLARY }\end{array} \\
28\end{array}$} & \multicolumn{2}{|c|}{$\frac{\text { ACCESS OPENING }}{(\text { A OR I) }}$} & \multirow{2}{*}{$\frac{\text { DATE }}{03 / 14 / 10}$} & \multicolumn{3}{|c|}{$\frac{\text { INSPECTION METHOD }}{\text { IDENTIFICATION NUMBER }}$} & \multirow{2}{*}{$\begin{array}{l}\text { REMARKS } \\
\text { Remote visual inspection of the } \\
\text { secondary vessel wall revealed no } \\
\text { areas of concern since last evaluated } \\
\text { on } 4 / 4 / 09 \text {. }\end{array}$} \\
\hline & & P-09 & $(\mathrm{A})$ & & DP & I & P10204:01-26 & \\
\hline $\mathrm{F}$ & 28 & P-09 & $(\mathrm{A})$ & $09 / 05 / 10$ & DP & l & P10235:01-30 & $\begin{array}{l}\text { Remote visual inspection of the } \\
\text { secondary vessel wall revealed no } \\
\text { areas of concern since last evaluated } \\
\text { on } 5 / 20 / 06 \text {. }\end{array}$ \\
\hline $\mathrm{F}$ & 28 & P-09 & (A) & $09 / 05 / 10$ & DP & l & P10234:01-26 & $\begin{array}{l}\text { Remote visual tank wall inspection } \\
\text { revealed no areas of concern since } \\
\text { last evaluated on } 4 / 4 / 09 \text {. }\end{array}$ \\
\hline $\mathrm{F}$ & 28 & P-10 & (A) & $03 / 14 / 10$ & DP & l & P10202:01-26 & $\begin{array}{l}\text { Remote visual tank wall inspection } \\
\text { revealed no areas of concern since } \\
\text { last evaluated on } 4 / 4 / 09 \text {. }\end{array}$ \\
\hline$F$ & 28 & $P-11$ & $(\mathrm{~A})$ & $02 / 28 / 10$ & WAP & I & P10199:04 & $\begin{array}{l}\text { Remote visual tank wall inspection } \\
\text { revealed no areas of concern since } \\
\text { last evaluated on } 4 / 4 / 09 \text {. }\end{array}$ \\
\hline$F$ & 28 & $\mathrm{P}-12$ & $(\mathrm{~A})$ & $02 / 28 / 10$ & WAP & l & P10199:02 & $\begin{array}{l}\text { Remote visual tank wall inspection } \\
\text { revealed no areas of concern since } \\
\text { last evaluated on } 7 / 6 / 09 \text {. }\end{array}$ \\
\hline $\mathrm{F}$ & 28 & P-13 & $(\mathrm{A})$ & $03 / 14 / 10$ & DP & l & P10201:01-27 & $\begin{array}{l}\text { Remote visual tank wall inspection } \\
\text { revealed no areas of concern since } \\
\text { last evaluated on } 4 / 4 / 09 \text {. }\end{array}$ \\
\hline $\mathrm{F}$ & 28 & $\mathrm{P}-14$ & $(\mathrm{~A})$ & $03 / 14 / 10$ & DP & l & P10200:01-27 & $\begin{array}{l}\text { Remote visual tank wall inspection } \\
\text { revealed no areas of concern since } \\
\text { last evaluated on } 4 / 4 / 09 \text {. }\end{array}$ \\
\hline $\mathrm{H}$ & 29 & COP \#101 & & $03 / 20 / 10$ & DSP & l & P10186:01-07 & $\begin{array}{l}\text { Inspection of the transfer lines within } \\
\text { the cleanout port was satisfactory per } \\
\text { T-DS-G-00001. The conductivity } \\
\text { probe was properly positioned. }\end{array}$ \\
\hline $\mathrm{H}$ & 29 & A-01 & $(\mathrm{A})$ & $02 / 13 / 10$ & WAP & I & P10072:06 & $\begin{array}{l}\text { Remote visual tank wall inspection } \\
\text { revealed no areas of concern since } \\
\text { last evaluated on } 2 / 11 / 09 \text {. }\end{array}$ \\
\hline $\mathrm{H}$ & 29 & A-02 & (A) & $02 / 13 / 10$ & WAP & l & P10072:09 & $\begin{array}{l}\text { Remote visual tank wall inspection } \\
\text { revealed no areas of concern since } \\
\text { last evaluated on } 2 / 11 / 09 \text {. }\end{array}$ \\
\hline
\end{tabular}


TANK OR ACCESS OPENING

AREA ANCILLARY

29

29

$\mathrm{H}$

$\mathrm{H}$

29

$\mathrm{H}$

29

29

$\mathrm{H}$

P-02 (A)

$02 / 13 / 10$

P-03 (A)

$02 / 23 / 10$

DP

I P10067:01-25

P-04 (A)

$02 / 13 / 10$

29

29

$\mathrm{H}$

$\mathrm{H}$

$\mathrm{H}$

29

29

29

A-04 (A)

$02 / 13 / 10$

$03 / 28 / 10$

$02 / 13 / 10$

WAP

I P10072:01

WAP I P10072:02

WAP / P10072:04

$\mathrm{P}-05 \quad$ (A)

$02 / 13 / 10$

WAP

P10072:05

P-06 (A)

$02 / 23 / 10$

DP

I P10068:01-26

$\mathrm{H}$

$r$

$02 / 13 / 10$

WAP

P10072:07

Remote visual tank wall inspection revealed no areas of concern since last evaluated on 2/11/09.

The magnetically mounted tank wall thermocouple was properly positioned per T-DS-G-00010.

Remote visual tank wall inspection revealed no areas of concern since last evaluated on 2/11/09.

Remote visual tank wall inspection revealed no areas of concern since last evaluated on 6/25/09.

Remote visual tank wall inspection revealed no areas of concern since last evaluated on 2/11/09.

Remote visual tank wall inspection revealed no areas of concern since last evaluated on 6/25/09.

Remote visual tank wall inspection revealed no areas of concern since last evaluated on 2/11/09.

Remote visual tank wall inspection revealed no areas of concern since last evaluated on 2/11/09.

Inspection verified that the condition of the exterior of the sump transfer line jacket from HDB-04 was satisfactory per T-DS-G-00001. 
TANK OR ACCESS OPENING

AREA ANCILLARY

29

29

$\mathrm{H}$

$\mathrm{H}$

29

P-09 (A)

$02 / 23 / 10$

P-09 (A)

$02 / 24 / 10$

DP / P10095:01-05

P-10 (A)

$02 / 23 / 10$

29

29

$\mathrm{H}$

$\mathrm{P}-11 \quad(\mathrm{~A})$

$02 / 13 / 10$

P-12 (A)

$02 / 13 / 10$

P-13 (A)

$02 / 23 / 10$

29

29

$\mathrm{H}$

$\mathrm{P}-14 \quad(\mathrm{~A})$

$02 / 13 / 10$

COP \#104

$29 / 30$

$\mathrm{H}$

$\mathrm{H}$

$29 / 30$

COP \#105

$03 / 20 / 10$

DSP

INSPECTION METHOD IDENTIFICATION NUMBER

WAP / P10072:08

DP I P10069:01-27

DP / P10070:01-25

WAP / P10072:10

WAP / P10072:11

DP / P10071:01-25

WAP / P10072:13

DSP / P10189:01-06

$03 / 20 / 10$
I P10187:01-07

$03 / 20110$

$$
\text { DSP }
$$

I

$\vdash$
COP \#112

$03 / 20 / 10$
Inspection of the transfer lines within the cleanout port was satisfactory per T-DS-G-00001. The conductivity probe was properly positioned.

\section{REMARKS}

Remote visual tank wall inspection revealed no areas of concern since last evaluated on 6/25/09.

Remote visual tank wall inspection revealed no areas of concern since last evaluated on 2/11/09. revealed no areas of concern since last evaluated on 2/11/09.

Remote visual tank wall inspection revealed no areas of concern since last evaluated on 2/11/09.

Remote visual tank wall inspection revealed no areas of concern since last evaluated on 6/25/09.

Remote visual tank wall inspection revealed no areas of concern since last evaluated on 6/25/09.

Remote visual tank wall inspection revealed no areas of concern since last evaluated on 2/11/09.

Remote visual tank wall inspection revealed no areas of concern since last evaluated on 6/25/09.

Inspection of the transfer lines within the cleanout port was satisfactory per T-DS-G-00001. The conductivity probe was properly positioned.

Inspection of the transfer lines within the cleanout port was satisfactory per T-DS-G-00001. The conductivity probe was properly positioned.
Remote visual tank wall inspection 
TANK OR ACCESS OPENING

AREA ANCILLARY

30

30

$\mathrm{H}$

$\mathrm{H}$

30

A-02 (A)

(A) $\quad 02 / 16 / 10$

$\mathrm{A}-01 \quad$ (A) $\quad 02 / 16 / 10$

DATE

INSPECTION METHOD

IDENTIFICATION NUMBER

WAP / P10094:05

WAP / P10094:08

WAP I P10094:11

A-03 (A) $\quad 02 / 16 / 10$

A-04 (A)

$02 / 16 / 10$

WAP

I P10094:02

A-04 (A)

$03 / 28 / 10$

CCTV

2090

P-01 (A)

$02 / 14 / 10$

30

30

$\mathrm{H}$

P-02 (A)

$02 / 16 / 10$

WAP

I P10094:01

30

P-03 (A)

$02 / 24 / 10$

DP

I P10096:01-27

P-04 (A)

$02 / 16 / 10$

WAP

I P10094:03

30

30
P-05 (A)

$02 / 16 / 10$
WAP / P10094:04

\section{REMARKS}

Remote visual tank wall inspection revealed no areas of concern since last evaluated on $2 / 11 / 09$. The annulus jet was satisfactory per T-DS-G-00043.

Remote visual tank wall inspection revealed no areas of concern since last evaluated on 2/11/09.

Remote visual tank wall inspection revealed no areas of concern since last evaluated on 2/11/09.

Remote visual tank wall inspection revealed no areas of concern since last evaluated on 2/11/09.

The magnetically mounted tank wall thermocouple was properly positioned per T-DS-G-00010.

Remote visual tank wall inspection revealed no areas of concern since last evaluated on 2/11/09.

Remote visual tank wall inspection revealed no areas of concern since last evaluated on $7 / 12 / 09$. Stains on the annulus floor were due to the inleakage of water.

Remote visual tank wall inspection revealed no areas of concern since last evaluated on 2/11/09. Stains on the tank wall and secondary vessel wall were due to water inleakage.

Remote visual tank wall inspection revealed no areas of concern since last evaluated on 2/11/09.

Remote visual tank wall inspection revealed no areas of concern since last evaluated on $7 / 12 / 09$. 
TANK OR ACCESS OPENING

AREA ANCILLARY

30

30

$\mathrm{H}$

$\mathrm{H}$

30

P-07 (A)

A) $\quad 02 / 16 / 10$

(A OR I)

P-06 (A)

DATE

$02 / 24 / 10$

$\mathrm{DP} \quad / \quad \mathrm{P} 10097: 01-25$

INSPECTION METHOD

IDENTIFICATION NUMBER

Remote visual tank wall inspection revealed no areas of concern since last evaluated on $2 / 11 / 09$. Stains on the tank wall and secondary vessel wall were due to water inleakage.

WAP I P10094:06

WAP I P10094:07

P-08 (A) $\quad 02 / 16 / 10$

$02 / 16 / 10$

$02 / 24 / 10$

P-09 (A)

$02 / 24 / 10$

DP / P10098:01-25

Remote visual tank wall inspection

$\mathrm{H}$

DP

I P10099:01-26

$\mathrm{P}-11 \quad(\mathrm{~A})$

$02 / 16 / 10$

WAP

I P10094:09

P-12 (A)

$02 / 16 / 10$

WAP

I P10094:10

$\mathrm{P}-13 \quad$ (A)

09/06/10

DP

I P10240:01-26
$\mathrm{H}$

30

30
P-14 (A)

$11 / 09 / 10$
WAP / P10281:01 revealed no areas of concern since last evaluated on 2/11/09. An increase in stains on the secondary vessel wall and ventilation duct was due to water inleakage.

Remote visual tank wall inspection revealed no areas of concern since last evaluated on 2/11/09.

Remote visual tank wall inspection revealed no areas of concern since last evaluated on $7 / 12 / 09$.

Remote visual tank wall inspection revealed no areas of concern since last evaluated on 2/11/09. An increase in stains on the secondary vessel wall was due to water inleakage.

Remote visual tank wall inspection revealed no areas of concern since last evaluated on 2/11/09.

Remote visual tank wall inspection revealed no areas of concern since last evaluated on 2/11/09.

Remote visual tank wall inspection revealed no areas of concern since last evaluated on 02/11/09. An increase in stains and marks observed on the top knuckle plate and annulus floor were caused by the inleakage of water.

Remote visual tank wall inspection revealed no areas of concern since last evaluated on 7/12/09. 
TANK OR ACCESS OPENING

AREA ANCILLARY

31

31

31

31

31

$\mathrm{H}$

$\mathrm{H}$

$31 \quad$ COP \#102

A-01 (A)

$02 / 10 / 10$

WAP

I P10100:13

A-02 (A)

$02 / 10 / 10$

WAP / P10100:08

A-03 (A)

$02 / 10 / 10$

WAP

I P10100:11

A-04 (A)

$02 / 10 / 10$

WAP

I P10100:03

A-04 (A)

$03 / 28 / 10$

CCTV

2090

$\mathrm{H}$

31

P-01 (A)

$02 / 10 / 10$

WAP

I P10100:01

31

P-02 (A)

$02 / 10 / 10$

WAP

I P10100:02

P-03 (A)

$02 / 24 / 10$

DP

/ P10101:01-25

$\mathrm{P}-04 \quad(\mathrm{~A})$

$02 / 10 / 10$

WAP / P10100:04

\section{REMARKS}

Inspection of the transfer lines within the cleanout port was satisfactory per T-DS-G-00001.

Remote visual tank wall inspection revealed no areas of concern since last evaluated on $2 / 10 / 09$. The annulus jet was satisfactory per T-DS-G-00043.

Remote visual tank wall inspection revealed no areas of concern since last evaluated on 2/10/09.

Remote visual tank wall inspection revealed no areas of concern since last evaluated on 2/10/09.

Remote visual tank wall inspection revealed no areas of concern since last evaluated on 2/10/09.

The magnetically mounted tank wall thermocouple was properly positioned per T-DS-G-00010.

Remote visual tank wall inspection revealed no areas of concern since last evaluated on 2/10/09.

Remote visual tank wall inspection revealed no areas of concern since last evaluated on 6/25/09.

Remote visual tank wall inspection revealed no areas of concern since last evaluated on 2/10/09.

Remote visual tank wall inspection revealed no areas of concern since last evaluated on 2/10/09.

Remote visual tank wall inspection revealed no areas of concern since last evaluated on 6/25/09. 
TANK OR ACCESS OPENING

AREA ANCILLARY

31

$\mathrm{H}$

31

$\mathrm{H}$

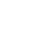

$31 \quad \mathrm{P}-08 \quad(\mathrm{~A})$

31

$\mathrm{H}$

$\mathrm{H}$

$\mathrm{H}$

31

P-10 (A)

$02 / 24 / 10$

P-11 (A)

$02 / 10 / 10$

P-12 (A)

$02 / 10 / 10$

31

31

P-13 (A)

$02 / 24 / 10$

P-14 (A)

$02 / 10 / 10$

COP \#109
32

32

31

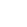

$\mathrm{H}$
$03 / 20 / 10$
COP \#110

(and

INSPECTION METHOD IDENTIFICATION NUMBER

DP / P10102:01-25

Remote visual tank wall inspection revealed no areas of concern since last evaluated on 2/10/09.

WAP / P10100:06

WAP / P10100:07

DP / P10103:01-26

DP / P10104:01-25

WAP / P10100:09

WAP / P10100:10

DP / P10105:01-25

WAP I P10100:12

DSP / P10215:01-07
$03 / 20 / 10$

DSP

Remote visual tank wall inspection revealed no areas of concern since last evaluated on 2/10/09.

Remote visual tank wall inspection revealed no areas of concern since last evaluated on 2/10/09.

Remote visual tank wall inspection revealed no areas of concern since last evaluated on 2/10/09.

Remote visual tank wall inspection revealed no areas of concern since last evaluated on 2/10/09.

Remote visual tank wall inspection revealed no areas of concern since last evaluated on 6/25/09.

Remote visual tank wall inspection revealed no areas of concern since last evaluated on 6/25/09.

Inspection of the transfer lines within the cleanout port was satisfactory per T-DS-G-00001. The conductivity probe was properly positioned.

Inspection of the transfer lines within the cleanout port was satisfactory per T-DS-G-00001. The conductivity probe was properly positioned. 


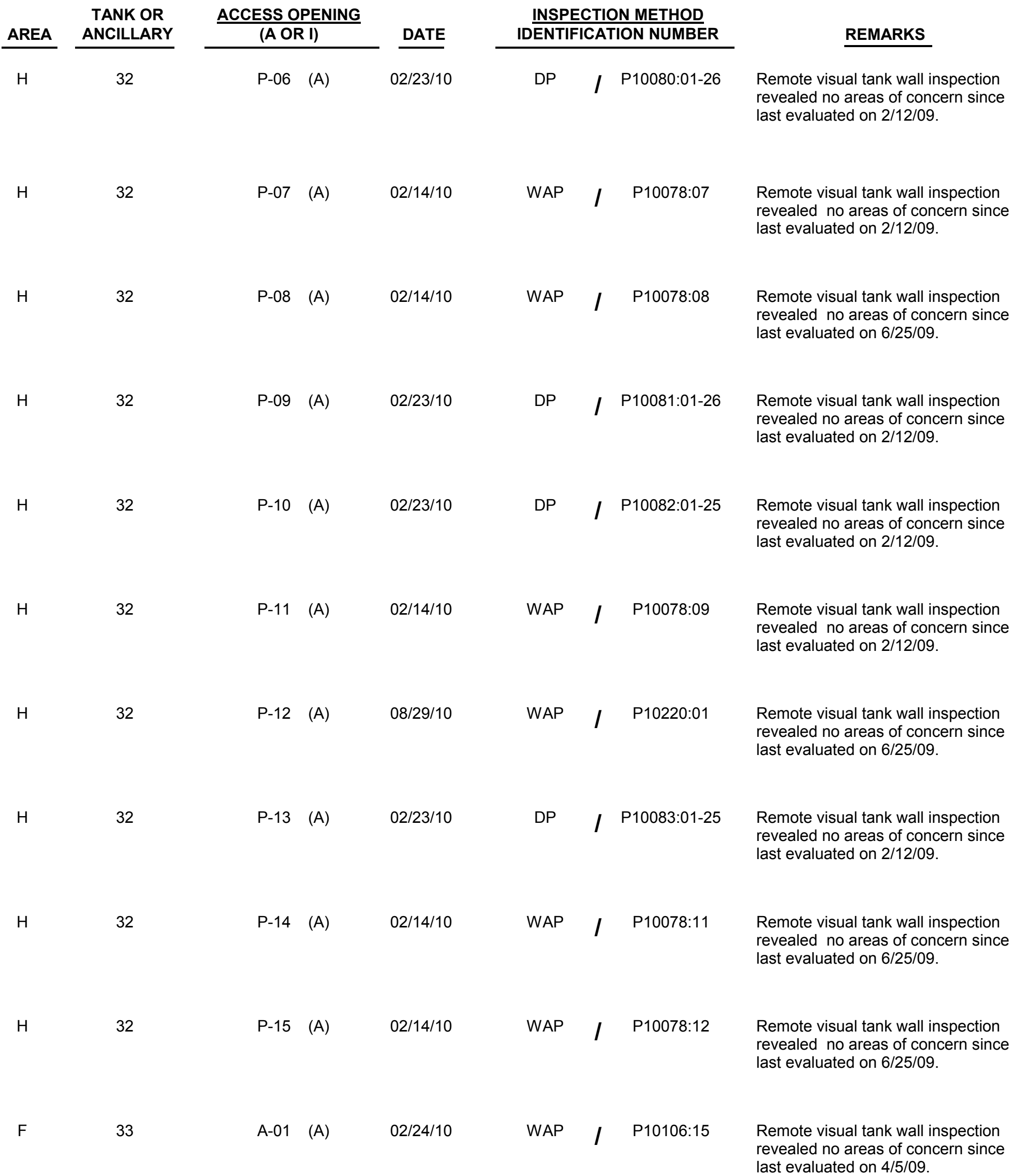




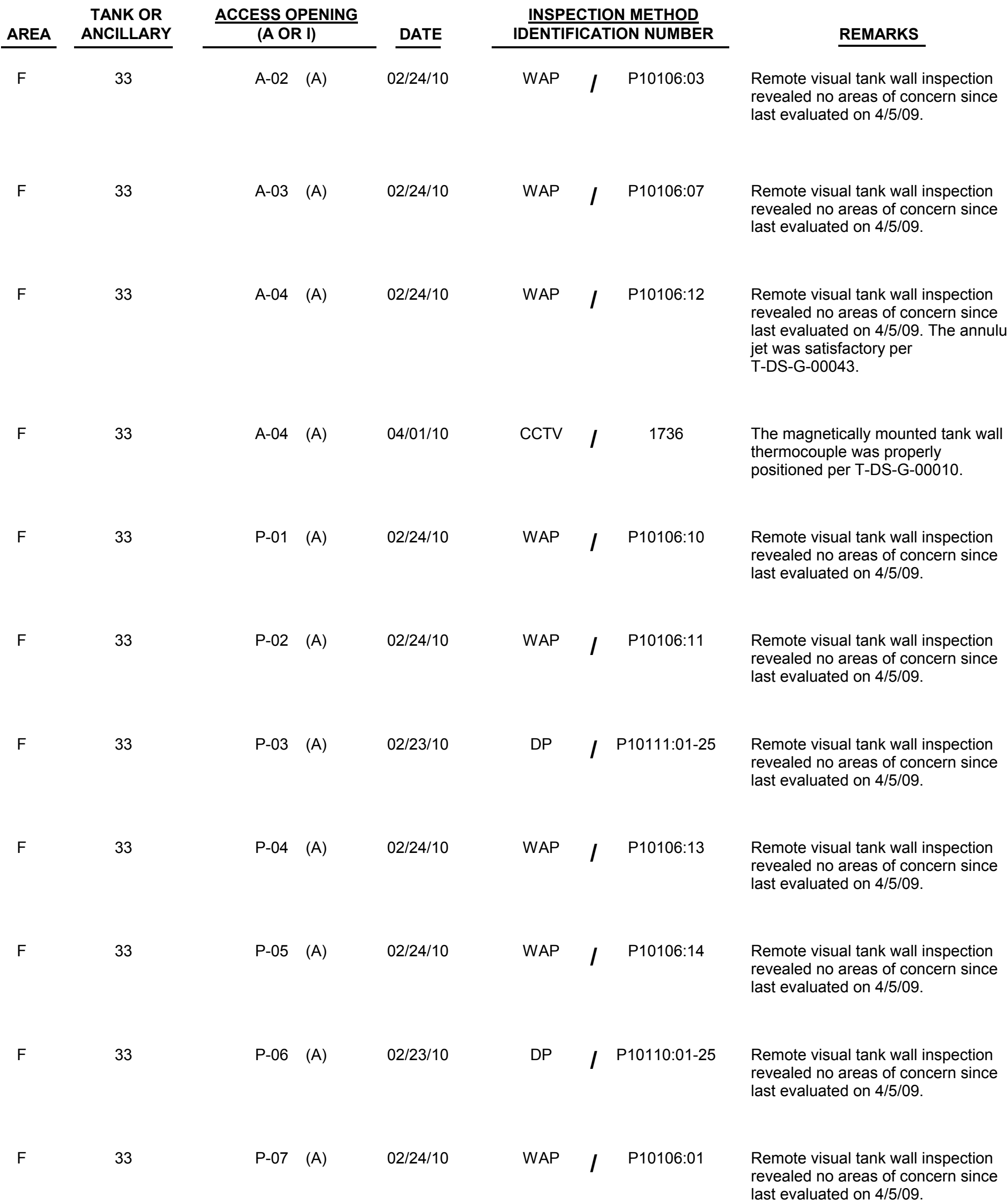




\begin{tabular}{|c|c|c|c|c|c|c|c|c|}
\hline \multirow{2}{*}{$\frac{\text { AREA }}{F}$} & \multirow{2}{*}{$\begin{array}{c}\begin{array}{c}\text { TANK OR } \\
\text { ANCILLARY }\end{array} \\
33\end{array}$} & \multicolumn{2}{|c|}{$\frac{\text { ACCESS OPENING }}{(A \text { OR I) }}$} & \multirow{2}{*}{$\frac{\text { DATE }}{02 / 24 / 10}$} & \multicolumn{3}{|c|}{$\frac{\text { INSPECTION METHOD }}{\text { IDENTIFICATION NUMBER }}$} & \multirow[b]{2}{*}{$\begin{array}{l}\text { Remote visual tank wall inspection } \\
\text { revealed no areas of concern since } \\
\text { last evaluated on } 4 / 5 / 09 \text {. }\end{array}$} \\
\hline & & P-08 & (A) & & WAP & l & P10106:02 & \\
\hline $\mathrm{F}$ & 33 & P-09 & (A) & $02 / 23 / 10$ & DP & I & P10109:01-25 & $\begin{array}{l}\text { Remote visual tank wall inspection } \\
\text { revealed no areas of concern since } \\
\text { last evaluated on } 4 / 5 / 09 \text {. }\end{array}$ \\
\hline $\mathrm{F}$ & 33 & $P-10$ & (A) & $02 / 23 / 10$ & DP & I & P10108:01-25 & $\begin{array}{l}\text { Remote visual tank wall inspection } \\
\text { revealed no areas of concern since } \\
\text { last evaluated on } 4 / 5 / 09 \text {. }\end{array}$ \\
\hline $\mathrm{F}$ & 33 & $P-11$ & (A) & $02 / 24 / 10$ & WAP & I & P10106:04 & $\begin{array}{l}\text { Remote visual tank wall inspection } \\
\text { revealed no areas of concern since } \\
\text { last evaluated on } 4 / 5 / 09 \text {. }\end{array}$ \\
\hline$F$ & 33 & P-12 & (A) & $02 / 24 / 10$ & WAP & I & P10106:05 & $\begin{array}{l}\text { Remote visual tank wall inspection } \\
\text { revealed no areas of concern since } \\
\text { last evaluated on } 4 / 5 / 09 \text {. }\end{array}$ \\
\hline $\mathrm{F}$ & 33 & $P-13$ & $(\mathrm{~A})$ & $02 / 23 / 10$ & DP & I & P10107:01-25 & $\begin{array}{l}\text { Remote visual tank wall inspection } \\
\text { revealed no areas of concern since } \\
\text { last evaluated on } 4 / 5 / 09 \text {. }\end{array}$ \\
\hline $\mathrm{F}$ & 33 & P-14 & $(\mathrm{A})$ & $02 / 24 / 10$ & WAP & I & P10106:06 & $\begin{array}{l}\text { Remote visual tank wall inspection } \\
\text { revealed no areas of concern since } \\
\text { last evaluated on } 4 / 5 / 09 \text {. }\end{array}$ \\
\hline $\mathrm{F}$ & 33 & P-15 & $(\mathrm{A})$ & $02 / 24 / 10$ & WAP & I & P10106:08 & $\begin{array}{l}\text { Remote visual tank wall inspection } \\
\text { revealed no areas of concern since } \\
\text { last evaluated on } 4 / 5 / 09 \text {. }\end{array}$ \\
\hline $\mathrm{F}$ & 33 & $P-16$ & (A) & $02 / 24 / 10$ & WAP & l & P10106:09 & $\begin{array}{l}\text { Remote visual tank wall inspection } \\
\text { revealed no areas of concern since } \\
\text { last evaluated on } 4 / 5 / 09 \text {. }\end{array}$ \\
\hline $\mathrm{F}$ & 34 & A-01 & $(\mathrm{A})$ & $03 / 06 / 10$ & WAP & l & P10112:01 & $\begin{array}{l}\text { Remote visual tank wall inspection } \\
\text { revealed no areas of concern since } \\
\text { last evaluated on } 4 / 5 / 09 \text {. }\end{array}$ \\
\hline $\mathrm{F}$ & 34 & A-02 & $(\mathrm{A})$ & 03/06/10 & WAP & l & P10112:04 & $\begin{array}{l}\text { Remote visual tank wall inspection } \\
\text { revealed no areas of concern since } \\
\text { last evaluated on } 4 / 5 / 09 \text {. }\end{array}$ \\
\hline
\end{tabular}




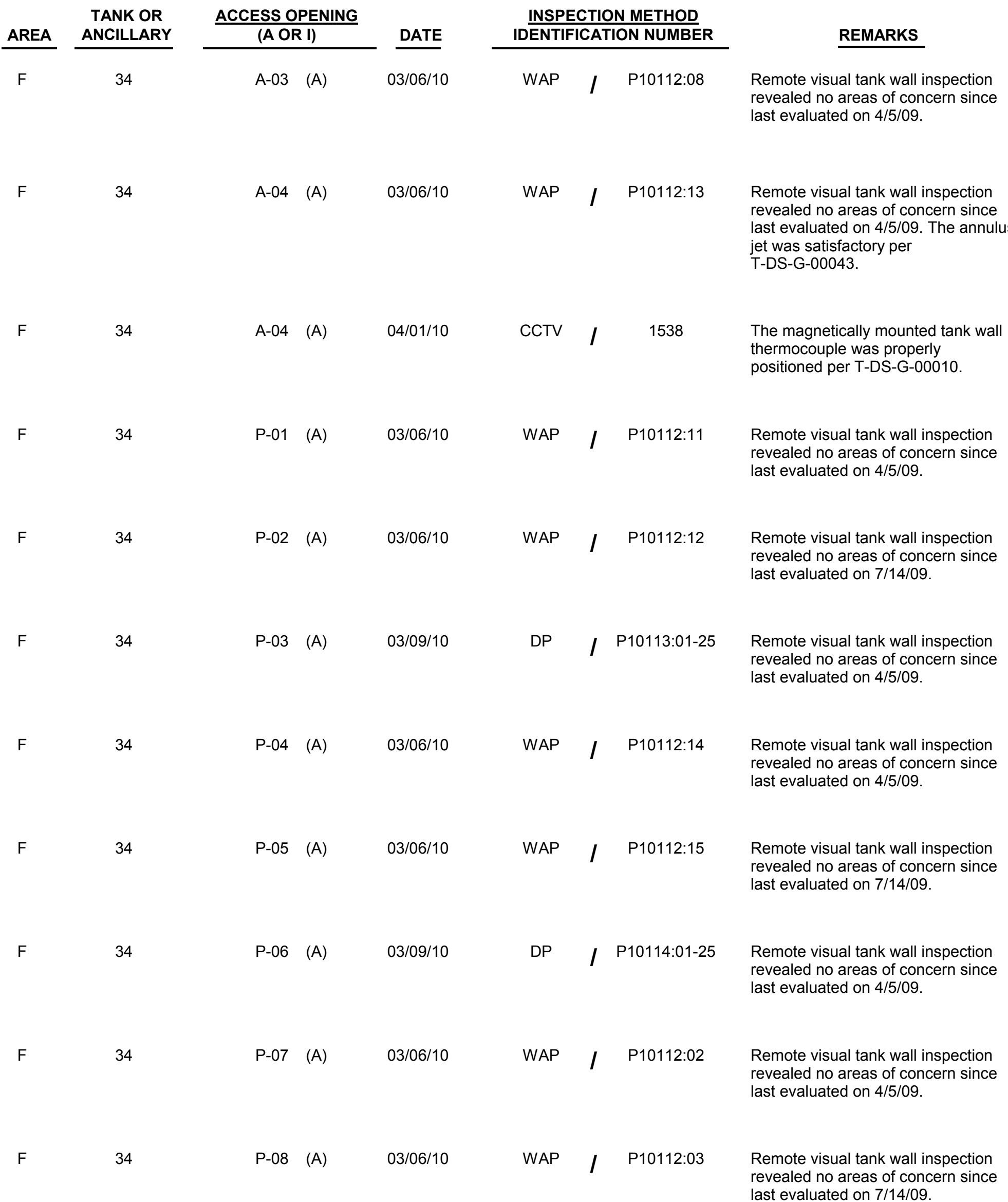




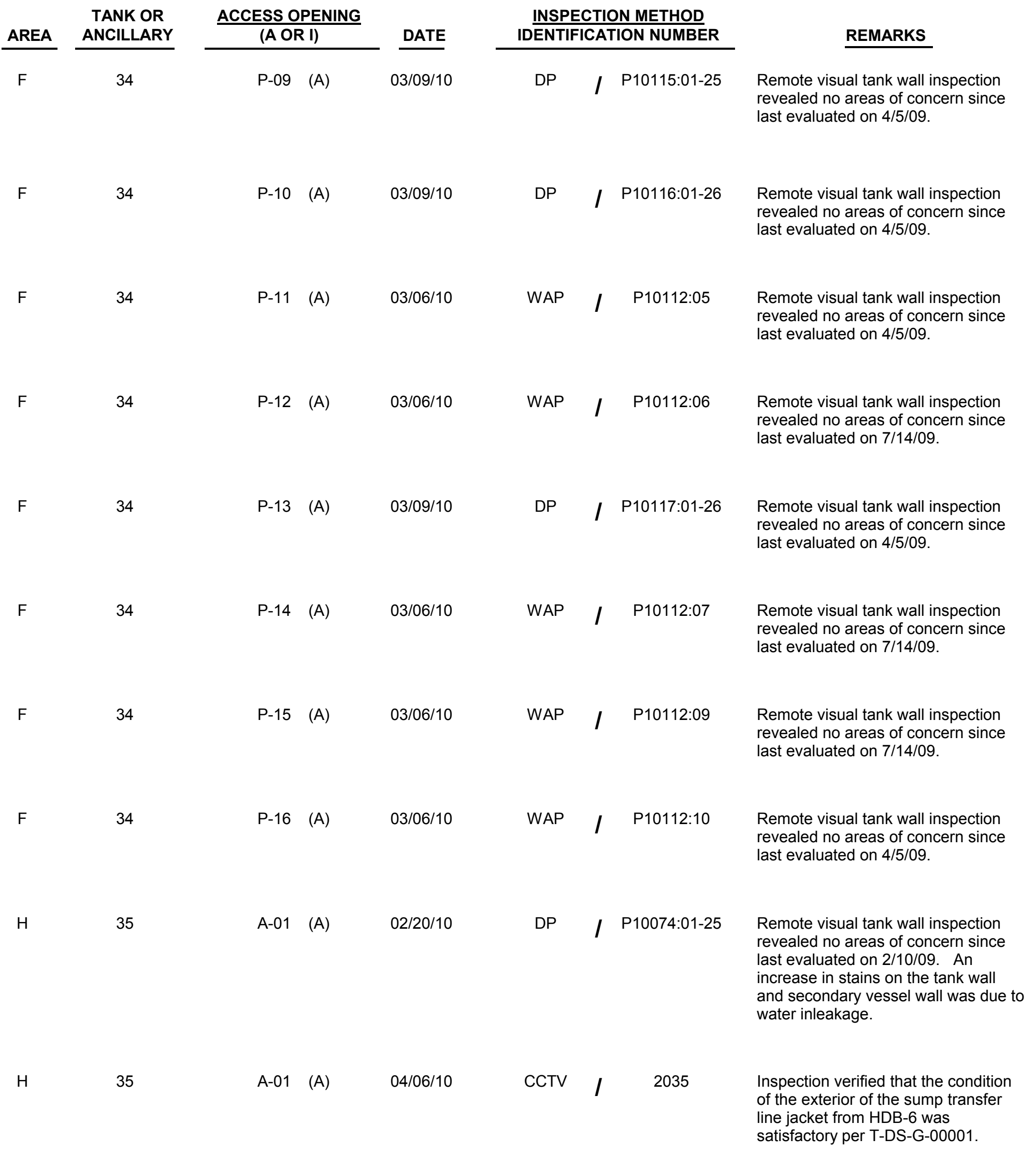


TANK OR ACCESS OPENING ANCILLARY

35

$\mathrm{H}$

AREA

35

$\mathrm{H}$

$\mathrm{H}$

35

35

$\mathrm{H}$

$\mathrm{H}$

35

35

$\mathrm{H}$

35

$\mathrm{H}$

35

35

(A OR I)

A-02 (A)

A-02 (A)

A-03 (A)

A-03 (A)

$\mathrm{A}-04 \quad(\mathrm{~A})$

$\mathrm{P}-01 \quad(\mathrm{~A})$

P-02 (A)

$\mathrm{P}-03 \quad(\mathrm{~A})$

P-04 (A)
DATE

$02 / 20 / 10$

$02 / 20 / 10$

$02 / 20 / 10$

DP / P10076:01-26

$02 / 20 / 10$

DP

P10076:22

A) $\quad 02 / 20 / 10$

DP / P10077:01-26

$02 / 16 / 10$

WAP

P10073:01

$02 / 16 / 10$

WAP

P10073:02

$02 / 16 / 10$

WAP

P10073:03

$02 / 16 / 10$

\section{REMARKS}

Remote visual tank wall inspection revealed no areas of concern since last evaluated on 2/10/09. An increase in stains on the secondary vessel wall was due to water inleakage.

The conductivity probe was properly positioned per J-JX-G-0001.

Remote visual tank wall inspection revealed no areas of concern since last evaluated on 2/9/09.

The conductivity probe was properly positioned per J-JX-G-0001.

Remote visual tank wall inspection revealed no areas of concern since last evaluated on 2/9/09.

Remote visual tank wall inspection revealed no areas of concern since last evaluated on 2/9/09. Stains and marks observed on the secondary vessel wall had increased due to the inleakage of water.

Remote visual tank wall inspection revealed no areas of concern since last evaluated on 2/9/09. Stains and marks observed on the secondary vessel wall had increased due to the inleakage of water.

Remote visual tank wall inspection revealed no areas of concern since last evaluated on 2/9/09.

Remote visual tank wall inspection revealed no areas of concern since last evaluated on 2/9/09. 
TANK OR ACCESS OPENING

AREA ANCILLARY

35

$\mathrm{H}$

35

$\mathrm{H}$

35



(A OR I)

DATE

P-05 (A)

$02 / 16 / 10$

INSPECTION METHOD

IDENTIFICATION NUMBER

WAP / P10073:05

\section{REMARKS}

Remote visual tank wall inspection revealed no areas of concern since last evaluated on $6 / 24 / 09$. The annulus transfer jet installed in the $F$ riser was satisfactory per T-DS-G-00043.

$\begin{array}{lll}\mathrm{P}-06 & \text { (A) } \quad 02 / 16 / 10\end{array}$

WAP / P10073:06

Remote visual tank wall inspection revealed no areas of concern since last evaluated on 2/9/09.

Remote visual tank wall inspection revealed no areas of concern since last evaluated on 6/24/09.

$02 / 16 / 10$

WAP / P10073:08

WAP I P10073:09

P-09 (A)

$02 / 16 / 10$

WAP

P10073:07

35

$\mathrm{H}$

$\mathrm{H}$

35

P-10 (A)

$02 / 16 / 10$

WAP

P10073:10

P-11 (A)

$02 / 16 / 10$

WAP

I P10073:11

35

P-12 (A)

$02 / 16 / 10$

WAP

I P10073:12

35

P-13 (A)

$02 / 16 / 10$

WAP

P10073:13

35

P-14 (A)

$02 / 16 / 10$

WAP

I P10073:14
Remote visual tank wall inspection revealed no areas of concern since last evaluated on 2/9/09.

Remote visual tank wall inspection revealed no areas of concern since last evaluated on 6/24/09.

Remote visual tank wall inspection revealed no areas of concern since last evaluated on 2/9/09.

Remote visual tank wall inspection revealed no areas of concern since last evaluated on 2/9/09.

Remote visual tank wall inspection revealed no areas of concern since last evaluated on 2/9/09.

Remote visual tank wall inspection revealed no areas of concern since last evaluated on 6/24/09.

Remote visual tank wall inspection revealed no areas of concern since last evaluated on 6/24/09.

Remote visual tank wall inspection revealed no areas of concern since last evaluated on 2/8/09. 
TANK OR ACCESS OPENING

AREA ANCILLARY

36

36

$\mathrm{H}$

$\mathrm{H}$

36

$\mathrm{H}$

$\mathrm{H}=36$

$\mathrm{H}$

36

36

$\mathrm{H}$

$\mathrm{H}$

36

36

$\mathrm{H}$

36

$\mathrm{H}$

36

36

(A OR I)

A-03 (A)

A-04 (A)

$\mathrm{P}-01 \quad(\mathrm{~A})$

P-02 (A)

P-03 (A)

$\mathrm{P}-04 \quad(\mathrm{~A})$
DATE

A-02 (A) $\quad 02 / 18 / 10$

A-02 (A) $\quad 02 / 18 / 10$

$\mathrm{DP} \quad$ / P10058:21

DP / P10059:01-26

A-03 (A) $\quad 02 / 18 / 10$

$02 / 18 / 10$

DP $\quad /$

P10059:21

DP / P10060:01-27

A-04 (A) $\quad 02 / 18 / 10$

$02 / 18 / 10$

DP

P10060:22

WAP / P10061:01

$02 / 22 / 10$

$02 / 22 / 10$

WAP

P10061:02

$02 / 22 / 10$

WAP

/ P10061:03

$02 / 22 / 10$

WAP / P10061:04

\section{REMARKS}

Remote visual tank wall inspection revealed no areas of concern since last evaluated on 2/8/09.

The conductivity probe was properly positioned per J-JX-G-0001.

Remote visual tank wall inspection revealed no areas of concern since last evaluated on 2/8/09.

The conductivity probe was properly positioned per J-JX-G-0001.

Remote visual tank wall inspection revealed no areas of concern since last evaluated on 2/8/09.

The conductivity probe was properly positioned per J-JX-G-0001.

Remote visual tank wall inspection revealed no areas of concern since last evaluated on 2/8/09.

Remote visual tank wall inspection revealed no areas of concern since last evaluated on 2/8/09.

Remote visual tank wall inspection revealed no areas of concern since last evaluated on 2/8/09.

Remote visual tank wall inspection revealed no areas of concern since last evaluated on 2/8/09.

Remote visual tank wall inspection revealed no areas of concern since last evaluated on 3/31/09. 
TANK OR ACCESS OPENING

AREA ANCILLARY

36

$\mathrm{H}$

$\mathrm{H}$

36

36

$\mathrm{H}$

36

36

$\mathrm{H}$

36

36

$\mathrm{H}$

36

36

(A OR I)

P-06 (A)

P-07 (A)

P-08 (A)

P-09 (A)

$\mathrm{P}-10$

$\mathrm{P}-11$ (A)

$\mathrm{P}-13 \quad(\mathrm{~A})$
DATE

$02 / 22 / 10$

$02 / 22 / 10$

WAP

I P10061:07

$02 / 22 / 10$

WAP

P10061:08

$02 / 22 / 10$

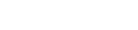

(A) $\quad 02 / 22 / 10$

WAP

I P10061:10

$02 / 22 / 10$

WAP / P10061:11

$\mathrm{P}-12$ (A)

$02 / 22 / 10$

WAP

I P10061:12

$02 / 22 / 10$

WAP

/ P10061:13

\section{REMARKS}

Remote visual tank wall inspection revealed no areas of concern since last evaluated on $2 / 8 / 09$. An increase in stains on the secondary vessel wall and ventilation duct was due to the inleakage of water.

Remote visual tank wall inspection revealed no areas of concern since last evaluated on $3 / 31 / 09$. An increase in stains on the secondary vessel wall and ventilation duct was due to the inleakage of water.

Remote visual tank wall inspection revealed no areas of concern since last evaluated on 2/8/09.

Remote visual tank wall inspection revealed no areas of concern since last evaluated on 3/31/09.

Remote visual tank wall inspection revealed no areas of concern since last evaluated on $2 / 8 / 09$.

Remote visual tank wall inspection revealed no areas of concern since last evaluated on 3/31/09.

Remote visual tank wall inspection revealed no areas of concern since last evaluated on 2/8/09.

Remote visual tank wall inspection revealed no areas of concern since last evaluated on $3 / 31 / 09$. The annulus jet installed in the $F$ riser was satisfactory per T-DS-G-00043.

Remote visual tank wall inspection revealed no areas of concern since last evaluated on $2 / 8 / 09$. The annulus jet installed in the $F$ riser was satisfactory per T-DS-G-00043. 
TANK OR ACCESS OPENING ANCILLARY

37

(A OR I)
DATE

$03 / 20 / 10$

$03 / 20 / 10$

COP \#107

COP \#108

$03 / 20 / 10$
INSPECTION METHOD IDENTIFICATION NUMBER

DSP

I P10218:01-06

DSP / P10217:01-07

DSP

I P10216:01-08

$02 / 21 / 10$

A-01 (A)

DP / P10090:01-26

$02 / 21 / 10$

A-02 (A)

DP

I P10091:01-26

A-02 (A)

$02 / 21 / 10$

$02 / 21 / 10$

A-03 (A)

DP

I P10092:01-27

A-03 (A)

$02 / 21 / 10$

DP /

P10092:21

DP

$02 / 21 / 10$

(A)

$02 / 21 / 10$

37

A-04 (A)

$02 / 21 / 10$

DP

P10093:23

Remote visual tank wall inspection revealed no areas of concern since last evaluated on 2/10/09.

The conductivity probe was properly positioned per J-JX-G-0001.

Remote visual tank wall inspection revealed no areas of concern since last evaluated on 2/9/09.

The conductivity probe was properly positioned per J-JX-G-0001.

Remote visual tank wall inspection revealed no areas of concern since last evaluated on $2 / 9 / 09$. Stains on the secondary vessel wall and ventilation duct were due to water inleakage.

The conductivity probe was properly positioned per J-JX-G-0001.

Remote visual tank wall inspection revealed no areas of concern since last evaluated on 2/9/09. 


\begin{tabular}{|c|c|c|c|c|c|c|c|c|}
\hline \multirow{2}{*}{$\frac{\text { AREA }}{\mathrm{H}}$} & \multirow{2}{*}{$\begin{array}{c}\begin{array}{c}\text { TANK OR } \\
\text { ANCILLARY }\end{array} \\
37\end{array}$} & \multicolumn{2}{|c|}{$\frac{\text { ACCESS OPENING }}{(A \text { OR I) }}$} & \multirow{2}{*}{$\frac{\text { DATE }}{02 / 21 / 10}$} & \multicolumn{3}{|c|}{$\frac{\text { INSPECTION METHOD }}{\text { IDENTIFICATION NUMBER }}$} & \multirow[b]{2}{*}{$\begin{array}{l}\text { Remote visual tank wall inspection } \\
\text { revealed no areas of concern since } \\
\text { last evaluated on } 2 / 9 / 09 \text {. }\end{array}$} \\
\hline & & P-02 & (A) & & WAP & l & P10089:02 & \\
\hline $\mathrm{H}$ & 37 & P-03 & (A) & $02 / 21 / 10$ & WAP & l & P10089:03 & $\begin{array}{l}\text { Remote visual tank wall inspection } \\
\text { revealed no areas of concern since } \\
\text { last evaluated on } 2 / 9 / 09 \text {. }\end{array}$ \\
\hline $\mathrm{H}$ & 37 & P-04 & (A) & $02 / 21 / 10$ & WAP & l & P10089:04 & $\begin{array}{l}\text { Remote visual tank wall inspection } \\
\text { revealed no areas of concern since } \\
\text { last evaluated on } 2 / 9 / 09 \text {. }\end{array}$ \\
\hline $\mathrm{H}$ & 37 & P-05 & (A) & $02 / 21 / 10$ & WAP & I & P10089:05 & $\begin{array}{l}\text { Remote visual tank wall inspection } \\
\text { revealed no areas of concern since } \\
\text { last evaluated on } 3 / 31 / 09 \text {. }\end{array}$ \\
\hline $\mathrm{H}$ & 37 & P-06 & (A) & $02 / 21 / 10$ & WAP & I & P10089:06 & $\begin{array}{l}\text { Remote visual tank wall inspection } \\
\text { revealed no areas of concern since } \\
\text { last evaluated on } 2 / 9 / 09 \text {. }\end{array}$ \\
\hline $\mathrm{H}$ & 37 & P-07 & $(\mathrm{A})$ & $02 / 21 / 10$ & WAP & I & P10089:07 & $\begin{array}{l}\text { Remote visual tank wall inspection } \\
\text { revealed no areas of concern since } \\
\text { last evaluated on } 3 / 31 / 09 \text {. }\end{array}$ \\
\hline $\mathrm{H}$ & 37 & P-08 & $(\mathrm{A})$ & $02 / 21 / 10$ & WAP & I & P10089:06 & $\begin{array}{l}\text { Remote visual tank wall inspection } \\
\text { revealed no areas of concern since } \\
\text { last evaluated on } 2 / 9 / 09 \text {. }\end{array}$ \\
\hline $\mathrm{H}$ & 37 & P-09 & $(\mathrm{A})$ & $02 / 21 / 10$ & WAP & I & P10089:09 & $\begin{array}{l}\text { Remote visual tank wall inspection } \\
\text { revealed no areas of concern since } \\
\text { last evaluated on } 3 / 31 / 09 \text {. }\end{array}$ \\
\hline $\mathrm{H}$ & 37 & $P-10$ & (A) & $02 / 21 / 10$ & WAP & l & P10089:04 & $\begin{array}{l}\text { Remote visual tank wall inspection } \\
\text { revealed no areas of concern since } \\
\text { last evaluated on } 2 / 9 / 09 \text {. }\end{array}$ \\
\hline $\mathrm{H}$ & 37 & $P-11$ & $(\mathrm{~A})$ & $02 / 21 / 10$ & WAP & l & P10089:11 & $\begin{array}{l}\text { Remote visual tank wall inspection } \\
\text { revealed no areas of concern since } \\
\text { last evaluated on } 3 / 31 / 09 \text {. }\end{array}$ \\
\hline $\mathrm{H}$ & 37 & $\mathrm{P}-12$ & $(\mathrm{~A})$ & $02 / 21 / 10$ & WAP & l & P10089:04 & $\begin{array}{l}\text { Remote visual tank wall inspection } \\
\text { revealed no areas of concern since } \\
\text { last evaluated on } 2 / 9 / 09 \text {. }\end{array}$ \\
\hline
\end{tabular}


TANK OR ACCESS OPENING ANCILLARY

37

37

$\mathrm{H}$

38

38

$\mathrm{H}$

$\mathrm{H}$

38

38

$\mathrm{H}$

$\mathrm{H}$

38

38

$\mathrm{H}$

38

38

$\mathrm{H}$

(A OR I)

$\mathrm{P}-13 \quad(\mathrm{~A})$

P-14 (A)

A-02 (A)

A-02 (A)

A-03 (A)

$\mathrm{A}-04 \quad(\mathrm{~A})$

A-04 (A)

$\mathrm{P}-01 \quad(\mathrm{~A})$
DATE

$02 / 21 / 10$

$02 / 21 / 10$

WAP

P10089:14

A-01 (A) $\quad 02 / 02 / 10$

A-01 (A) $\quad 04 / 06 / 10$

$02 / 02 / 10$

DP / P10032:01-25

$02 / 02 / 10$

DP

I P10032:21-22

$02 / 02 / 10$

DP / P10029:01-26

$02 / 02 / 10$

DP

I P10030:01-25

$02 / 02 / 10$

DP $\quad$ I

P10030:21

$01 / 29 / 10$

WAP

/ P10027:01

38
P-02 (A)

$01 / 29 / 10$
WAP / P10027:02

\section{REMARKS}

Remote visual tank wall inspection revealed no areas of concern since last evaluated on 3/31/09.

Remote visual tank wall inspection revealed no areas of concern since last evaluated on 2/9/09.

Remote visual tank wall inspection revealed no areas of concern since last evaluated on 2/22/09.

Inspection verified that the condition of the exterior of the sump transfer line jacket from HDB-07 was satisfactory per T-DS-G-00001.

Remote visual tank wall inspection revealed no areas of concern since last evaluated on 2/22/09.

The conductivity probe was properly positioned per J-JX-G-0001.

Remote visual tank wall inspection revealed no areas of concern since last evaluated on 2/22/09.

Remote visual tank wall inspection revealed no areas of concern since last evaluated on 2/22/09.

The conductivity probe was properly positioned per J-JX-G-0001.

Remote visual tank wall inspection revealed no areas of concern since last evaluated on 2/22/09.

Remote visual tank wall inspection revealed no areas of concern since last evaluated on $2 / 22 / 09$. An increase in stains and marks observed on the secondary vessel wall were due to the inleakage of water. 
TANK OR ACCESS OPENING

AREA ANCILLARY

38

38

38

38

$\mathrm{H}$

38

$\mathrm{H}$

$\mathrm{H}$

38

$\mathrm{H}$

$\mathrm{H}$

38

38

$\mathrm{H}$

.

$\mathrm{H}$

P-03 (A)

$\mathrm{P}-04 \quad(\mathrm{~A})$

P-05 (A)

P-06 (A)

P-07 (A)

P-08 (A)

P-09 (A)

$\mathrm{P}-10 \quad(\mathrm{~A})$

38

P-11 (A)

\section{(A OR I)}

DATE

01/29/10

01/29/10

$01 / 29 / 10$

WAP

I P10027:05

$01 / 29 / 10$

WAP

I P10027:06

$01 / 29 / 10$

$01 / 29 / 10$

WAP

I P10027:08

01/29/10

WAP

I P10027:09

$01 / 29 / 10$

WAP

I P10027:10

$01 / 29 / 10$

WAP

I P10027:11

\section{REMARKS}

Remote visual tank wall inspection revealed no areas of concern since last evaluated on 2/22/09.

Remote visual tank wall inspection revealed no areas of concern since last evaluated on 2/22/09. An increase in stains and marks observed on the secondary vessel wall were due to the inleakage of water.

Remote visual tank wall inspection revealed no areas of concern since last evaluated on 2/22/09.

Remote visual tank wall inspection revealed no areas of concern since last evaluated on 2/22/09.

Remote visual tank wall inspection revealed no areas of concern since last evaluated on 2/22/09.

Remote visual tank wall inspection revealed no areas of concern since last evaluated on $2 / 22 / 09$. Stains and marks were observed on top of the refractory pad.

Remote visual tank wall inspection revealed no areas of concern since last evaluated on 2/22/09.

Remote visual tank wall inspection revealed no areas of concern since last evaluated on $7 / 7 / 09$.

Remote visual tank wall inspection revealed no areas of concern since last evaluated on 7/7/09.

Remote visual tank wall inspection revealed no areas of concern since last evaluated on $7 / 7 / 09$. The annulus jet installed in the $F$ riser was satisfactory per T-DS-G-00043. 
TANK OR ACCESS OPENING

AREA ANCILLARY

38

39

39

$\mathrm{H}$

$\mathrm{H}$

38

$\mathrm{H}$

$\mathrm{P}-14 \quad(\mathrm{~A})$

$01 / 29 / 10$

WAP

P10027:14

A-01 (A) $\quad 02 / 07 / 10$

A-02 (A)

$02 / 07 / 10$

DP

I P10035:01-26

A-02 (A)

$02 / 07 / 10$

DP

P10035:21

DP / P10034:01-25

$\mathrm{A}-03 \quad(\mathrm{~A})$

$02 / 07 / 10$

A-03 (A)

02/07/10

39

39

$\mathrm{H}$

A-04 (A)

$02 / 07 / 10$

DP

/ P10033:01-28

$\mathrm{H}$
39

39

39

A-04 (A) $\quad 02 / 07 / 10$

P-01 (A)

$01 / 29 / 10$

WAP

DP

P10033:22

$H$

\section{REMARKS}

Remote visual tank wall inspection revealed no areas of concern since last evaluated on 7/7/09.

Remote visual tank wall inspection revealed no areas of concern since last evaluated on 7/7/09.

Remote visual tank wall inspection revealed no areas of concern since last evaluated on 2/23/09.

Remote visual tank wall inspection revealed no areas of concern since last evaluated on $2 / 23 / 09$. Mild surface corrosion was observed on the primary vessel wall.

The conductivity probe was properly positioned per J-JX-G-0001.

Remote visual tank wall inspection revealed no areas of concern since last evaluated on $2 / 23 / 09$. Mild surface corrosion was observed on the primary vessel wall.

The conductivity probe was properly positioned per J-JX-G-0001.

Remote visual tank wall inspection revealed no areas of concern since last evaluated on $2 / 23 / 09$. Mild surface corrosion was observed on the primary vessel wall.

The conductivity probe was properly positioned per J-JX-G-0001.

Remote visual tank wall inspection revealed no areas of concern since last evaluated on 1/30/08.

Remote visual tank wall inspection revealed no areas of concern since last evaluated on 1/30/08. 
TANK OR ACCESS OPENING

AREA ANCILLARY

39

39

39

39

$\mathrm{H}$

39

$\mathrm{H}$
P-06

(A)

$01 / 29 / 10$

WAP I P10028:06

P-07 (A) 01/29/10

P-08 (A)

$01 / 29 / 10$

WAP

WAP I P10028:07

39

$\mathrm{H}$

39

39

$\mathrm{H}$

$\mathrm{H}$

$\mathrm{H}$

39

$\mathrm{H}$

39

P-11 (A)

$01 / 29 / 10$

WAP

P10028:11

$01 / 29 / 10$

WAP

P10028:12

P-12 (A)

39

(1)

$\mathrm{P}-13 \quad$ (A)

$01 / 29 / 10$

WAP I P10028:13

\section{REMARKS}

Remote visual tank wall inspection revealed no areas of concern since last evaluated on 1/30/08.

Remote visual tank wall inspection revealed no areas of concern since last evaluated on 1/30/08.

Remote visual tank wall inspection revealed no areas of concern since last evaluated on 1/30/08.

Remote visual tank wall inspection revealed no areas of concern since last evaluated on 1/30/08.

Remote visual tank wall inspection revealed no areas of concern since last evaluated on 1/30/08.

Remote visual tank wall inspection revealed no areas of concern since last evaluated on 1/30/08.

Remote visual tank wall inspection revealed no areas of concern since last evaluated on 1/30/08.

Remote visual tank wall inspection revealed no areas of concern since last evaluated on 1/30/08.

Remote visual tank wall inspection revealed no areas of concern since last evaluated on 7/7/09.

Remote visual tank wall inspection revealed no areas of concern since last evaluated on 7/7/09.

Remote visual tank wall inspection revealed no areas of concern since last evaluated on 7/7/09. 
TANK OR ACCESS OPENING

AREA ANCILLARY

40

40

40

40

$\mathrm{H}$

$\mathrm{H}$

40

40

$\mathrm{H}$

$\mathrm{H}$

40

40

40

ACCESS OPENING

(A OR I)

P-14 (A)

$\mathrm{A}-01 \quad(\mathrm{~A})$

A-02 (A)

A-03 (A)

A-03 (A)

A-04 (A)

P-01 (A)

P-03 (A)

P-04 (A)

$\mathrm{H}$
DATE

$01 / 29 / 10$

$02 / 08 / 10$

WAP

P10037:02

$02 / 08 / 10$

$02 / 08 / 10$

WAP

I P10037:04

$02 / 08 / 10$

WAP

I P10037:08

$08 / 08 / 10$

CCTV

2038

$02 / 08 / 10$

WAP

I P10037:11

$02 / 15 / 10$

WAP

I P10038:01

$02 / 08 / 10$

WAP

I P10037:03

$02 / 08 / 10$

WAP I P10037:05

P-05 (A) 02/08/10

$\mathrm{DP} \quad$ / P10042:01-27

Remote visual tank wall inspection revealed no areas of concern since last evaluated on 2/22/09. An increase in stains on the annulus

floor was observed.

Remote visual tank wall inspection revealed no areas of concern since last evaluated on $2 / 22 / 09$. An increase in stains on the annulus floor was observed.

Remote visual tank wall inspection revealed no areas of concern since last evaluated on 2/22/09. 
TANK OR ACCESS OPENING

AREA ANCILLARY

40

40

$\mathrm{H}$

$\mathrm{H}$

$\mathrm{H}$

40

40

40

40

$\mathrm{H}$

$\mathrm{H}$

$\mathrm{H}$

P-08 (A) 02/08/10

P-09 (A) 02/08/10

P-10 (A)

$02 / 08 / 10$

I P10037:10

$\mathrm{P}-11$ (A)

$02 / 08 / 10$

40

$\mathrm{H}$

$\mathrm{H}$

40

$\mathrm{H}$

40

40
WAP

P10037:09

WAP

DP

I P10040:01-25

INSPECTION METHOD

IDENTIFICATION NUMBER

DP / P10043:01-25

WAP / P10037:06

WAP / P10037:07

DP I P10039:01-26

Remote visual tank wall inspection revealed no areas of concern since last evaluated on 2/22/09.

Remote visual tank wall inspection revealed no areas of concern since last evaluated on 2/22/09.

Remote visual tank wall inspection revealed no areas of concern since last evaluated on 2/22/09.

Remote visual tank wall inspection revealed no areas of concern since last evaluated on 2/22/09.

WAP / P10037:01

WAP I P10038:02
Remote visual tank wall inspection revealed no areas of concern since last evaluated on 7/8/09. An increase or the reconfiguration of the white deposits on the annulus floor was observed.

Remote visual tank wall inspection revealed no areas of concern since last evaluated on 2/22/09. 
TANK OR ACCESS OPENING

AREA ANCILLARY

41

41

$\mathrm{H}$

$\mathrm{H}$

41

41

$\mathrm{H}$

41

41

$\mathrm{H}$

$\mathrm{H}$

41

41

$\mathrm{H}$

41

41

$\mathrm{H}$

(A OR I)

A-04 (A)

$\mathrm{P}-02$

P-03 (A)

$\mathrm{P}-04 \quad(\mathrm{~A})$
A-01 (A) $\quad 02 / 08 / 10$

A-02 (A) $\quad 02 / 08 / 10$

A-02 (A) $\quad 02 / 08 / 10$

A-03 (A) $\quad 02 / 08 / 10$

A-04 (A) $\quad 02 / 08 / 10$

$02 / 08 / 10$

$\mathrm{DP} \quad / \quad \mathrm{P} 10047: 22$

WAP I P10044:01

P-01 (A) 01/29/10

(A) $\quad 01 / 29 / 10$

WAP

$01 / 29 / 10$

WAP

I P10044:03

$01 / 29 / 10$

WAP

P10044:04

P-05 (A) $\quad 01 / 29 / 10$

DP / P10046:01-29
P10044:02

INSPECTION METHOD

Remote visual tank wall inspection revealed no areas of concern since last evaluated on 2/21/09.

Remote visual tank wall inspection revealed no areas of concern since last evaluated on 2/21/09.

The conductivity probe was properly positioned per J-JX-G-00001.

Remote visual tank wall inspection revealed no areas of concern since last evaluated on 2/21/09.

Remote visual tank wall inspection revealed no areas of concern since last evaluated on 2/21/09.

The conductivity probe was properly positioned per J-JX-G-00001.

Remote visual tank wall inspection revealed no areas of concern since last evaluated on 2/21/09.

Remote visual tank wall inspection revealed no areas of concern since last evaluated on 2/21/09.

Remote visual tank wall inspection revealed no areas of concern since last evaluated on 2/21/09.

Remote visual tank wall inspection revealed no areas of concern since last evaluated on 2/21/09.

Remote visual tank wall inspection revealed no areas of concern since last evaluated on 2/21/09. 
TANK OR ACCESS OPENING

AREA ANCILLARY

41

41

$\mathrm{H}$

$\mathrm{H}$

41

41

41

$\mathrm{H}$

$\mathrm{H}$

41

$\mathrm{H}$

41

41

$\mathrm{H}$

$\mathrm{H}$

41

42

$\mathrm{H}$

$r$

P-06 (A)

P-07 (A)

P-08 (A)

P-09 (A)

P-10 (A)

P-11 (A)

P-12 (A)

P-13 (A)

P-14 (A)

\section{(A OR I)}

DATE

$01 / 29 / 10$

02/08/10

WAP

P10045:01

$01 / 29 / 10$

WAP

I

P10044:07

$01 / 29 / 10$

WAP

I P10044:08

$01 / 29 / 10$

WAP

P10044:09

$01 / 29 / 10$

WAP

I P10044:10

$01 / 29 / 10$

WAP

I P10044:11

$01 / 29 / 10$

WAP

I P10044:12

$01 / 29 / 10$

WAP

I P10044:13

A-01 (A) $\quad 02 / 08 / 10$

WAP

l P10050:08

\section{REMARKS}

Remote visual tank wall inspection revealed no areas of concern since last evaluated on 2/21/09.

Remote visual tank wall inspection revealed no areas of concern since last evaluated on 2/21/09.

Remote visual tank wall inspection revealed no areas of concern since last evaluated on 2/21/09.

Remote visual tank wall inspection revealed no areas of concern since last evaluated on 2/21/09.

Remote visual tank wall inspection revealed no areas of concern since last evaluated on 2/21/09.

Remote visual tank wall inspection revealed no areas of concern since last evaluated on 2/21/09.

Remote visual tank wall inspection revealed no areas of concern since last evaluated on 2/21/09.

Remote visual tank wall inspection revealed no areas of concern since last evaluated on 2/21/09.

Remote visual tank wall inspection revealed no areas of concern since last evaluated on 2/21/09.

Remote visual tank wall inspection revealed no areas of concern since last evaluated on $7 / 8 / 09$.

Remote visual tank wall inspection revealed no areas of concern since last evaluated on $7 / 8 / 09$. 
TANK OR ACCESS OPENING

AREA ANCILLARY

42

42

$\mathrm{H}$

$\mathrm{H}$

42

42

$\mathrm{H}$

$\mathrm{H}$

42

42

$\mathrm{H}$

$\mathrm{H}$

42

42

$\mathrm{H}$

A-03 (A)

A-04 (A)

$02 / 08 / 10$

WAP

I P10050:05

$\mathrm{P}-01 \quad(\mathrm{~A})$

$02 / 06 / 10$

WAP

P10051:02

$02 / 06 / 10$

P-02 (A)

WAP

P10051:03

P-03 (A)

$02 / 08 / 10$

DP

I P10052:01-25

P-03 (A)

$02 / 08 / 10$

DP

/ P10053:01-25

P-04 (A)

$02 / 06 / 10$

WAP

/ P10051:05

P-05 (A) 02/08/10

WAP

P10050:01

42
42

42

$r$
P-06 (A) 02/08/10

$\mathrm{DP} \quad$ / P10056:01-28

Remote visual tank wall inspection revealed no areas of concern since last evaluated on 2/22/09.

Remote visual tank wall inspection revealed no areas of concern since last evaluated on 2/22/09.

Remote visual inspection of the secondary vessel wall revealed no areas of concern since last evaluated on $7 / 15 / 06$.

Remote visual tank wall inspection revealed no areas of concern since last evaluated on $7 / 8 / 09$.

Remote visual tank wall inspection revealed no areas of concern since last evaluated on $7 / 8 / 09$.

Remote visual tank wall inspection revealed no areas of concern since last evaluated on 2/22/09. 
TANK OR ACCESS OPENING

AREA ANCILLARY

42

42

$\mathrm{H}$

$\mathrm{H}$

42

42

42

$\mathrm{H}$

$\mathrm{H}$

P-11 (A) 02/08/10

P-12 (A)

$02 / 08 / 10$

P-13 (A)

$02 / 08 / 10$

42

$\mathrm{H}$

42

43

$\mathrm{H}$

$\mathrm{H}$

43

$\mathrm{H}$

43

(A OR I)

$\mathrm{P}-08 \quad(\mathrm{~A})$

P-09 (A)

$02 / 08 / 10$

$02 / 08 / 10$

P-14 (A)

02/06/10

$\mathrm{A}-01 \quad(\mathrm{~A})$

02/07/10

A-02 (A)

$02 / 07 / 10$

A-03 (A) $\quad 02 / 07 / 10$
43
WAP

I

P10050:09

DP

I P10054:01-27

WAP / P10051:01

DP

I P10063:01-27

DP

I P10064:01-25

INSPECTION METHOD

IDENTIFICATION NUMBER

\section{REMARKS}

Remote visual tank wall inspection revealed no areas of concern since last evaluated on $7 / 8 / 09$.

Remote visual tank wall inspection revealed no areas of concern since last evaluated on $7 / 8 / 09$.

Remote visual tank wall inspection revealed no areas of concern since last evaluated on $7 / 8 / 09$.

Remote visual tank wall inspection revealed no areas of concern since last evaluated on 2/22/09.

Remote visual tank wall inspection revealed no areas of concern since last evaluated on $7 / 8 / 09$.

Remote visual tank wall inspection revealed no areas of concern since last evaluated on $7 / 8 / 09$.

Remote visual tank wall inspection revealed no areas of concern since last evaluated on $7 / 8 / 09$.

Remote visual tank wall inspection revealed no areas of concern since last evaluated on 2/20/09.

Remote visual tank wall inspection revealed no areas of concern since last evaluated on 2/23/09.

Remote visual tank wall inspection revealed no areas of concern since last evaluated on 2/20/09.

The conductivity probe was properly positioned per J-JX-G-0001. 
TANK OR ACCESS OPENING

AREA ANCILLARY

43

43

$\mathrm{H}$

$\mathrm{H}$

43

43

$\mathrm{H}$

$\mathrm{H}$

43

43

$\mathrm{H}$

$\mathrm{H}$

43

43

$\mathrm{H}$

43

43

$\mathrm{H}$

P-03 (A)

(A) $\quad 02 / 08 / 10$

$\mathrm{A}-04$ (A) $\quad 02 / 07 / 10$

$\mathrm{P}-01 \quad(\mathrm{~A})$

$02 / 08 / 10$

WAP

I P10066:08

P-02 (A)

$02 / 08 / 10$

WAP

I P10066:09

WAP I P10066:10

P-04 (A)

$02 / 08 / 10$

WAP

P10066:11

$\mathrm{P}-05 \quad$ (A)

$02 / 08 / 10$

WAP

I P10066:12

P-06 (A)

$02 / 08 / 10$

WAP

P10066:13

P-07 (A)

$02 / 08 / 10$

WAP I P10066:14

P-08 (A)

$02 / 08 / 10$

WAP

P10066:01
43

\begin{abstract}
P-09 (A)
\end{abstract}
02/08/10

\section{REMARKS}

Remote visual tank wall inspection revealed no areas of concern since last evaluated on 2/23/09.

The conductivity probe was properly positioned per J-JX-G-0001.

Remote visual tank wall inspection revealed no areas of concern since last evaluated on $2 / 20 / 09$. The annulus jet installed in the $F$ riser was satisfactory per T-DS-G-00043.

Remote visual tank wall inspection revealed no areas of concern since last evaluated on 2/20/09.

Remote visual tank wall inspection revealed no areas of concern since last evaluated on 2/20/09.

Remote visual tank wall inspection revealed no areas of concern since last evaluated on 2/20/09.

Remote visual tank wall inspection revealed no areas of concern since last evaluated on 2/20/09.

Remote visual tank wall inspection revealed no areas of concern since last evaluated on 2/20/09.

Remote visual tank wall inspection revealed no areas of concern since last evaluated on 2/20/09.

Remote visual tank wall inspection revealed no areas of concern since last evaluated on 2/20/09.

Remote visual tank wall inspection revealed no areas of concern since last evaluated on 2/20/09. 
TANK OR ACCESS OPENING

AREA ANCILLARY

43

$\mathrm{H}$

$\mathrm{H}$

43

43

$\mathrm{H}$

43

43

44

44

44

$\mathrm{F}$

$\mathrm{F}$

$\mathrm{F}$

A-01

(A)

$02 / 08 / 10$

$01 / 01 / 10$

COP \#30

A-02 (A)

$02 / 08 / 10$

44

A-03 (A)

$02 / 08 / 10$

$\mathrm{F}$
WAP

I P10161:06

WAP

WAP / P10161:01

INSPECTION METHOD IDENTIFICATION NUMBER

WAP / P10066:03

WAP / P10066:04

WAP / P10066:05

WAP I P10066:06

WAP I P10066:07

DSP / P10001:01-08

Inspection of the transfer lines within the clean out port was satisfactory per T-DS-G-00001.

Remote visual tank wall inspection revealed no areas of concern since last evaluated on 7/10/09.

Remote visual tank wall inspection revealed no areas of concern since last evaluated on 7/10/09.

Remote visual tank wall inspection revealed no areas of concern since last evaluated on $7 / 10 / 09$. The annulus jet installed in the $F$ riser was satisfactory per T-DS-G-00043.

Remote visual tank wall inspection revealed no areas of concern since last evaluated on 7/10/09.

Remote visual tank wall inspection revealed no areas of concern since last evaluated on 2/26/09. 


\section{AREA}

TANK OR

$\mathrm{F}$

44

44

44

44

44

44

44

$\mathrm{F}$

F

$\mathrm{F}$

44

44

44
ACCESS OPENING

(A OR I)

P-01 (A)

DATE

03/09/10

A) $\quad 03 / 01 / 10$

DP

/ P10160:01-28

P-02 (A)

P-03 (A)

02/08/10

WAP / P10161:02

P-04 (A)

$02 / 08 / 10$

WAP

/ P10161:03

P-05 (A)

$02 / 08 / 10$

WAP / P10161:04

P-06 (A)

02/08/10

WAP

/ P10161:05

P-07 (A)

$02 / 08 / 10$

WAP

I

P10161:07

03/01/10

P-08 (A)

DP

/ P10159:01-25

P-09 (A)

$02 / 08 / 10$

WAP

/ P10161:08
P-11 (A) 03/03/10

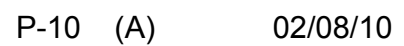

WAP

P10161:10

\section{REMARKS}

Remote visual inspection of the secondary vessel wall revealed no areas of concern since last evaluated on $5 / 19 / 06$.

Remote visual tank wall inspection revealed no areas of concern since last evaluated on 2/26/09.

Remote visual tank wall inspection revealed no areas of concern since last evaluated on 2/26/09.

Remote visual tank wall inspection revealed no areas of concern since last evaluated on 7/19/09.

Remote visual tank wall inspection revealed no areas of concern since last evaluated on 2/26/09.

Remote visual tank wall inspection revealed no areas of concern since last evaluated on 2/26/09.

Remote visual tank wall inspection revealed no areas of concern since last evaluated on 2/26/09.

Remote visual tank wall inspection revealed no areas of concern since last evaluated on 2/26/09.

Remote visual tank wall inspection revealed no areas of concern since last evaluated on 7/10/09.

Remote visual tank wall inspection revealed no areas of concern since last evaluated on 2/26/09.

Remote visual tank wall inspection revealed no areas of concern since last evaluated on 2/26/09. 


\begin{tabular}{|c|c|c|c|c|c|c|c|c|}
\hline \multirow{2}{*}{$\frac{\text { AREA }}{F}$} & \multirow{2}{*}{$\begin{array}{c}\text { TANK OR } \\
\text { ANCILLARY } \\
44\end{array}$} & \multicolumn{2}{|c|}{$\frac{\text { ACCESS OPENING }}{(A \text { OR I) }}$} & \multirow{2}{*}{$\frac{\text { DATE }}{03 / 03 / 10}$} & \multicolumn{3}{|c|}{$\frac{\text { INSPECTION METHOD }}{\text { IDENTIFICATION NUMBER }}$} & \multirow{2}{*}{$\begin{array}{l}\text { REMARKS } \\
\text { sual tank wall inspection } \\
\text { o areas of concern since } \\
\text { ted on } 2 / 26 / 09 \text {. }\end{array}$} \\
\hline & & $\mathrm{P}-12$ & $(\mathrm{~A})$ & & WAP & l & P10162:01 & \\
\hline $\mathrm{F}$ & 44 & $P-13$ & $(\mathrm{~A})$ & 02/08/10 & WAP & l & P10161:12 & $\begin{array}{l}\text { Remote visual tank wall inspection } \\
\text { revealed no areas of concern since } \\
\text { last evaluated on } 2 / 26 / 09 \text {. }\end{array}$ \\
\hline $\mathrm{F}$ & 44 & P-14 & (A) & $02 / 08 / 10$ & WAP & l & P10161:13 & $\begin{array}{l}\text { Remote visual tank wall inspection } \\
\text { revealed no areas of concern since } \\
\text { last evaluated on } 2 / 26 / 09 \text {. }\end{array}$ \\
\hline $\mathrm{F}$ & 45 & A-01 & $(\mathrm{A})$ & $02 / 15 / 10$ & WAP & l & P10164:01 & $\begin{array}{l}\text { Remote visual tank wall inspection } \\
\text { revealed no areas of concern since } \\
\text { last evaluated on } 7 / 13 / 09 \text {. }\end{array}$ \\
\hline $\mathrm{F}$ & 45 & A-02 & (A) & $02 / 15 / 10$ & WAP & l & P10164:06 & $\begin{array}{l}\text { Remote visual tank wall inspection } \\
\text { revealed no areas of concern since } \\
\text { last evaluated on } 7 / 13 / 09 \text {. }\end{array}$ \\
\hline $\mathrm{F}$ & 45 & A-03 & (A) & $02 / 15 / 10$ & WAP & l & P10164:08 & $\begin{array}{l}\text { Remote visual tank wall inspection } \\
\text { revealed no areas of concern since } \\
\text { last evaluated on } 7 / 13 / 09 \text {. }\end{array}$ \\
\hline $\mathrm{F}$ & 45 & A-04 & (A) & $02 / 15 / 10$ & WAP & I & P10164:12 & $\begin{array}{l}\text { Remote visual tank wall inspection } \\
\text { revealed no areas of concern since } \\
\text { last evaluated on } 7 / 13 / 09 \text {. }\end{array}$ \\
\hline$F$ & 45 & P-01 & $(\mathrm{A})$ & $03 / 01 / 10$ & DP & I & P10167:01-26 & $\begin{array}{l}\text { Remote visual tank wall inspection } \\
\text { revealed no areas of concern since } \\
\text { last evaluated on } 2 / 26 / 09 \text {. }\end{array}$ \\
\hline$F$ & 45 & P-01 & (A) & 03/01/10 & DP & l & P10168:01-26 & $\begin{array}{l}\text { Remote visual inspection of the } \\
\text { secondary vessel wall revealed no } \\
\text { areas of concern since last evaluated } \\
\text { on } 5 / 19 / 06 \text {. }\end{array}$ \\
\hline$F$ & 45 & P-02 & $(A)$ & 03/01/10 & DP & l & P10166:01-25 & $\begin{array}{l}\text { Remote visual tank wall inspection } \\
\text { revealed no areas of concern since } \\
\text { last evaluated on } 2 / 26 / 09 \text {. }\end{array}$ \\
\hline $\mathrm{F}$ & 45 & P-03 & $(A)$ & $02 / 15 / 10$ & WAP & l & P10164:02 & $\begin{array}{l}\text { Remote visual tank wall inspection } \\
\text { revealed no areas of concern since } \\
\text { last evaluated on } 7 / 19 / 09 \text {. }\end{array}$ \\
\hline
\end{tabular}




\begin{tabular}{|c|c|c|c|c|c|c|c|}
\hline \multirow{2}{*}{$\frac{\text { AREA }}{F}$} & \multirow{2}{*}{$\begin{array}{c}\begin{array}{c}\text { TANK OR } \\
\text { ANCILLARY }\end{array} \\
45\end{array}$} & \multicolumn{2}{|c|}{$\frac{\text { ACCESS OPENING }}{(A \text { OR I) }}$} & \multirow{2}{*}{$\frac{\text { DATE }}{02 / 15 / 10}$} & \multicolumn{2}{|c|}{$\frac{\text { INSPECTION METHOD }}{\text { IDENTIFICATION NUMBER }}$} & \multirow[b]{2}{*}{$\begin{array}{l}\text { Remote visual tank wall inspection } \\
\text { revealed no areas of concern since } \\
\text { last evaluated on } 2 / 26 / 09 \text {. }\end{array}$} \\
\hline & & P-04 & (A) & & WAP & P10164:04 & \\
\hline $\mathrm{F}$ & 45 & P-05 & (A) & $02 / 15 / 10$ & WAP & P10164:03 & $\begin{array}{l}\text { Remote visual tank wall inspection } \\
\text { revealed no areas of concern since } \\
\text { last evaluated on } 2 / 26 / 09 \text {. }\end{array}$ \\
\hline $\mathrm{F}$ & 45 & P-06 & (A) & $02 / 15 / 10$ & WAP & P10164:05 & $\begin{array}{l}\text { Remote visual tank wall inspection } \\
\text { revealed no areas of concern since } \\
\text { last evaluated on } 2 / 26 / 09 \text {. }\end{array}$ \\
\hline $\mathrm{F}$ & 45 & P-07 & (A) & $04 / 27 / 10$ & WAP & P10169:01 & $\begin{array}{l}\text { Remote visual tank wall inspection } \\
\text { revealed no areas of concern since } \\
\text { last evaluated on } 2 / 26 / 09 \text {. }\end{array}$ \\
\hline$F$ & 45 & P-08 & (A) & 03/01/10 & DP & / P10165:01-21 & $\begin{array}{l}\text { Remote visual tank wall inspection } \\
\text { revealed no areas of concern since } \\
\text { last evaluated on } 2 / 26 / 09 \text {. }\end{array}$ \\
\hline $\mathrm{F}$ & 45 & P-09 & (A) & $02 / 15 / 10$ & WAP & P10164:07 & $\begin{array}{l}\text { Remote visual tank wall inspection } \\
\text { revealed no areas of concern since } \\
\text { last evaluated on } 7 / 13 / 09 \text {. }\end{array}$ \\
\hline $\mathrm{F}$ & 45 & $P-10$ & $(\mathrm{~A})$ & $02 / 15 / 10$ & WAP & P10164:09 & $\begin{array}{l}\text { Remote visual tank wall inspection } \\
\text { revealed no areas of concern since } \\
\text { last evaluated on } 2 / 26 / 09 \text {. }\end{array}$ \\
\hline $\mathrm{F}$ & 45 & $P-11$ & (A) & $02 / 15 / 10$ & WAP & P10164:10 & $\begin{array}{l}\text { Remote visual tank wall inspection } \\
\text { revealed no areas of concern since } \\
\text { last evaluated on } 2 / 26 / 09 \text {. }\end{array}$ \\
\hline $\mathrm{F}$ & 45 & $P-12$ & (A) & $02 / 15 / 10$ & WAP & P10164:11 & $\begin{array}{l}\text { Remote visual tank wall inspection } \\
\text { revealed no areas of concern since } \\
\text { last evaluated on } 2 / 26 / 09 \text {. }\end{array}$ \\
\hline $\mathrm{F}$ & 45 & $P-13$ & $(\mathrm{~A})$ & $02 / 15 / 10$ & WAP & P10164:13 & $\begin{array}{l}\text { Remote visual tank wall inspection } \\
\text { revealed no areas of concern since } \\
\text { last evaluated on } 2 / 26 / 09 \text {. }\end{array}$ \\
\hline $\mathrm{F}$ & 45 & P-14 & $(\mathrm{A})$ & $02 / 15 / 10$ & WAP & P10164:14 & $\begin{array}{l}\text { Remote visual tank wall inspection } \\
\text { revealed no areas of concern since } \\
\text { last evaluated on } 2 / 26 / 09 \text {. }\end{array}$ \\
\hline
\end{tabular}




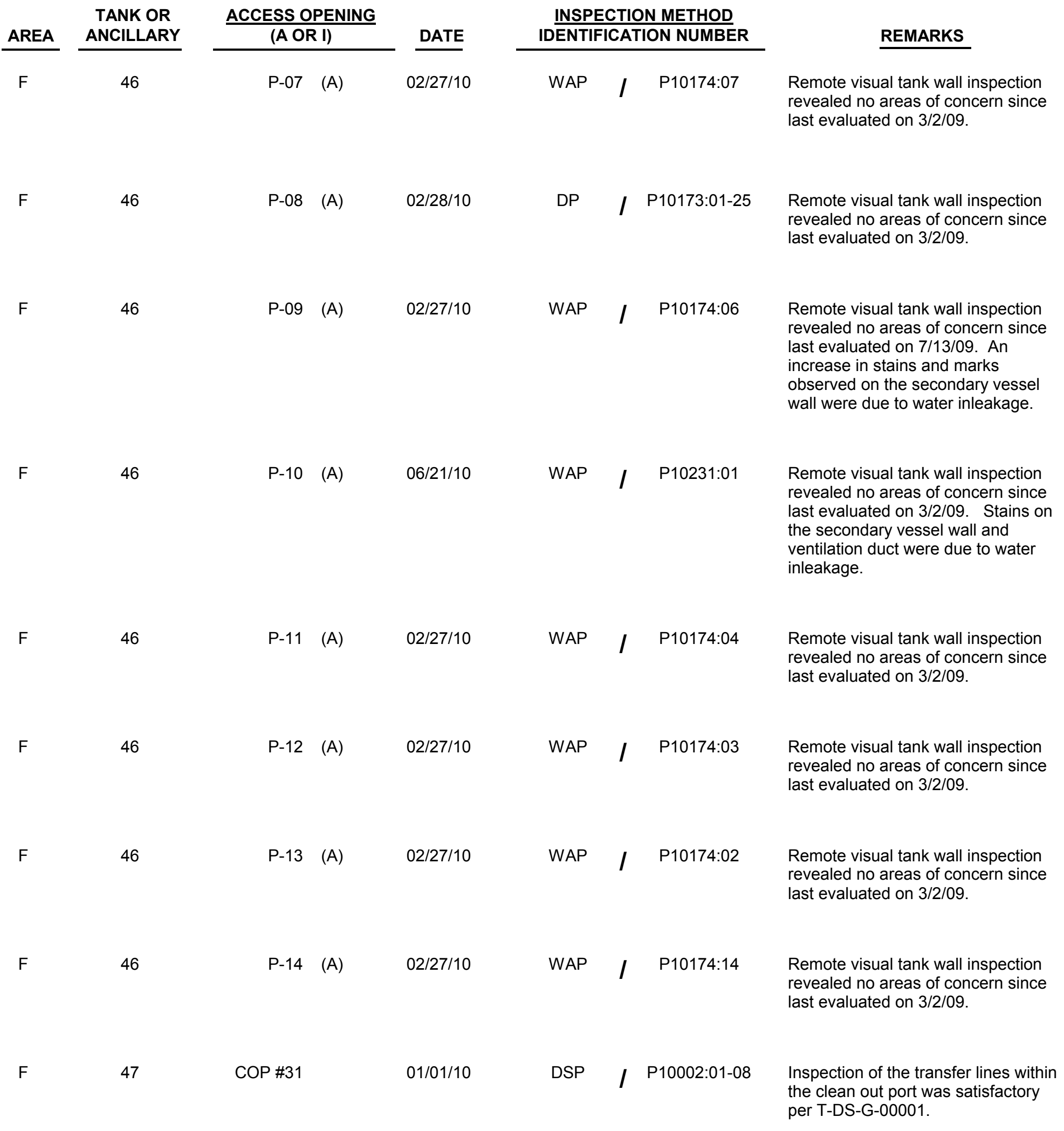




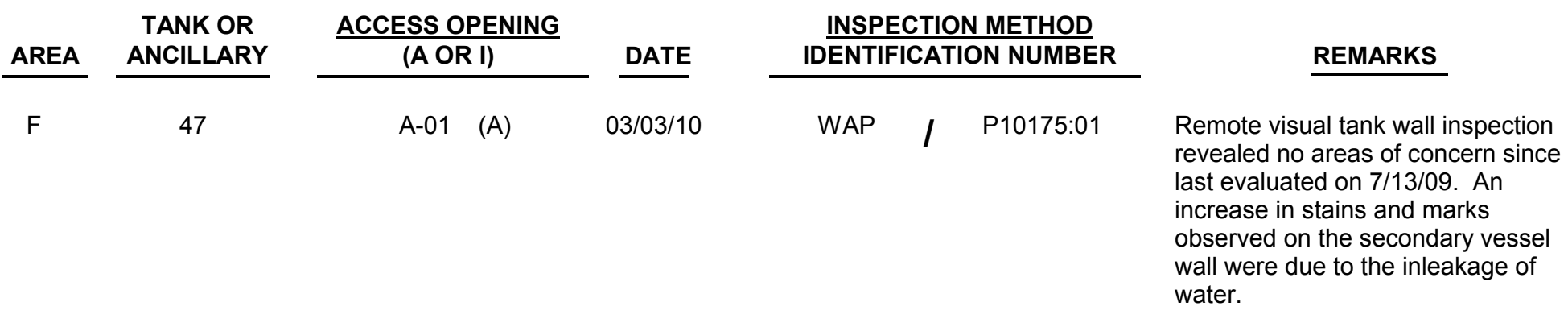

(A) $\quad 03 / 03 / 10$

WAP / P10175:03

Remote visual tank wall inspection revealed no areas of concern since last evaluated on $7 / 13 / 09$.

03/03/10

WAP

/ P10175:07

Remote visual tank wall inspection revealed no areas of concern since last evaluated on $7 / 13 / 09$.

Remote visual tank wall inspection revealed no areas of concern since last evaluated on 7/13/09. revealed no areas of concern since last evaluated on 3/2/09.

Remote visual inspection of the secondary vessel wall revealed no areas of concern since last evaluated on $5 / 19 / 06$.

Remote visual tank wall inspection revealed no areas of concern since last evaluated on 3/2/09.

Remote visual tank wall inspection revealed no areas of concern since last evaluated on $3 / 2 / 09$. revealed no areas of concern since last evaluated on 3/2/09. last evaluated on 3/2/09. 


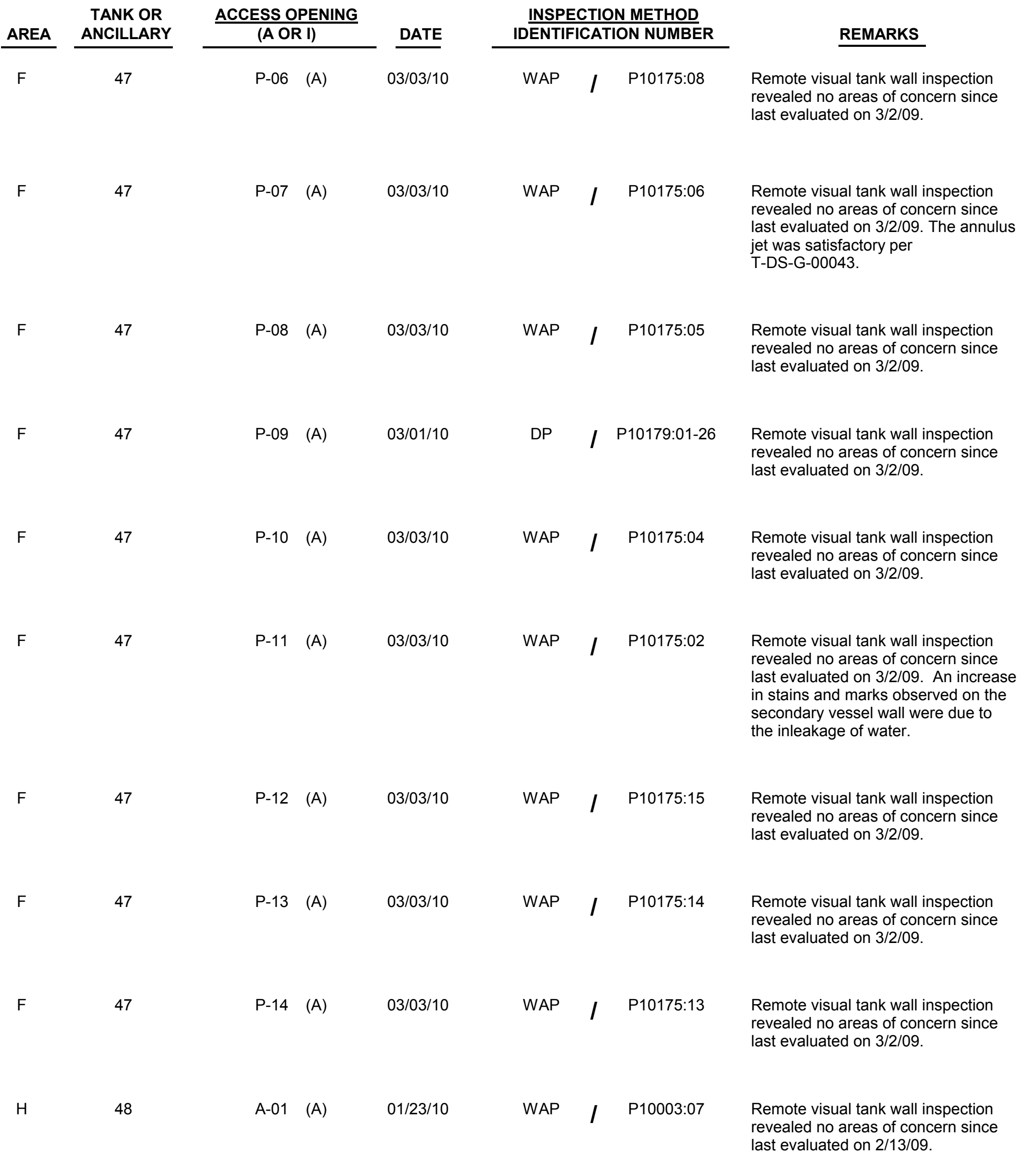


TANK OR ACCESS OPENING

AREA ANCILLARY

48

48

48

48

48

$\mathrm{H}$

$\mathrm{H}$

$\mathrm{H}$

48

$\frac{\frac{\text { ACCESS OPENING }}{(A \text { OR I) }}}{}$

DATE

A-02 (A) $\quad 01 / 23 / 10$

A-03 (A)

$01 / 23 / 10$

WAP

P10003:13

A-03 (A)

$04 / 06 / 10$

CCTV

I

2035

A-04 (A)

$01 / 23 / 10$

WAP

I P10003:04

P-01

(A)

$01 / 23 / 10$

WAP

P10003:08

P-02 (A)

$01 / 23 / 10$

WAP

I P10003:09

48

$\mathrm{H}$

P.03 (A)

(A) $\quad 01 / 23 / 10$

48

$\mathrm{H}$

48

$\mathrm{H}$

P-04 (A) 01/23/10

$\mathrm{DP} \quad$ / P10005:01-25

Remote visual tank wall inspection revealed no areas of concern since last evaluated on 2/13/09.

Remote visual tank wall inspection revealed no areas of concern since last evaluated on $7 / 15 / 09$. The annulus jet installed in the F-riser was satisfactory per T-DS-G-00043.

Remote visual tank wall inspection revealed no areas of concern since last evaluated on 2/13/09.

Remote visual tank wall inspection last evaluated on 2/13/09.

Remote visual tank wall inspection revealed no areas of concern since last evaluated on 7/15/09.

Remote visual inspection of the secondary vessel wall revealed no areas of concern since last evaluated on $5 / 15 / 07$.

Remote visual tank wall inspection revealed no areas of concern since last evaluated on 2/13/09. 
TANK OR ACCESS OPENING

AREA ANCILLARY

48

48

48

48

$\mathrm{H}$

48

$\mathrm{H}$

$\mathrm{H}$

$\mathrm{H}$

$\mathrm{H}$

48

$\mathrm{H}$

48

48

$\mathrm{H}$

$\mathrm{H}$

49

49

P-07 (A)

P-08 (A)

P-09 (A)

P-10 (A)

P-11 (A)

P-13 (A)

P-14 (A)

$\mathrm{A}-01 \quad(\mathrm{~A})$

$\frac{\text { ACCESS OPENING }}{(\text { A OR I) }}$

DATE

$\begin{array}{lll}\text { P-06 } & \text { (A) } \quad 01 / 23 / 10\end{array}$

$01 / 23 / 10$

$01 / 23 / 10$

WAP

/ P10003:01

$01 / 23 / 10$

WAP

I P10003:02

$01 / 23 / 10$

DP

I P10007:01-25

$01 / 23 / 10$

WAP

/ P10003:03

$01 / 23 / 10$

WAP

/ P10003:05

$01 / 23 / 10$

WAP

I P10003:06

$01 / 25 / 10$

WAP

I P10014:12

A-02 (A)

$01 / 25 / 10$

WAP

I P10014:09

\section{REMARKS}

Remote visual tank wall inspection revealed no areas of concern since last evaluated on $7 / 15 / 09$.

Remote visual tank wall inspection revealed no areas of concern since last evaluated on 7/15/09.

Remote visual tank wall inspection revealed no areas of concern since last evaluated on 7/15/09.

Remote visual tank wall inspection revealed no areas of concern since last evaluated on $7 / 15 / 09$.

Remote visual tank wall inspection revealed no areas of concern since last evaluated on 2/13/09.

Remote visual tank wall inspection revealed no areas of concern since last evaluated on 2/13/09.

Remote visual tank wall inspection revealed no areas of concern since last evaluated on 2/13/09.

Remote visual tank wall inspection revealed no areas of concern since last evaluated on 2/13/09.

Remote visual tank wall inspection revealed no areas of concern since last evaluated on 7/14/09.

Remote visual tank wall inspection revealed no areas of concern since last evaluated on 7/14/09.

Remote visual tank wall inspection revealed no areas of concern since last evaluated on $7 / 14 / 09$. 
TANK OR ACCESS OPENING ANCILLARY

49

49

49

49

49

$\mathrm{H}$

$\mathrm{H}$

$\mathrm{H}$

$\mathrm{H}$

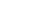

$\mathrm{H}$

49

49

$\mathrm{H}$

$\mathrm{H}$

49

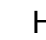

49

49

49

(A OR I)

P-02 (A)

$\mathrm{P}-03 \quad(\mathrm{~A})$

P-04 (A)

P-05 (A)

$\mathrm{P}-06$

(A)

P-07 (A)

P-08 (A)
DATE

$\mathrm{A}-04 \quad$ (A) $\quad 01 / 25 / 10$

P-01 (A) $\quad 01 / 26 / 10$

P-01 (A) $\quad 01 / 26 / 10$

$01 / 26 / 10$

DP / P10012:01-27

WAP / P10014:11

$01 / 25 / 10$

$01 / 25 / 10$

WAP

P10014:10

$01 / 25 / 10$

WAP / P10014:08

$01 / 25 / 10$

WAP / P10014:07

$01 / 25 / 10$

WAP

P10014:06

$01 / 25 / 10$

WAP

I P10014:13

ATIONER
INSPECTION METHOD

\section{REMARKS}

Remote visual tank wall inspection revealed no areas of concern since last evaluated on 7/14/09.

Remote visual tank wall inspection revealed no areas of concern since last evaluated on $2 / 14 / 09$. The annulus jet installed in the F-riser was satisfactory per T-DS-G-00043.

Remote visual inspection of the secondary vessel wall revealed no areas of concern since last evaluated on $8 / 15 / 06$.

Remote visual tank wall inspection revealed no areas of concern since last evaluated on 2/18/09.

Remote visual tank wall inspection revealed no areas of concern since last evaluated on 2/14/09.

Remote visual tank wall inspection revealed no areas of concern since last evaluated on 2/14/09.

Remote visual tank wall inspection revealed no areas of concern since last evaluated on 2/18/09.

Remote visual tank wall inspection revealed no areas of concern since last evaluated on 2/14/09.

Remote visual tank wall inspection revealed no areas of concern since last evaluated on 2/14/09.

Remote visual tank wall inspection revealed no areas of concern since last evaluated on $7 / 14 / 09$.

Remote visual tank wall inspection revealed no areas of concern since last evaluated on 2/18/09. 
TANK OR ACCESS OPENING

AREA ANCILLARY

49

49

49

49

$\mathrm{H}$

P-14 (A)

$01 / 29 / 10$

A-01 (A)

$01 / 25 / 10$

A-02

(A)

$01 / 25 / 10$

50

$\mathrm{H}$

50

$\mathrm{H}$

50

50
WAP

/ P10022:09

WAP

I P10022:06

INSPECTION METHOD IDENTIFICATION NUMBER

WAP / P10014:04

WAP / P10014:03

WAP I P10014:02

WAP / P10016:02

WAP / P10016:01

Remote visual tank wall inspection revealed no areas of concern since last evaluated on 2/18/09.

Remote visual tank wall inspection revealed no areas of concern since last evaluated on 7/11/09.

Remote visual tank wall inspection revealed no areas of concern since last evaluated on 7/11/09.

Remote visual tank wall inspection revealed no areas of concern since last evaluated on 7/11/09.

Remote visual tank wall inspection revealed no areas of concern since last evaluated on $7 / 11 / 09$.

Remote visual tank wall inspection revealed no areas of concern since last evaluated on $2 / 20 / 09$. The annulus jet installed in the $F$ riser was satisfactory per T-DS-G-00043.

Remote visual inspection of the seconday vessel wall revealed no areas of concern since last evaluated on $8 / 15 / 06$. 


\begin{tabular}{|c|c|c|c|c|c|c|c|}
\hline \multirow{2}{*}{$\frac{\text { AREA }}{\mathrm{H}}$} & \multirow{2}{*}{$\begin{array}{c}\text { TANK OR } \\
\text { ANCILLARY } \\
50\end{array}$} & \multicolumn{2}{|c|}{$\frac{\text { ACCESS OPENING }}{(A \text { OR I) }}$} & \multirow{2}{*}{$\frac{\text { DATE }}{01 / 28 / 10}$} & \multicolumn{2}{|c|}{$\frac{\text { INSPECTION METHOD }}{\text { IDENTIFICATION NUMBER }}$} & \multirow{2}{*}{$\begin{array}{l}\text { REMARKS } \\
\text { Remote visual tank wall inspection } \\
\text { revealed no areas of concern since } \\
\text { last evaluated on } 2 / 20 / 09 \text {. }\end{array}$} \\
\hline & & P-02 & $(\mathrm{A})$ & & DP & / P10024:01-25 & \\
\hline $\mathrm{H}$ & 50 & P-03 & $(\mathrm{A})$ & $01 / 25 / 10$ & WAP & P10022:08 & $\begin{array}{l}\text { Remote visual tank wall inspection } \\
\text { revealed no areas of concern since } \\
\text { last evaluated on } 2 / 20 / 09 \text {. }\end{array}$ \\
\hline $\mathrm{H}$ & 50 & P-04 & (A) & $01 / 25 / 10$ & WAP & P10022:07 & $\begin{array}{l}\text { Remote visual tank wall inspection } \\
\text { revealed no areas of concern since } \\
\text { last evaluated on } 2 / 20 / 09 \text {. }\end{array}$ \\
\hline $\mathrm{H}$ & 50 & P-05 & (A) & $01 / 25 / 10$ & WAP & P10022:05 & $\begin{array}{l}\text { Remote visual tank wall inspection } \\
\text { revealed no areas of concern since } \\
\text { last evaluated on } 2 / 20 / 09 \text {. }\end{array}$ \\
\hline $\mathrm{H}$ & 50 & P-06 & (A) & $01 / 25 / 10$ & WAP & P10022:04 & $\begin{array}{l}\text { Remote visual tank wall inspection } \\
\text { revealed no areas of concern since } \\
\text { last evaluated on } 2 / 20 / 09 \text {. }\end{array}$ \\
\hline $\mathrm{H}$ & 50 & P-07 & (A) & $01 / 25 / 10$ & WAP & P10022:03 & $\begin{array}{l}\text { Remote visual tank wall inspection } \\
\text { revealed no areas of concern since } \\
\text { last evaluated on } 2 / 20 / 09 \text {. }\end{array}$ \\
\hline $\mathrm{H}$ & 50 & P-08 & (A) & $01 / 25 / 10$ & WAP & P10022:01 & $\begin{array}{l}\text { Remote visual tank wall inspection } \\
\text { revealed no areas of concern since } \\
\text { last evaluated on } 7 / 11 / 09 \text {. }\end{array}$ \\
\hline $\mathrm{H}$ & 50 & P-09 & (A) & $01 / 28 / 10$ & DP & / P10023:01-25 & $\begin{array}{l}\text { Remote visual tank wall inspection } \\
\text { revealed no areas of concern since } \\
\text { last evaluated on } 2 / 20 / 09 \text {. }\end{array}$ \\
\hline $\mathrm{H}$ & 50 & $P-10$ & $(\mathrm{~A})$ & $01 / 25 / 10$ & WAP & P10022:14 & $\begin{array}{l}\text { Remote visual tank wall inspection } \\
\text { revealed no areas of concern since } \\
\text { last evaluated on } 2 / 20 / 09 \text {. }\end{array}$ \\
\hline $\mathrm{H}$ & 50 & $P-11$ & $(\mathrm{~A})$ & $02 / 11 / 10$ & WAP & P10163:01 & $\begin{array}{l}\text { Remote visual tank wall inspection } \\
\text { revealed no areas of concern since } \\
\text { last evaluated on } 2 / 20 / 09 \text {. }\end{array}$ \\
\hline $\mathrm{H}$ & 50 & P-12 & $(\mathrm{A})$ & $01 / 25 / 10$ & WAP & P10022:12 & $\begin{array}{l}\text { Remote visual tank wall inspection } \\
\text { revealed no areas of concern since } \\
\text { last evaluated on } 2 / 23 / 09 \text {. }\end{array}$ \\
\hline
\end{tabular}


TANK OR ACCESS OPENING

AREA ANCILLARY

50

51

$\mathrm{H}$

$\mathrm{H}$

50

51

51

$\mathrm{H}$

$\mathrm{H}$

51

$\mathrm{H}$

51

51

$\mathrm{H}$

$\mathrm{H}$

51

51

$H$

P-14 (A)

$01 / 25 / 10$

A-01 (A)

$01 / 27 / 10$

A-02 (A)

$02 / 11 / 10$

WAP

I P10288:01

A-03 (A)

$01 / 25 / 10$

WAP

I P10020:05

A-03 (A)

$08 / 17 / 10$

CCTV

I

1756

A-04 (A)

$01 / 25 / 10$

WAP

I P10020:01

A-04 (A)

$08 / 17 / 10$

CCTV

I 1756

P-01 (A) $\quad 01 / 27 / 10$

DP

I P10017:01-25

51

P-01 (A)

$01 / 27 / 10$

DP

/ P10018:01-25

\section{REMARKS}

Remote visual tank wall inspection revealed no areas of concern since last evaluated on 2/20/09

Remote visual tank wall inspection revealed no areas of concern since last evaluated on 2/20/09.

Remote visual tank wall inspection revealed no areas of concern since last evaluated on $7 / 18 / 09$.

Remote visual tank wall inspection revealed no areas of concern since last evaluated on 7/18/09.

Remote visual tank wall inspection revealed no areas of concern since last evaluated on 7/18/09.

The conductivity probe was properly positioned per J-JX-G-0001.

Remote visual tank wall inspection revealed no areas of concern since last evaluated on $7 / 18 / 09$.

The conductivity probe was properly positioned per J-JX-G-0001.

Remote visual tank wall inspection revealed no areas of concern since last evaluated on 2/18/09.

Remote visual inspection of the secondary vessel wall revealed no areas of concern since last evaluated on $2 / 18 / 09$.

Remote visual tank wall inspection revealed no areas of concern since last evaluated on 2/18/09. 
TANK OR ACCESS OPENING

AREA ANCILLARY

51

51

$\mathrm{H}$

$\mathrm{H}$

51

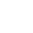

51

$\mathrm{H}$

51

51

$\mathrm{H}$

$\mathrm{H}$

51

51

$\mathrm{H}$

51

$\mathrm{H}$

51

51

(A OR I)

$\mathrm{P}-03 \quad(\mathrm{~A})$

P-04 (A)

P-05 (A)

P-06 (A)

P-07 (A)

P-08 (A)

P-09 (A)

P-10 (A)

P-11 (A)

P-12 (A)
DATE

01/27/10

$01 / 27 / 10$

WAP

I P10021:05

$01 / 27 / 10$

$01 / 25 / 10$

WAP

P10020:08

$01 / 25 / 10$

WAP I P10020:07

$01 / 25 / 10$

WAP

P10020:06

$01 / 25 / 10$

WAP

I P10020:04

$01 / 27 / 10$

DP

/ P10015:01-25

$01 / 25 / 10$

WAP

P10020:03

$01 / 25 / 10$

WAP

$01 / 25 / 10$

$01 / 27 / 10$

WAP

I P10021:01

$51 \quad$ P-13 (A) $\quad 01 / 27 / 10 \quad$ WAP $\quad$ / P10021:06

INSPECTION METHOD

REMARKS

Remote visual tank wall inspection revealed no areas of concern since last evaluated on 2/14/09.

Remote visual tank wall inspection revealed no areas of concern since last evaluated on 2/14/09.

Remote visual tank wall inspection revealed no areas of concern since last evaluated on 2/14/09.

Remote visual tank wall inspection revealed no areas of concern since last evaluated on $2 / 18 / 09$.

Remote visual tank wall inspection revealed no areas of concern since last evaluated on 2/14/09.

Remote visual tank wall inspection revealed no areas of concern since last evaluated on $7 / 18 / 09$.

Remote visual tank wall inspection revealed no areas of concern since last evaluated on 2/14/09.

Remote visual tank wall inspection revealed no areas of concern since last evaluated on 2/14/09.

Remote visual tank wall inspection revealed no areas of concern since last evaluated on 2/14/09.

Remote visual tank wall inspection revealed no areas of concern since last evaluated on 2/14/09.

Remote visual tank wall inspection revealed no areas of concern since last evaluated on 2/14/09. 
TANK OR ACCESS OPENING

AREA ANCILLARY

DB-02

DB-02

DB-02

DB-02

DB-03

DB-03

$\mathrm{F}$

$\mathrm{F}$

$\mathrm{H}$

$\mathrm{H}$

$\mathrm{F}$

$\mathrm{F}$

North

$11 / 01 / 10$

CCTV

1821

West

$11 / 01 / 10$

CCTV

1821

NE

$06 / 03 / 10$

CCTV

2111

SW

$06 / 03 / 10$

CCTV

I

2111

North

04/07/10

CCTV

l

1473

South

04/07/10

FLWB

$10 / 25 / 10$

CCTV

1922

DB-04

Sump

$04 / 02 / 10$

CCTV

1937

\section{REMARKS}

Remote visual tank wall inspection revealed no areas of concern since last evaluated on 2/14/09.

Inspection of the stainless steel liner, cell covers, jumpers, valves, and piping was satisfactory per SW11.6-SVP-45, Section 7.9.

Inspection of the stainless steel liner, cell covers, jumpers, valves, and piping was satisfactory per SW11.6-SVP-45, Section 7.9.

Inspection of the stainless steel liner, cell covers, jumpers, valves, piping and floor was satisfactory per SW11.6-SVP-45, Section 7.9.

Inspection of the stainless steel liner, cell covers, jumpers, valves, piping and floor was satisfactory per SW11.6-SVP-45, Section 7.9.

Inspection of the walls, cell covers, jumpers, valves, piping and floor was satisfactory per SW11.6-SVP-45, Section 7.9

Inspection of the walls, cell covers, jumpers, valves, piping, and floors was satisfactory per SW11.6-SVP-45, Section 7.9

Inspection of the walls, floor, valves, and piping was satisfactory per T-DS-G-00001.

Inspection of the stainless steel liner, cell covers, jumpers, valves, piping and floor was satisfactory per SW11.6-SVP-45, Section 7.9.

Inspection of the walls, floor, valves, and piping was satisfactory per T-DS-G-00001. 
TANK OR ACCESS OPENING ANCILLARY

DB-05

DB-06

$\mathrm{H}$

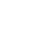

\section{FLWB}

04/10/10

CCTV

2089

$\mathrm{H}$

DB-06

Sump

$03 / 22 / 10$

CCTV

2089

$\mathrm{H}$

DB-07

FLWB

$04 / 10 / 10$

CCTV

2019

$\mathrm{H}$

DB-07

FLWB

$04 / 10 / 10$

CCTV I

2019

NW

$04 / 16 / 10$

CCTV

2095

$\mathrm{H}$

DB-07

DB-07

Sump

$04 / 16 / 10$

CCTV

2095

$\mathrm{H}$

DB-08

FLWB

$04 / 13 / 10$

CCTV

1973

NE

$03 / 10 / 10$

CCTV

1973

\section{REMARKS}

Inspection of the walls, floor, jumpers, valves and piping visible from the sump inspection port was satisfactory per SW11.6-SVP-45, Section 7.9.

Inspection of the walls, floor, valves, and piping was satisfactory per T-DS-G-00001.

Inspection of the stainless steel liner, cell covers, jumpers, valves, piping and floor was satisfactory per SW11.6-SVP-45, Section 7.9.

Inspection of the walls, floor, valves, and piping visible from the south inspection port was satisfactory per T-DS-G-00001.

Inspection of the walls, floor, valves, and piping visible from the north inspection port was satisfactory per T-DS-G-00001.

Inspection of the stainless steel liner, cell covers, jumpers, valves, piping and floor was satisfactory per SW11.6-SVP-45, Section 7.9.

Inspection of the stainless steel liner, cell covers, jumpers, valves, piping and floor was satisfactory per SW11.6-SVP-45, Section 7.9.

Inspection of the walls, piping, floor, and valves was satisfactory per T-DS-G-00001.

Inspection of the stainless steel liner, cell covers, jumpers, valves, piping and floor was satisfactory per SW11.6-SVP-45, Section 7.9.

Inspection of the stainless steel liner, cell covers, jumpers, valves, piping and floor was satisfactory per SW11.6-SVP-45, Section 7.9. 
TANK OR ACCESS OPENING

ANCILLARY

EVAP-16

EVAP-16

$\mathrm{F}$
$\mathrm{F}$

FVAP-16

F $\quad$ EVAP-16

EVAP-16

EVAP-16

$\mathrm{F}$

$\mathrm{F}$

EVAP-16

EVAP-16

$\mathrm{H}$

E-03

NW

$03 / 31 / 10$

CCTV

2076

SE

$03 / 31 / 10$

CCTV

2076

SE

$04 / 13 / 10$

CCTV

2076

03/09/10

CCTV

2083

\section{REMARKS}

The inspection of the evaporator pot revealed no unusual conditions and the vessel was essentially clean. The inspection is documented in SRR-LWE-2010-00040.

Inspection of the evaporator pot revealed no unusual conditions and the vessel was clean. The inspection is documented in LWO-LWE-2010-00330.

Inspection of the cell covers, floor, stainless steel liner, jumpers, valves and evaporator pot exterior visible from the NW riser was satisfactory per SW11.6-SVP-45, Section 4.5.

Inspection of the cell covers, stainless steel liner, jumpers, valves and evaporator pot exterior visible from the SE riser was satisfactory per SW11.6-SVP-45, Section 4.5.

Inspection of the cell floor visible from the SE riser was satisfactory per SW11.6-SVP-45, Section 4.5.

Inspection of the interior of the $2 \mathrm{H}$ evaporator pot revealed that scale and deposits continue to increase as expected since chemical cleaning. Two areas were observed that had deposits ranging from 2-10 inches thick. The evaporator had operated 281 days since cleaning was completed in September 2008. This inspection is documented in SRR-LWE-2010-00076.

Inspection of the interior of the $2 \mathrm{H}$ evaporator pot revealed that scale and deposits continue to increase as expected since chemical cleaning. Three areas were observed that had deposits ranging from 2-10 inches thick. The evaporator had operated 331 days since cleaning was completed in September 2008. This inspection is documented in SRR-LWE-2010-00165. 
TANK OR ACCESS OPENING ANCILLARY

EVAP-16

EVAP-16

EVAP-16

$\mathrm{H}$

$\mathrm{H}$

E-03

NE

$08 / 28 / 10$

CCTV

I

2150

EVAP-16

SW

$08 / 28 / 10$

CCTV

I

2150

EVAP-25

GDL Cell

$09 / 22 / 10$

CCTV

2170

NW

$09 / 22 / 10$

\section{REMARKS}

Scale and deposits continue to increase as expected since chemical cleaning. Three areas were observed that had deposits ranging from 1-12 inches thick. The evaporator had operated 386 days since cleaning was completed in September 2008. Also, the evaporator had operated 55 days since the last inspection on $6 / 8 / 10$. Changes observed since 6/8/10 are increases of 1-2 inches in thickness and an increase in the area of accumulated solids on the vessel wall. This inspection is documented in SRR-LWE-2010-00228.

Inspection of the evaporator pot after acid cleaning revealed that the vessel was essentially clean. The inspection is documented in

SRR-LWE-2010-00321.

Inspection of the cell covers, stainless steel liner, valves, jumpers, piping and floor were satisfactory per SW11.6-SVP-45, Section 4.6.

Inspection of the cell covers, stainless steel liner, jumpers, valves, piping, floor and pot exterior was satisfactory per SW11.6-SVP-45, Section 4.6.

Inspection of the walls, floor, piping, and cell covers was satisfactory per SW11.6-SVP-45, Section 4.6.

Inspection of the cell walls, stainless steel liner, jumpers, valves, piping, floor, pot exterior and cell covers visible from the NW riser was satisfactory per SW11.6-SVP-45, Section 4.6 with the following exception. A thin layer of salt was observed covering almost the entire cell floor. 
TANK OR ACCESS OPENING

AREA ANCILLARY

EVAP-25

H EVAP-25

$\mathrm{H}$

EVAP-25

IAL

IT-V-43 Port

$11 / 09 / 10$

CCTV

I

2191

$\mathrm{H}$

IAL

SW

$11 / 09 / 10$

CCTV

l

2191

\section{REMARKS}

Inspection of the interior of the evaporator pot revealed no deposits or solids on the exposed surfaces. Conditions observed were consistent with normal operations. This evaluation is documented in SRR-LWE-2010-00208.

Inspection of the cell walls, stainless steel liner, jumpers, valves, piping, floor, pot exterior and cell covers visible from the SE riser was satisfactory per SW11.6-SVP-45, Section 4.6 with the following exception. The U-2 nozzle on the east lift jumper had leaked. Salt was observed on the connector head, the nozzle plate, down the outside of the evaporator pot, and on the cell floor. A thin layer of salt was observed covering almost the entire cell floor.

Inspection of the cell walls, stainless steel liner, jumpers, valves, piping, floor, pot exterior and cell covers visible from the SW riser was satisfactory per SW11.6-SVP-45, Section 4.6 with the following exception. A thin layer of salt was observed covering almost the entire cell floor. The U-1 nozzle on the west lift jumper had leaked. The amount appeared the same as observed in previous inspections.

Inspection of the walls, floor, jumpers, valves, piping, and cell covers was satisfactory per SW11.6-SVP-45, Section 4.11.

Inspection of the walls, floor, jumpers, valves, piping, and cell covers was satisfactory per SW11.6-SVP-45, Section 4.11.

Inspection of the walls, jumpers, valves and piping was satisfactory per SW11.6-SVP-45, Section 7.9. 
TANK OR ACCESS OPENING

AREA ANCILLARY

PP-02

$\mathrm{F}$

$\mathrm{H}$

PP-02

PP-02

$\mathrm{H}$

PP-02

PP-03

$\mathrm{F}$

PP-03

$\mathrm{H}$

(A OR I)

Sump

Sump

$\mathrm{NE}$

$\mathrm{NE}$

SW

Sump

NE

\section{ACCESS OPENING}

$11 / 01 / 10$

CCTV

2187

$04 / 02 / 10$

CCTV

1872

$06 / 12 / 10$

CCTV

1838

$10 / 02 / 10$

CCTV

1838

$11 / 11 / 10$

CCTV

2193

$04 / 02 / 10$

CCTV I

2091

09/20/10

CCTV

I

1839

\section{REMARKS}

Inspection of the walls, jumpers, valves, and piping was satisfactory per SW11.6-SVP-45, Section 7.9. The passive vent was clear of obstructions.

Inspection of the walls, floor, jumpers, valves, piping and cell covers was satisfactory per SW11.6-SVP-45, Section 7.9.

Inspection of the stainless steel liner, cell covers, jumpers, valves, piping and floor was satisfactory per SW11.6-SVP-45, Section 7.9.

Inspection of the stainless steel liner, cell covers, jumpers, valves, and piping was satisfactory per SW11.6-SVP-45, Section 7.9.

Inspection of the cell walls, floor, jumpers, valves, piping and cell covers was satisfactory per SW11.6-SVP-45, Section 7.9.

Inspection of the cell walls, floor, jumpers, valves, piping and cell covers was satisfactory per SW11.6-SVP-45, Section 7.9.

Inspection of the cell covers, jumpers, and piping was satisfactory per SW11.6-SVP-45 section 7.9. Numerous abandoned jumpers, dummy connector heads, equipment and other extraneous items were observed

Inspection of the cell covers, jumpers and piping was satisfactory per SW11.6-SVP-45 section 7.9. Abandoned jumpers, dummy connector heads and other extranous items were observed throughout the cell. 
TANK OR ACCESS OPENING

AREA ANCILLARY

PP-04

PP-04
(A OR I)

NE

$06 / 06 / 10$

$06 / 06 / 10$

SW
INSPECTION METHOD IDENTIFICATION NUMBER

CCTV / 1840

CCTV

I

1840

\section{REMARKS}

Inspection of the stainless steel liner, cell covers, jumpers, valves, piping and floor was satisfactory per SW11.6-SVP-45, Section 7.9.

Inspection of the stainless steel liner, cell covers, jumpers, valves, piping and floor was satisfactory per SW11.6-SVP-45, Section 7.9. 
This page intentionally left blank. 


\section{DISTRIBUTION}

\section{DOE-SR}

M. A. Mikolanis, 707-H

M. P. Dholakia (4), 707-H

D. J. Blake, 707-H

T. S. Gutmann, 704-S

J. K. Seitz, 704-S

S. R. Ross, 210-S

\section{SRS}

L. D. Olson, 766-H

W. C. Clark, 766-H

C. J. Winkler, 766-H

D. B. Little, 766-H

M. E. Maryak, 704-60H

W. L. Payne, 705-3C

J. W. Cook, 730-4B

R. R. Salmon, 704-26F

B. L. Green, 704-26F

G. E. Johnson, 704-56H

N. F. Chapman, 766-H

J. B. Elder, 730-A

D. C. Blair, 707-8E

M. Hubbard, 241-162H

D. P. Chew, 766-H
K. A. Hauer, 740-9A

W. L. Isom, 704-26F

N. C. Iyer (5), 773-41A

E. J. Freed, 704-56H

C. E. Blair, 704-56H

M. N. Borders, 704-56H

R. M. Campbell, 705-1C

M. D. Buxton, 241-156H

R. V. Doniphan, 241-156H

A. S. Plummer, 704-82H

W. R. West (15), 707-8E

R. S. Waltz (15), 707-5E

R. D. Robbins, 707-8E

M. T. Jackson, 707-5E

C. J. Smalls, 707-5E 